\title{
(1)
}

AUTARQUIA ASSOCIADA À UNIVERSIDADE DE SÃO PAULO

\section{DESENVOLVIMENTO E IMPLEMENTAÇÃO DE UM OBJETO SIMULADOR PARA DOSIMETRIA DE EQUIPAMENTOS GAMMA KNIFE ${ }^{\circledR}$}

\author{
NATHALIA ALMEIDA COSTA
}

Tese apresentada como parte dos requisitos para obtenção do Grau de Doutor em Ciências na Área de Tecnologia Nuclear - Aplicações

Orientadora:

Profa. Dra. MARIA DA PENHA

ALBUQUERQUE POTIENS 
INSTITUTO DE PESQUISAS ENERGÉTICAS E NUCLEARES

Autarquia associada à Universidade de São Paulo

DESENVOLVIMENTO E IMPLEMENTAÇÃO DE UM OBJETO SIMULADOR PARA DOSIMETRIA DE EQUIPAMENTOS GAMMA KNIFE ${ }^{\circledR}$

NATHALIA ALMEIDA COSTA

Tese apresentada como parte dos requisitos para obtenção do Grau de Doutor em Ciências na Área de Tecnologia Nuclear - Aplicações

Orientadora:

Profa. Dra. MARIA DA PENHA

ALBUQUERQUE POTIENS

Versão Corrigida

Versão Original disponível no IPEN

São Paulo

2018 


\section{FOLHA DE APROVAÇÃO}

Autor: Nathalia Almeida Costa

Título: Desenvolvimento e implementação de um objeto simulador para dosimetria de equipamentos Gamma Knife ${ }^{\circledR}$

Tese apresentada ao Programa de Pós-Graduação em Tecnologia Nuclear da Universidade de São Paulo para obtenção do título de Doutor em Ciências.

Data: $26 / 04 / 2018$

\section{Banca Examinadora}

Profa. Dra. Maria da Penha Albuquerque Potiens

Instituição: Instituto de Pesquisas Energéticas e Nucleares - IPEN Julgamento: Aprovada

Profa. Dra. Letícia Lucente Campos Rodrigues

Instituição: Instituto de Pesquisas Energéticas e Nucleares - IPEN Julgamento: Aprovada

Profa. Dra. Linda Viola Ehlin Caldas

Instituição: Instituto de Pesquisas Energéticas e Nucleares - IPEN Julgamento: Aprovada

Profa. Dra. Tereza Cristina Nathan Outeiro Pinto

Instituição: Externo

Julgamento: Aprovada

Prof. Dr. Roberto Kenji Sakuraba

Instituição: Externo

Julgamento: Aprovada 
Dedico este trabalho à minha amada mãe, Veronica e ao meu querido irmão, Rodrigo, pela motivação em íniciar este trabalho. 


\section{Agradecimentos}

Em especial à Deus, por ter me guiado no caminho certo das minhas escolhas e me dado forças quando mais precisei.

À minha orientadora, Dra. Maria da Penha, pela confiança, apoio, incentivo, suporte, amizade, companheirismo, paciência e sobretudo dedicação.

À Crystian Saraiva, por ter sido meu grande mestre, estar sempre presente nas dúvidas, decisões e pela ajuda constante na obtenção de dados deste trabalho.

À lleana Silvestre Patallo pela supervisão no estágio do National Physical Laboratory e pela amizade.

Ao Dr. Alexis Dimitriades por todo o ensinamento, pela disponibilidade de tempo e contribuição dada nas incansáveis medições realizadas.

Ao Dr. Hugo Palmans pelas excelentes sugestões e recomendações recebidas para finalização desse trabalho.

A Hamza Bemakhlouf pela supervisão no estágio da Universidade de Estocolmo.

Ao Dr. Vitor Vivolo pela disponibilidade e auxílio nesse trabalho.

À Dra. Linda V. E. Caldas, pela confiança e apoio constante neste projeto.

À Coordenação de Aperfeiçoamento de Pessoal de Nível Superior (CAPES) pela oportunidade e pelos recursos financeiros, sem os quais não seria possível a realização deste projeto.

Ao Banco Santander por proporcionar uma bolsa de estudos para a Universidade de Estocolmo.

Ao Instituto de Pesquisas Energéticas e Nucleares (IPEN) por possibilitar meu desenvolvimento acadêmico. 
Ao Hospital do Coração (HCor) e toda a equipe de física médica pela disponibilidade de sua infraestrutura para obtenção de dados deste trabalho.

Ao Hospital Albert Einstein pelo fornecimento de instrumento de medição para obtenção de dados neste trabalho.

À Universidade de Estocolmo/Hospital Karolisnka por me acolher em Estocolmo e permitir à obtenção de dados para este trabalho.

Ao National Physical Laboratory por permitir acesso ao laboratório por 5 meses para finalização na obtenção de dados deste trabalho.

Ao Queen Square Radiosurgery Center pela disponibilidade do centro do Gamma Knife $\circledast$ Perfexion para a realização das medições deste trabalho.

Aos amigos Daniela, Ladyjane, Patricia, Eduardo, Amanda, Fernanda, Camila, Felipe, Maira, Lilian, Lucas, Cristiane e todo o grupo do GMR pelo companheirismo e amizade nesses quatro anos.

A toda minha família que sempre me apoiou na busca deste título.

A Kyle Fallon, que sempre me incentivou, apoiou, se orgulhou do meu trabalho, além de ter sido paciente no tempo de espera e nas minhas incansáveis horas de escrita e estudo.

A todos os outros que, direta ou indiretamente, contribuíram para a conclusão deste trabalho. 
"Ele é a minha rocha firme, o meu refúgio. Confiem n'Ele em todos os momentos...derramem diante d'Ele o coração, pois $\mathcal{E} l e$ é o nosso refúgio." 


\section{RESUMO}

COSTA, N.A. Desenvolvimento e implementação de um objeto simulador para dosimetria de equipamentos Gamma Knife®). 2018. 73 p. Tese (Doutorado em Tecnologia Nuclear) - Instituto de Pesquisas Energéticas e Nucleares - IPEN-CNEN/SP. São Paulo.

A radiocirurgia estereotáxica é um procedimento que trata principalmente lesões intracranianas para destruir células tumorais inacessíveis cirurgicamente. $\bigcirc$ Gamma Knife® é uma unidade de radiocirurgia estereotáxica que trata lesões exclusivamente cerebrais com feixes de ${ }^{60} \mathrm{Co}$ de forma não-invasiva. De forma a garantir a acurácia na entrega da dose, esse tipo de equipamento necessita de detectores adequados para determinar a dose a ser entregue com exatidão. O protocolo da IAEA, TRS 483, é um guia padronizado para procedimentos dosimétricos e indicação de detectores relativos à dosimetria de referência de campos pequenos usados em feixes de radioterapia. Este trabalho seguiu as recomendações do TRS 483 na dosimetria do Gamma Knife® e foram realizadas medições utilizando duas câmaras de ionização, Exradin A16 e PTW Pinpoint 3D 31016, a alanina como detector de referência e os objetos simuladores indicados pela Elekta, fabricante do Gamma Knife®, sendo um de ABS e outro de Solid Water®. Um objeto simulador de acrílico foi construído, com as mesmas dimensões dos indicados pela Elekta, e implementado na dosimetria de equipamentos Gamma Knifeß. A calibração das câmaras de ionização utilizadas foi realizada em um laboratório padrão primário e o coeficiente de calibração obtido foi utilizado no cálculo da dose absorvida na água dessas câmaras. Os estudos e testes dosimétricos realizados com o objeto simulador construído demonstraram resultados próximos aos simuladores existentes. Todos os fatores de correção indicados pelo TRS 483 foram considerados para o cálculo da dose absorvida. Foi constatado que o novo objeto simulador pode ser utilizado na dosimetria de Gamma Knife® e também para calibração de câmaras de ionização de volume pequeno, garantindo uma configuração de dosimetria e calibração similares e proporcionando ao usuário uma calibração próxima à configuração da dosimetria clínica. O projeto e a execução do objeto simulador utilizado neste trabalho visa contribuir para o TRS 483, de forma que seja utilizado na aplicação da dosimetria de Gamma Knife® e na calibração de câmaras de ionização de volume pequeno.

Palavras-chave: Gamma Knifeß; dosimetria; campos pequenos; objeto simulador. 


\section{ABSTRACT}

COSTA, N.A. Phantom development and implementation for Gamma Knife® dosimetry. 2018. 73 p. Tese (Doutorado em Tecnologia Nuclear) - Instituto de Pesquisas Energéticas e Nucleares - IPEN-CNEN/SP. São Paulo.

Stereotactic radiosurgery is a procedure that primarily treats intracranial lesions to destroy tumor cells that are inaccessible surgically. Gamma Knife® is a stereotactic radiosurgery unit that treats exclusively cerebral lesions using ${ }^{60} \mathrm{Co}$ beams non-invasively. In order to ensure accurate dose delivery, this type of equipment requires adequate detectors to determine the dose is delivered accurately. The IAEA TRS 483 protocol is a standardized guide for dosimetric procedures and indication of detectors for reference dosimetry of small fields used in radiotherapy beams. Following TRS 483 recommendations in Gamma Knife $\AA$ dosimetry, the measurements performed in this work used two ionization chambers; Exradin A16 and PTW Pinpoint 3D 31016, alanine as reference detector and phantoms indicated by Elekta, Gamma Knife's $₫$ manufacturer, which are made of $A B S$ and Solid Water $\AA$. An acrylic phantom was built with the same dimensions as those indicated by Elekta, and implemented for the Gamma Knife $\AA$ dosimetry. The calibration of the ionization chambers used was performed in a primary standard laboratory and the calibration coefficient obtained was used to calculate the absorbed dose in the water for these chambers. The dosimetry and tests performed with the acrylic phantom showed results close to the existing phantoms. All the correction factors indicated by TRS 483 were considered for the absorbed dose to water calculation. The new phantom can be used in Gamma Knife® dosimetry and also for calibration of small volume ionization chambers, assuring a similar dosimetry and calibration configuration and providing a calibration close to the clinical dosimetry configuration for the user. The design and implementation of the simulator object used in this work aims to contribute to the TRS 483, for the use in Gamma Knife® dosimetry and in the calibration of small volume ionization chambers.

Key words: Gamma Knife®; dosimetry; small fields; phantom. 


\section{LISTA DE TABELAS}

Página

Tabela 1 - Fatores de correção $k_{Q_{m s r}}^{f_{m s r} f_{r e f}}$ para o Gamma Knife® Perfexion...

Tabela 2 - Componentes de incerteza que foram considerados para os cálculos das medições realizadas neste trabalho

Tabela 3 - Variação máxima obtida nos testes da IEC 60731:2011 60

Tabela 4 - Resultado das leituras para as variações de inclinação do objeto simulador

Média de carga coletada para cada câmara de ionização com

Tabela 5 - ambos os objetos simuladores (ABS e Solid Water ${ }^{\circledR}$ ) e a taxa de dose calculada.

Tabela 6 - Comparação da taxa de dose calculada para cada configuração de medição com a taxa de dose fornecida pelo Gamma Plan

Tabela 7 - Coeficiente de calibração para as câmaras de ionização de volume pequeno em feixe de ${ }^{60} \mathrm{Co}$

Tabela 8 - Coeficiente de calibração para as câmaras de ionização de volume pequeno em feixe de $6 \mathrm{MV}$ de um acelerador linear

Tabela 9 - Dosimetria do Gamma Knife® com objeto simulador Solid Water ${ }^{\circledR}$ e câmara de ionização PTW Semiflex 31010

Tabela 10 - Dosimetria do Gamma Knife® com objeto simulador Solid Water $\AA^{\circledR}$ e câmara de ionização Exradin A16 70

Tabela 11 - Dosimetria do Gamma Knife® com objeto simulador Solid Water $\AA^{\circledR}$ e câmara de ionização PTW Pinpoint 31016.

Tabela 12 - Dosimetria do Gamma Knife® com objeto simulador de acrílico e câmara de ionização Exradin A16. 
Tabela 13 - Dosimetria do Gamma Knife® com objeto simulador de acrílico e câmara de ionização PTW Pinpoint 31016

Dosimetria do Gamma Knife $\AA^{\circledR}$ com objeto simulador de Solid

Tabela 14 - Water e acrílico e pastilhas de alanina de 2,5 mm. Tempo de irradiação: 20 min

Diferença percentual das taxas de dose de todas as

Tabela 15 - configurações de dosimetria utilizando o objeto simulador de acrílico e a alanina como dosimetria referência

Tabela 16 - Fator output fornecido pela Elekta para o Gamma Knife®, calculado por simulação Monte Carlo.

Fator output para todas as configurações de dosimetria

Tabela 17 - realizadas e o valor da diferença percentual em relação ao fator estabelecido pela Elekta por simulação....................................... 76 


\section{LISTA DE FIGURAS}

Página

Figura 1 - Equipamento Gamma Knife® Perfexion.

Figura 2 - Principais componentes do Gamma Knife® Perfexion

20

Figura 3 - Posicionamento do paciente na mesa de tratamento com o adaptador.

Diagrama da unidade do Gamma Knife $\circledast$ Perfexion e o sistema de colimação. Em A) Seção transversal do Gamma Knife® Perfexion. Em B) Cada setor contém 24 fontes de cobalto-60 e pode se

Figura 4 - mover independentemente de outros setores para a posição desejada, definindo o tamanho do colimador ou grupos de blocos do feixe. Em C) Posição do colimador de $4 \mathrm{~mm}$. Em D) Posição do colimador de $8 \mathrm{~mm}$ e em E) Posição do colimador de $16 \mathrm{~mm}$.

Figura 5 - Coordenadas cartesianas para radiocirurgia estereotáxica

Figura 6 - Detalhes internos do Gamma Knife® Perfexion.

Figura 7 - Câmaras de ionização Exradin A16 (preta) e PinPoint 31016 (azul)......

Figura 8 - Câmara de lonização Semiflex 31010

Figura 9 - Câmara de ionização NE2611, padrão secundário do NPL

Figura 10 -

Pastilhas de alanina de diferentes diâmetros produzidas pelo NPL

Figura 11 - Objeto simulador de poliestireno (ABS) e de água sólida (Solid Water $(\AA)$

Figura 12 - Razão da dose na água pela kerma na água calculado por Monte Carlo numa profundidade de $5 \mathrm{~cm}$ no centro do feixe de fótons. 
llustração do efeito de oclusão da fonte de radiação. Em A visão
Figura 13 - $\quad$ total do feixe direto de radiação estendido e em B visão parcial do feixe direto de radiação estendido

llustração do efeito de volume em uma dimensão. A curva preta é a curva Gaussiano aproximando um perfil de campo pequeno. A

Figura 14 - curva tracejada representa a medição de um detector em $5 \mathrm{~mm}$ de comprimento. A seta dupla representa a dimensão do detector ao longo do eixo. A linha tracejada com pontos mostra a diferença entre as duas curvas como fração da dose máxima.

Figura 15 - Configuração de dosimetria do HCor para o Gamma Knife® Perfexion.

Figura 16 - Configuração de dosimetria realizada no Hospital Karolinska em Estocolmo, Suécia.

Figura 17 - Produção do furo no objeto simulador para inserção da câmara de ionização.

Figura 18 - Objeto simulador de acrílico finalizado com a PTW Pinpoint 31016

Figura 19 - Dosimetria do objeto simulador de acrílico com a PTW Pinpoint 31016 no HCor.

Figura 20 - Arranjo de calibração de câmaras de ionização cilíndricas utilizadas em radioterapia no laboratório de calibração.

Figura 21 - Calibração da câmara de ionização Exradin A16 no laboratório de calibração primário do NPL

Figura 22 Dosimetria realizada no QSRC com o objeto simulador de acrílico desenvolvido neste trabalho.

Figura 23 - Posições do objeto simulador: Em A, sem inclinação, em B inclinação externa e em $C$ inclinação interna.

Figura 24 - Objeto simulador de acrílico, obtido na primeira etapa de sua construção, posicionado no Gamma Knifeß do HCor.

Figura 25 - Objeto simulador de acrílico modificado para dosimetria do Gamma Knife® Perfexion..... 


\section{SUMÁRIO}

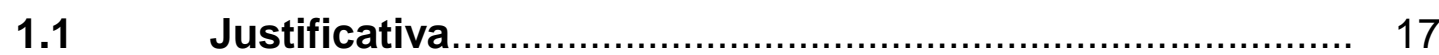

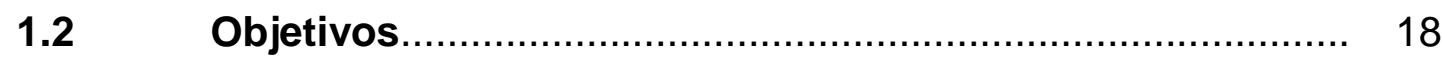

2 REVISÃO DA LITERATURA ............................................ 19

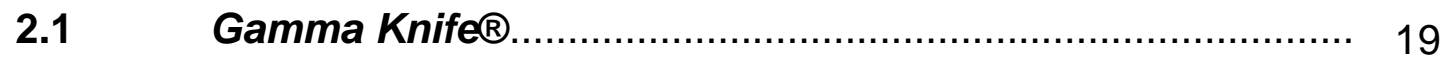

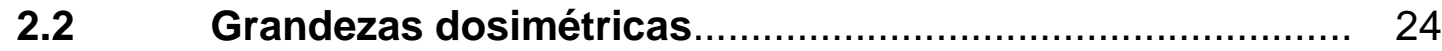

2.2.1 Dose absorvida............................................................... 24

2.2.2 Dose absorvida na água para campos pequenos.................... 26

2.3 Teoria da Cavidade e Stopping-power............................... 27

2.3.1 Teoria da cavidade de Bragg-Gray e Spencer-Attix.................. 27

2.3.2 Stopping-power.............................................................. 28

$2.4 \quad$ Detectores de radiação ..................................................... 29

2.4.1 Câmaras de ionização............................................................. 29

2.4.1.1 Câmara de lonização PTW Pinpoint 3D 31016........................ 30

2.4.1.2 Câmara de lonização Exradin A16 ......................................... 31

2.4.1.3 Câmara de lonização Semiflex PTW31010............................. 32

2.4.1.4 Câmara de lonização NE2611 .................................... 32

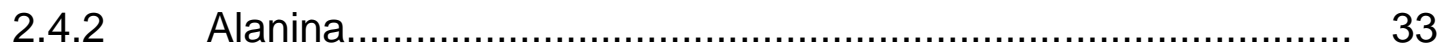

$2.5 \quad$ Objetos simuladores ....................................................... 35

2.6 Dosimetria em campos pequenos …………………….... 36

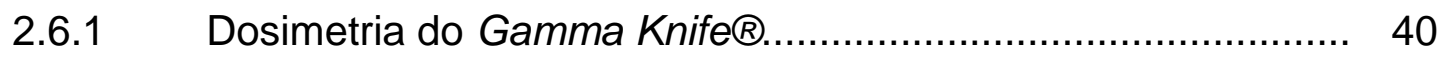

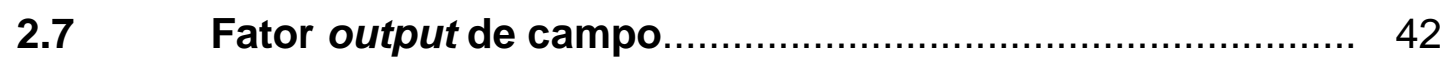

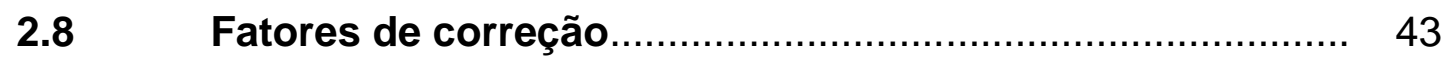

3 METODOLOGIA ......................................................... 46

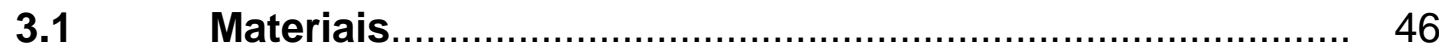


3.2.1 Controle de qualidade da câmara de ionização Exradin $16 \quad 48$

3.2.2 Dosimetria de equipamentos Gamma Knife® Perfexion.......... 49

3.2.3 Construção de um objeto simulador de acrílico para dosimetria em equipamentos Gamma Knife $\Theta$.

Calibração das câmaras de ionização em laboratório padrão primário.

Dosimetria do Gamma Knife® Perfexion com as câmaras de ionização calibradas.

3.2.6 Análise de Incertezas...................................................... 57

RESULTADOS E DISCUSSÕES

4.1

Programa de controle de qualidade de uma câmara de ionização de volume pequeno

Estudo da variação no posicionamento do objeto

simulador na dosimetria do Gamma Knife ${ }^{\circledR}$ Perfexion........

Dosimetria de um equipamento Gamma Knife $\circledast$ Perfexion

Primeira dosimetria realizada com o objeto simulador de acrílico

Resultado do projeto, construção e aperfeiçoamento do objeto simulador de acrílico.

Cálculo do coeficiente de calibração $\mathrm{N}_{\mathrm{D}, \mathrm{w}}$ em um feixe

4.6 padrão primário para as câmaras de ionização PTW

Pinpoint 31016 e Exradin A16.

4.7 Dosimetria no Gamma Knife ${ }^{\circledR}$ Perfexion............................ 68

4.8 Uso do objeto simulador de acrílico e pastilhas de alanina como dosimetria de referência............................... 74

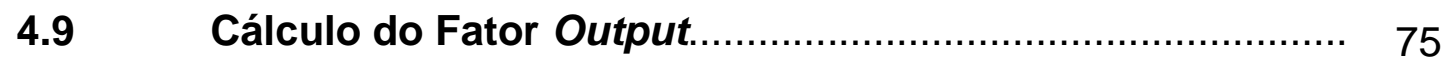

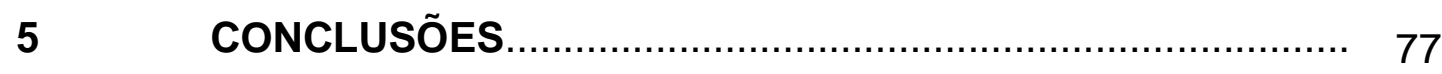

6 REFERÊNCIAS BIBLIOGRÁFICAS .................................. 78 


\section{INTRODUÇÃO}

Assim como a cirurgia e a quimioterapia, a radioterapia é uma das formas convencionais de tratamento do câncer que, através do uso da radiação ionizante, visa danificar as moléculas de DNA do tumor. O tratamento do câncer através da radioterapia teve seu início em 1902 com o Dr. Henri-Alexandre Danlos, que realizou um tratamento com fonte radioativa de rádio colocada diretamente na superfície de um tumor ${ }^{1,2}$.

O principal objetivo da radioterapia é, a partir de uma determinada dose de radiação, provocar a destruição de células cancerígenas produzindo o menor dano possível aos tecidos saudáveis ao redor do tumor. Vários mecanismos, como a inativação de sistemas vitais para a célula e sua incapacidade de reprodução, podem ser responsáveis pela morte celular ${ }^{3,4}$.

A radioterapia pode ser classificada em teleterapia e braquiterapia. A teleterapia emprega uma fonte de radiação externa colocada a certa distância da região a ser tratada enquanto na braquiterapia a fonte radioativa está em contato direto com a região do tumor $^{4-6}$.

A cada dia são apresentados novos avanços tecnológicos e inovações na radioterapia. Dentre esses avanços tecnológicos está a radiocirurgia estereotáxica, um procedimento que trata principalmente lesões intracranianas para destruir células tumorais inacessíveis cirurgicamente.

Em 1951, o neurocirurgião Lars Leksell propôs a radiocirurgia estereotáxica, que se tratava do uso de radiação externa em conjunto com um guia estereotáxico, para localizar e destruir com precisão alvos inacessíveis dentro do cérebro. Esta técnica combina o uso de um dispositivo estereotáxico e feixes de radiação energéticos para irradiar uma lesão cerebral em um único tratamento. Essa combinação permite definir com acurácia o formato, a localização da lesão e a anatomia neurológica referencial do sistema estereotáxico, com a utilização de tomografia computadorizada, ressonância magnética e angiografia, além de desenvolver e definir o plano de tratamento ${ }^{7}$.

O desenvolvimento do tratamento estereotáxico tem levado a um aumento no uso de feixes pequenos de raios $X$ e radiação gama de ${ }^{60}$ Co na faixa de 5-40 mm de diâmetro. A radiocirurgia estereotáxica é usada para o tratamento de tumores pequenos (com menos de $20 \mathrm{~cm}^{3}$ ), benignos ou malignos, intra ou extra-craniais. Além disso, necessita de uma alta acurácia no posicionamento do paciente e também na entrega da dose, de modo a evitar riscos de danos próximos a órgãos críticos ${ }^{2}$. Ela tem sido o único tratamento 
praticável para alguns pacientes com lesões cerebrais que não podem ser removidas cirurgicamente, para pacientes com lesões residuais após tentativa de ressecção ou para pacientes onde a saúde em geral ou a idade avançada impedem cirurgias intracraniais convencionais ${ }^{8}$.

Novos desenvolvimentos em radioterapia têm mostrado um aumento no uso de campos de radiação pequenos, como os utilizados em radioterapia e radiocirurgia estereotáxica, além de radioterapia de intensidade modulada. Esses tratamentos utilizam máquinas especializadas e dedicadas como a TomoTherapy ${ }^{\circledR}$, CyberKnife® e Gamma Knife®.

O Gamma Knife® é uma unidade de radiocirurgia estereotáxica que trata lesões exclusivamente cerebrais com feixes de ${ }^{60} \mathrm{Co}$ de forma não-invasiva. Essa técnica utiliza feixes de fótons pequenos garantindo a entrega de dose de alta conformidade ao alvo e poupando tecidos saudáveis adjacentes.

Novos tratamentos de feixes pequenos de fótons, como o Gamma Knife®, não permitem condições de referência convencionais, em termos de tamanho de campo e distância fonte-detector. Além disso, fornecem exclusivamente campos de radiação pequenos. Isso fez com que a incerteza na dosimetria clínica aumentasse e sua rastreabilidade a uma dosimetria de referência fosse reduzida, baseada nos códigos de prática para radioterapia convencional ${ }^{9-12}$.

De forma a garantir a acurácia na entrega da dose, equipamentos radioterápicos, especialmente os que utilizam feixes pequenos de fótons, necessitam de detectores adequados para determinar a dose a ser entregue com exatidão. $O$ material deste detector deve ser o mais próximo possível do tecido equivalente e apresentar um volume de detecção pequeno comparado ao tamanho de campo irradiado por causa da ausência de equilíbrio eletrônico lateral em feixes pequenos ${ }^{2}$.

Dado o problema da dosimetria de campos pequenos, o protocolo Technical Series Report (TRS) $483^{13}$, da International Atomic Energy Agency (IAEA) em parceria com a American Association of Physicists in Medicine (AAPM) para dosimetria de campos pequenos estáticos usados em radioterapia, foi publicado de forma a atender a necessidade de um sistema com abordagem internacional consolidada para a dosimetria de campos pequenos. O protocolo é um guia padronizado para procedimentos dosimétricos e indicação de detectores relativos à dosimetria de referência de campos pequenos usados em feixes de radioterapia. 
Este trabalho seguiu as recomendações do TRS $483^{13}$ na dosimetria do Gamma Knife $\circledast$, utilizando câmaras de ionização recomendadas pelo protocolo e os objetos simuladores indicados também pelo fabricante do Gamma Knife®. Embora este documento tenha sido publicado no final do ano de 2017, as etapas deste trabalho já estavam em andamento e vieram de acordo com o proposto pelo TRS $483^{13}$.

Um objeto simulador de acrílico foi construído e implementado na dosimetria de equipamentos Gamma Knife®. O projeto e a execução do objeto simulador utilizado neste trabalho visa contribuir para esse protocolo de forma que seja utilizado na aplicação da dosimetria de Gamma Knife®e na calibração de câmaras de ionização de volume pequeno.

\subsection{Justificativa}

O número de pacientes que tratam lesões cerebrais com radiocirurgia estereotáxica tem crescido a cada ano. O equipamento Gamma Knife $\Theta$ Perfexion, desenvolvido para radiocirurgia, está presente em muitos centros de radioterapia no mundo e apenas em duas cidades no Brasil, São Paulo e Curitiba, e é mais uma opção de tratamento para este tipo de lesão. Por se tratar de um equipamento que utiliza fontes de ${ }^{60} \mathrm{Co}$ para tratamento das lesões, é importante manter um rigoroso controle de qualidade neste equipamento.

O controle de qualidade deste equipamento é feito com a utilização do objeto simulador fornecido pela própria Elekta, marca que produz o Gamma Knife $\Theta$ e com detectores de radiação que podem ser filmes dosimétricos, diodos ou câmaras de ionização de volume pequeno. A utilização de câmaras de ionização de volume pequeno para o controle de qualidade de equipamentos Gamma Knife $\Theta^{\circledR}$ está cada vez mais difundida. Quanto maior a precisão na calibração dessas câmaras, melhor será o resultado esperado para o tratamento do paciente. Muitos estudos têm sido realizados quanto à utilização de equipamentos de radioterapia com feixes pequenos de fótons e que utilizam câmaras de ionização de volume pequeno ${ }^{14-21}$.

A publicação do protocolo TRS $483^{13}$ permitiu a criação de um guia padronizado para a dosimetria de referência em campos pequenos e fornece um formalismo para o cálculo da dose absorvida na água em feixes não-referência.

No caso do Gamma Knife®, o protocolo utiliza, para o cálculo da dose absorvida na água, câmaras de ionização de volume pequeno e os objetos simuladores fornecidos pela Elekta. Este trabalho visou, então, a utilização de um novo objeto simulador, construído e projetado para utilização em Gamma Knife®, para aplicação na dosimetria do equipamento 
e para calibração de câmaras de ionização de volume pequeno. O novo objeto simulador permite a utilização de câmaras de ionização de volume pequeno, além de outros materiais, que podem ser utilizados como detectores de referência.

\subsection{Objetivos}

- Gerais

Este trabalho teve como principais objetivos:

$\checkmark$ Desenvolver e implementar um objeto simulador para a dosimetria de equipamentos Gamma Knife®.

$\checkmark$ Realizar a dosimetria do equipamento Gamma Knife® utilizando diferentes detectores de radiação, de forma a minimizar erros dosimétricos.

- Específicos

$\checkmark$ Estudar, analisar e escolher $o$ material e 0 design para desenvolvimento e construção do objeto simulador.

$\checkmark$ Testar o objeto simulador em feixes clínicos e de referência.

$\checkmark$ Determinar o coeficiente de calibração $N_{\mathrm{D}, \mathrm{w}, \text {, em termos de dose }}$ absorvida na água, para câmaras de ionização de volume pequeno, em um laboratório de calibração padrão primário.

$\checkmark$ Estudar a metodologia aplicada na dosimetria de campos pequenos na clínica, identificando os fatores de correção utilizados.

$\checkmark$ Comparar a dosimetria clínica com a dosimetria proposta pelo TRS $483^{13}$. 


\section{REVISÃO DA LITERATURA}

\subsection{Gamma Knife $\AA$}

O Gamma Knife ${ }^{\circledR}$, desenvolvido pela Elekta Instrument $A B$, tem sido um dos métodos principais de realização de radiocirurgia estereotáxica para tratamento de lesões intracraniais em muitos hospitais ao redor do mundo 22,23 .

O equipamento de Gamma Knife® (Figura 1) foi especialmente desenvolvido para radiocirurgia não-invasiva, com a intenção de entregar uma única e alta dose de radiação a uma lesão pequena e de difícil localização no cérebro.

O Gamma Knife® fornece acurácia no alcance do alvo, alta eficiência e excelentes resultados. O paciente se beneficia de um tratamento rápido, sem dor e sem necessidade de anestesia.

Figura 1 - Equipamento Gamma Knife® Perfexion

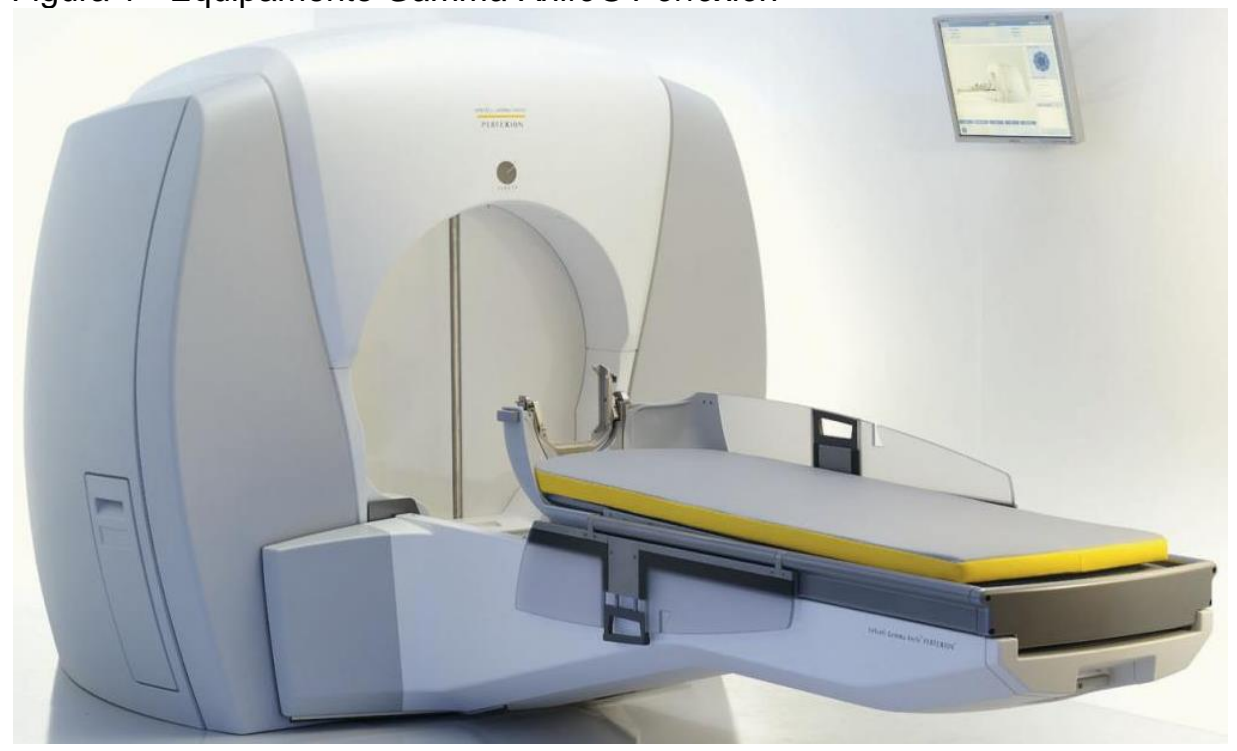

Fonte: Elekta,2015.23

O primeiro equipamento Gamma Knife® foi projetado para produzir radiação como fenda em lesões de procedimentos neurocirúrgicos funcionais para tratar a dor, distúrbios de movimento ou distúrbios de comportamento, que não responderam ao tratamento radioterápico convencional. A partir daí, equipamentos Gamma Knife®foram desenvolvidos para tratar tumores no cérebro e má-formações intracraniais artereovenosas.

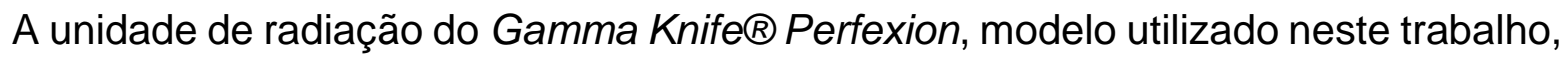
consiste em uma blindagem esférica contendo uma porta de entrada também blindada. 
Dentro da blindagem existe um corpo central hemisférico que acopla 192 fontes de ${ }^{60} \mathrm{Co}$. Cada fonte possui $1 \mathrm{~mm}$ de diâmetro. A blindagem e o corpo central são feitos de ferro fundido. A porta de entrada é feita de aço. Todas as 192 fontes estão focadas para um único ponto no centro da unidade de radiação ${ }^{21}$.

Os principais componentes do equipamento de Gamma Knifeß Perfexion são mostrados na Figura 2, sendo eles a unidade de radiação, que contém as 192 fontes de ${ }^{60} \mathrm{Co}$, a blindagem e os colimadores, que possuem tamanhos diferentes; o sistema de posicionamento do paciente e o adaptador onde a cabeça do paciente é posicionada.

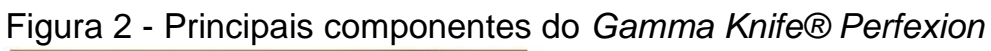

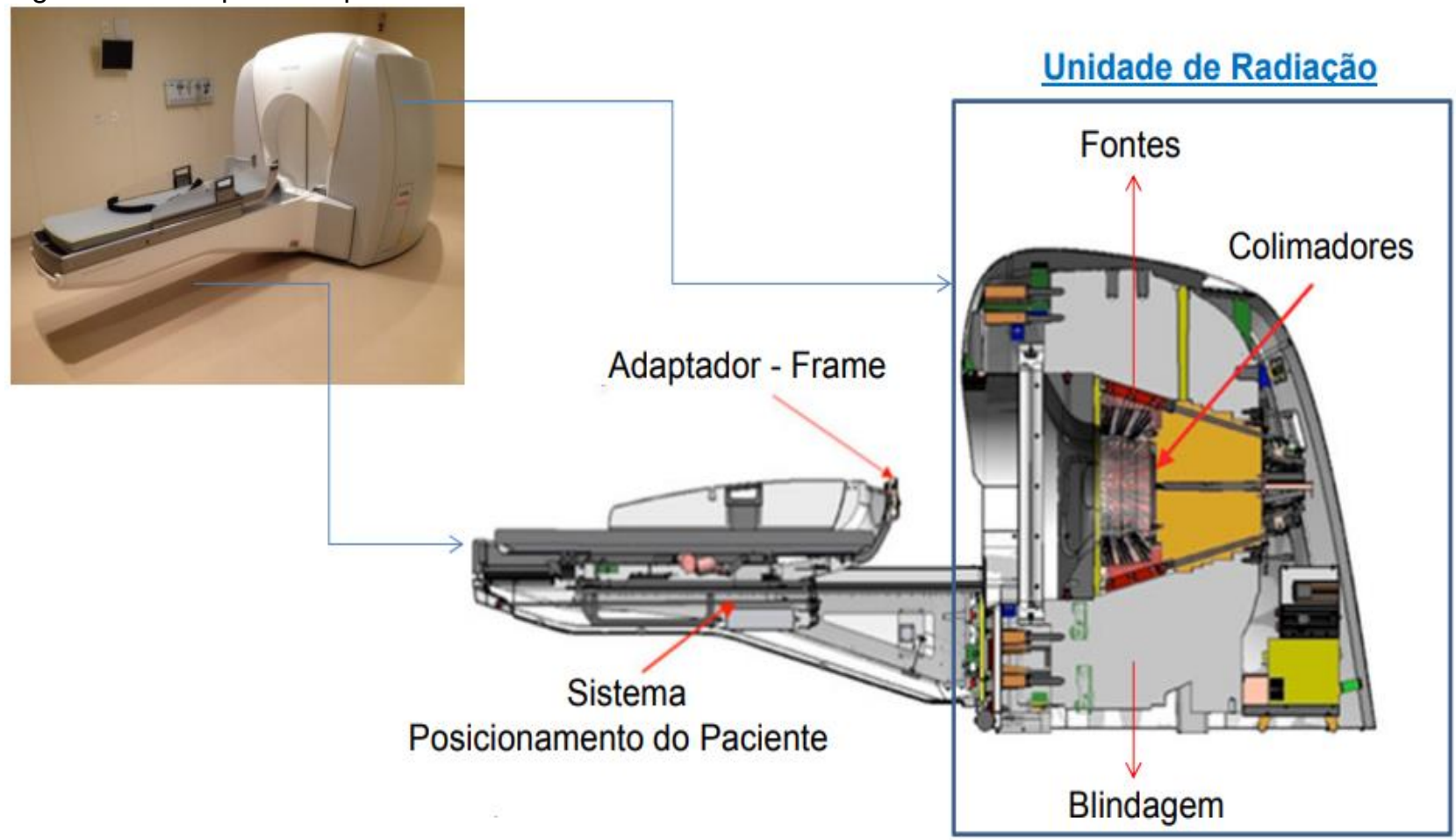

Fonte: SARAIVA, $2014^{24}$.

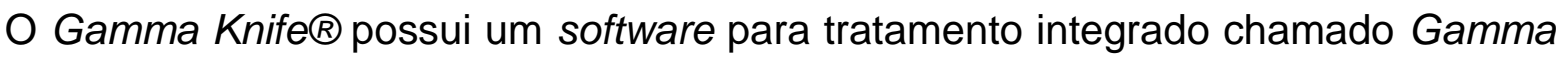
Plan. Este software fornece o cálculo da dose absorvida em tempo real, de acordo com o decaimento do ${ }^{60} \mathrm{Co}$. Ele também permite a utilização de ferramentas que tornam possível a realização de planejamentos de tratamento complexos em poucos minutos.

A Figura 3 mostra o adaptador que é utilizado para posicionamento do paciente na mesa de tratamento. 
Figura 3 - Posicionamento do paciente na mesa de tratamento com o adaptador.

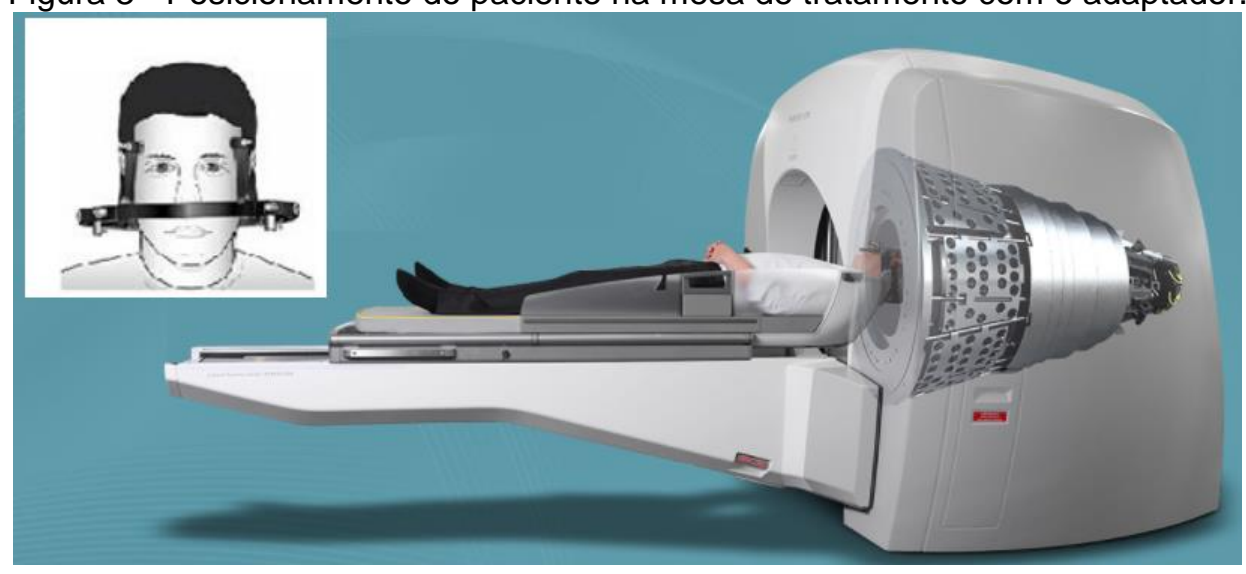

Fonte: SARAIVA, $2014^{24}$.

A Figura 4 mostra o diagrama do Gamma Knife® Perfexion e o sistema de colimação presente no mesmo. O Gamma Knife® Perfexion possui 3 colimadores de diâmetros diferentes (16, 8 e $4 \mathrm{~mm})$.

Figura 4 - Diagrama da unidade do Gamma Knife® Perfexion e o sistema de colimação. Em A) Seção transversal do Gamma Knife $\Theta$ Perfexion. Em B) Cada setor contém 24 fontes de cobalto-60 e pode se mover independentemente de outros setores para a posição desejada, definindo o tamanho do colimador ou grupos de blocos do feixe. Em C) Posição do colimador de $4 \mathrm{~mm}$. Em D) Posição do colimador de $8 \mathrm{~mm}$ e em E) Posição do colimador de $16 \mathrm{~mm}$.
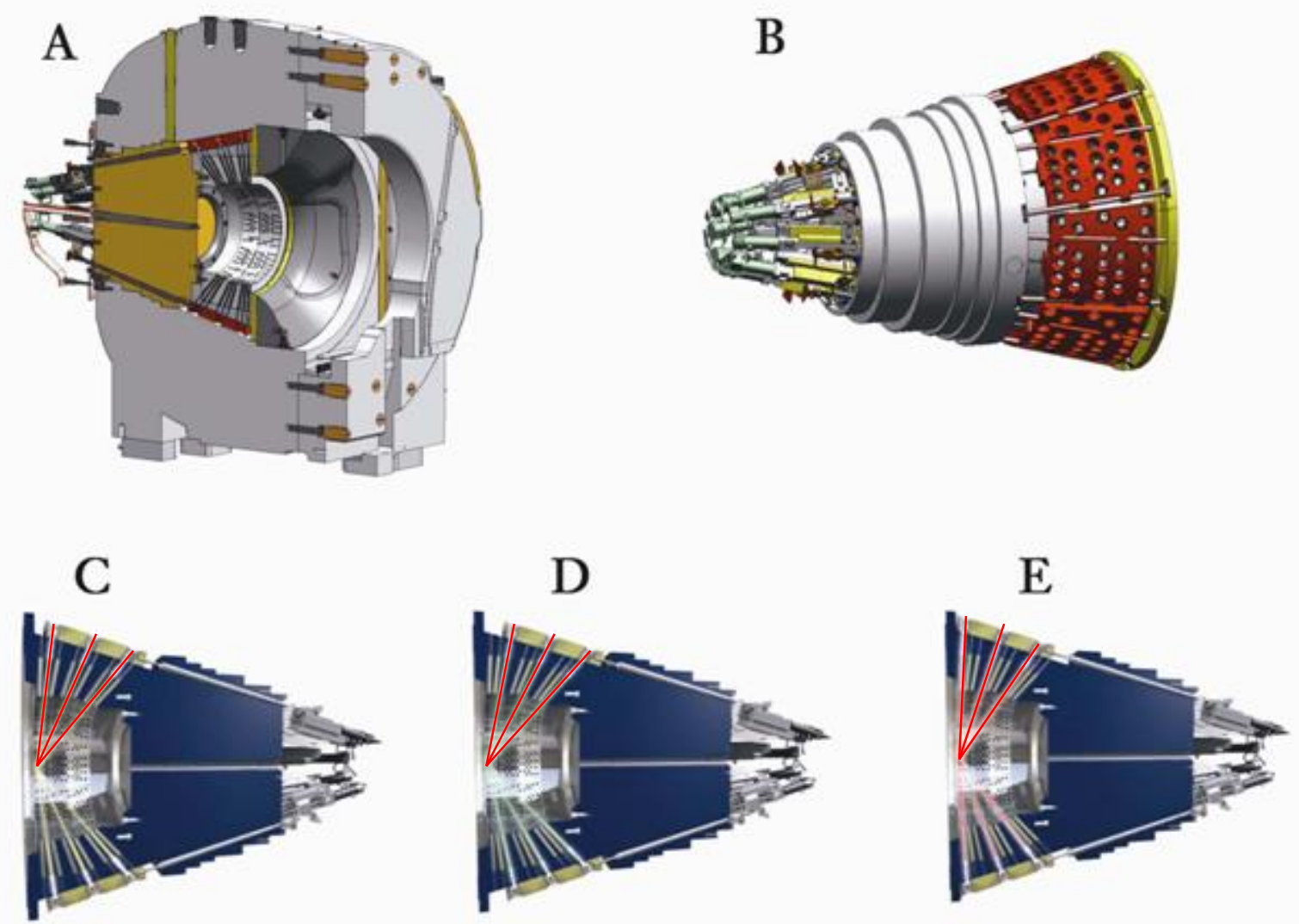

Fonte: Elekta ${ }^{23}$. 
Para um tratamento comum, grupos de feixes convergem em um único ponto no espaço, o isocentro. $O$ formato da abertura do feixe é geralmente definido por uma colimação secundária próxima ao paciente, para reduzir a penumbra do feixe. Após a localização estereotáxica da lesão, usando uma modalidade de imagem, o posicionamento apropriado de um ou mais isocentros dentro da lesão pode fornecer um gradiente de dose excessivo próximo ao tecido periférico da lesão. O equipamento estereotáxico deve ser acoplado ao paciente para acurácia na imagem e no tratamento estereotáxico ${ }^{8}$.

Cada dispositivo estereotáxico está equipado num par de apoios giratórios, que servem como pontos de fixação para a armação estereotáxica. Essa armação estereotáxica é presa por quatro pinos perfurados dentro da superfície externa do crânio do paciente. Uma vez fixos, a armação permanece no local até o fim do tratamento22.

A mesa de tratamento move o paciente dentro da larga blindagem de ferro fundido, onde o capacete de colimação acopla no corpo central as fontes de ${ }^{60} \mathrm{Co}$, sendo a colimação final alcançada pelo capacete com 192 plugues de colimação removíveis.

Placas indicadoras são utilizadas para visualizar o sistema de coordenadas da armação no diagnóstico por imagem. Esse sistema de coordenadas cartesianas tridimensional $(X, Y, Z)$ é usado para localizar as coordenadas do alvo no espaço estereotáxico (Figura 5). O eixo Z (superior-inferior) do sistema de coordenadas se situa no plano coronal do paciente. $O$ eixo $X$ (direita-esquerda) se situa no plano transverso e o eixo $Y$ (anterior-posterior) se situa no plano sagital. O sistema de coordenadas é orientado de forma que o centro do capacete (o foco das 192 fontes) está a $X=100, Y=100$ e $Z=100$, eliminando assim o uso de coordenadas negativas. Atualmente, imagens por ressonância magnética, tomografia computadorizada ou angiografia cerebral com filmes de raios $X$ ortogonais são utilizadas para localização do alvo ${ }^{14}$.

Figura 5 - Coordenadas cartesianas para radiocirurgia estereotáxica

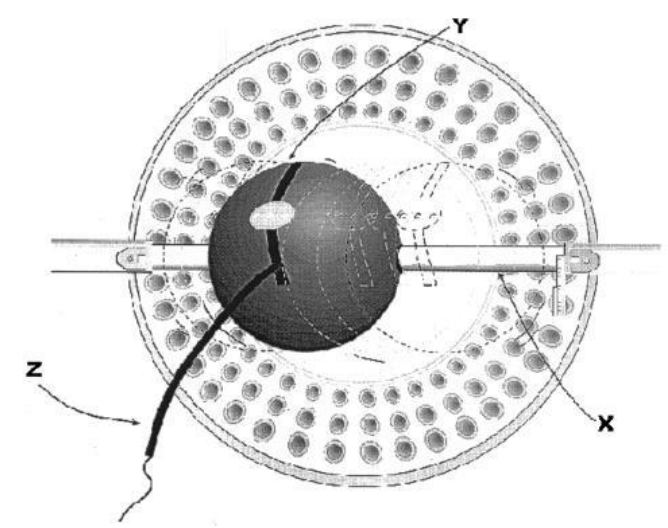

Fonte: MAITZ, $1995^{22}$. 
A Figura 6 mostra e descreve o equipamento Gamma Knife® Perfexion internamente.

Figura 6 - Detalhes internos do Gamma Knife® Perfexion

A mesa de tratamento pode ser facilmente ajustada para completo conforto do paciente.

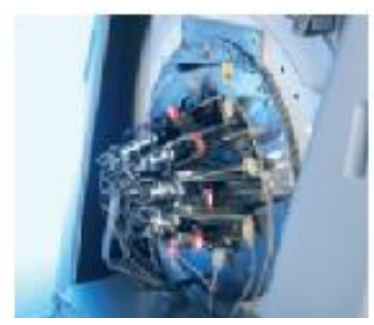

O mecanismo de setores permite a configuração de colimação automática dentro de segundos.

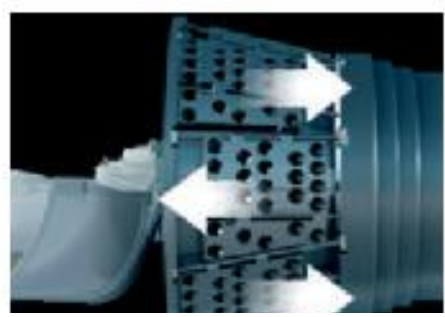

O sistema de colimação consiste em 192 fontes de cobalto-60 divididas em 8 setores que podem ser posicionados individualmente. Durante o tratamento, as fontes são posicionadas pelo mecanismo dos setores para fornecer o feixe de radiação desejado.
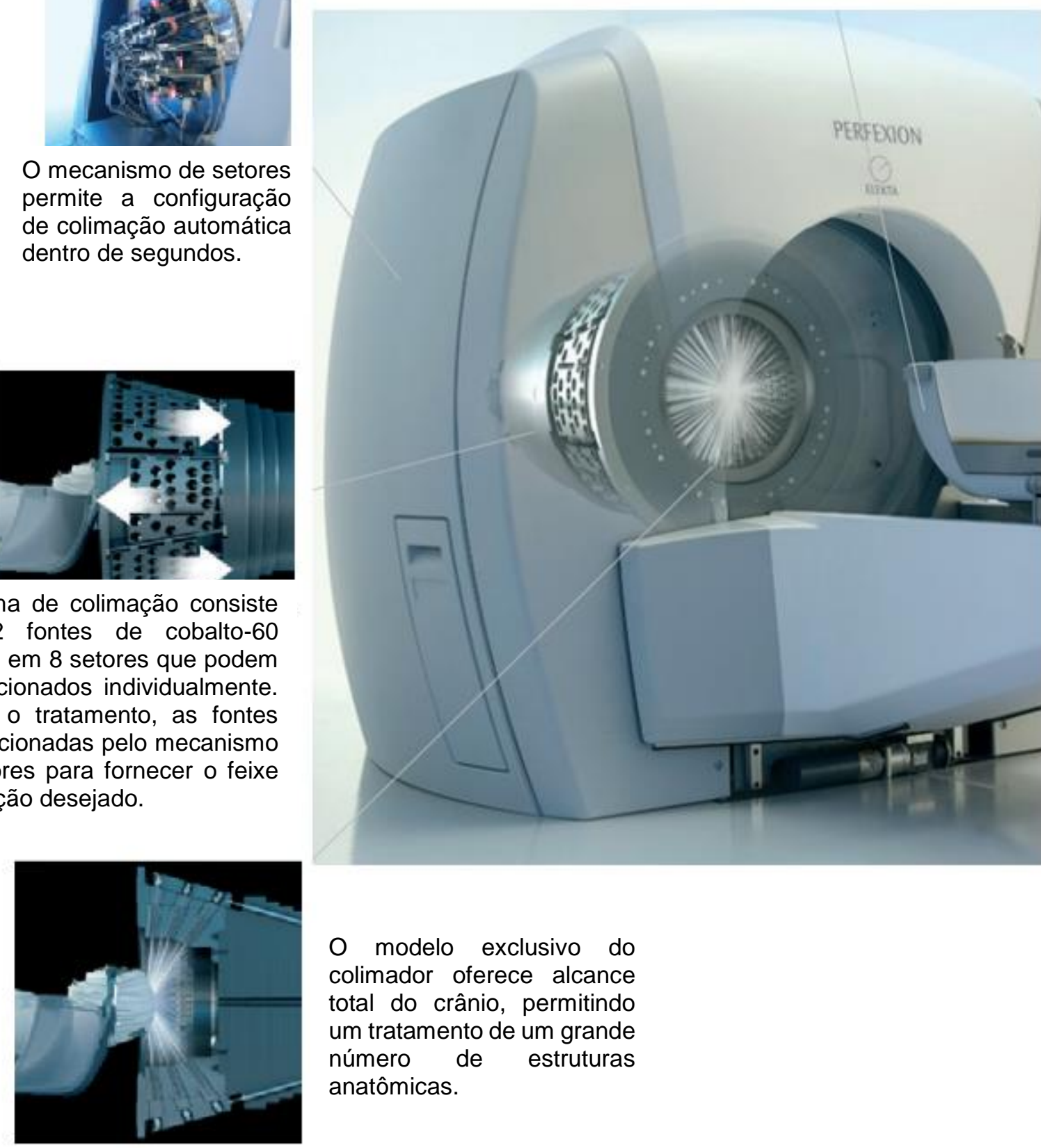

O modelo exclusivo do colimador oferece alcance total do crânio, permitindo um tratamento de um grande número de estruturas anatômicas.

Fonte: Elekta ${ }^{23}$ 
A radiocirurgia com o Gamma Knife $B^{\circledR}$ está se expandindo constantemente, com diversas pesquisas sendo realizadas, novas indicações de tratamentos e desenvolvimento de novos protocolos. O design do Gamma Knife ${ }^{B}$ permite que sejam realizados tratamentos que são adequados para o tratamento de múltiplas lesões, sendo estas em muitos casos, metástases cranianas ${ }^{23}$.

O controle de qualidade do Gamma Knifeß é realizado com uma configuração que inclui um detector de radiação, que podem ser câmaras de ionização, filmes dosimétricos, diodos, dosímetros termoluminescentes de fluoreto de lítio $(\mathrm{LiF})^{8}$, etc., e um objeto simulador, que é fornecido pela Elekta Instrument $A B^{23}$.

\subsection{Grandezas dosimétricas}

A determinação da dose absorvida com exatidão é crucial para o sucesso de um tratamento radioterápico, sobretudo porque se deve considerar o controle do tumor e evitar os danos ao tecido saudável.

O principal procedimento para a determinação da distribuição de dose absorvida no paciente inclui o uso de medições com um detector de radiação em um objeto simulador posicionado no campo de radiação. Essas medições incluem a determinação da dose absoluta em uma profundidade e campo de radiação de referência e a dose relativa em diversos pontos do objeto simulador de forma a mapear a completa distribuição de dose ${ }^{25}$.

\subsubsection{Dose Absorvida}

A dose absorvida é uma grandeza relacionada à quantidade de energia estocástica transmitida. É definida como a energia média $\bar{\varepsilon}$ transmitida por radiação ionizante em um meio de massa $m$ em um determinado volume $V$, conforme Equação 1:

$$
D=\frac{d \bar{\varepsilon}}{d m}
$$


A energia transmitida $\bar{\varepsilon}$ é a soma de todas as energias de entrada no volume de interesse menos a de saída. A unidade de dose absorvida é joule por kilograma (J/kg) e o nome da unidade é gray (Gy $)^{26}$.

O procedimento para obtenção da dose absorvida na água em um feixe de radioterapia, usando uma câmara de ionização ou um detector com um fator ou coeficiente de calibração $\mathrm{N}_{\mathrm{D}, \mathrm{W}}$, determinado pelo TRS $398^{9}$, pode ser aplicado em hospitais e instalações que fornecem tratamento radioterápico a pacientes. O TRS 398 utiliza condições de referência para determinação da dose absorvida na água, que são: campo de radiação $10 \mathrm{~cm} \times 10 \mathrm{~cm}$ na superfície do objeto simulador ou na profundidade da medição e um SSD (distância fonte-superfície) ou SDD (distância fonte-detector) de $100 \mathrm{~cm}$.

A dose absorvida, $D_{w, Q}$, na água em uma profundidade de referência Zref em água para um usuário de um feixe com qualidade de radiação $Q$ e na ausência da câmara de ionização é dado por (Equação 2):

$$
D_{w, Q}=M_{Q} N_{D, w, Q}
$$

Onde $M_{Q}$ é a leitura da câmara de ionização do usuário no feixe com qualidade de radiação $Q$, corrigidos para os valores de referência com as grandezas de influência e $N_{D, w, Q}$ é o coeficiente de calibração em termos de dose absorvida na água para a câmara de ionização utilizada, calculada em um laboratório padrão para a qualidade de radiação $Q$ do usuário.

Quando não existe a disponibilidade da calibração direta em um feixe clínico, ou quando o feixe com qualidade de radiação $Q$ do usuário é diferente da qualidade do feixe de calibração Q0, a Equação 3 é dada por:

$$
D_{w, Q}=M_{Q} N_{D, w, Q_{0}} k_{Q, Q_{0}}
$$

Onde $N_{D, w, Q_{0}}$ é o coeficiente de calibração em termos de dose absorvida na água de uma câmara de ionização, medida em um laboratório padrão para calibração do feixe com qualidade de radiação $Q_{0}$ e $k_{Q, Q_{0}}$ é o fator que corrige $N_{D, w, Q_{0}}$ pela diferença entre o feixe com qualidade de radiação $Q_{0}$ e o feixe do usuário com qualidade de radiação $Q$. 
A dose absorvida na água é uma grandeza de interesse em radioterapia, uma vez que está diretamente relacionada com os efeitos biológicos da radiação. Algumas vantagens da calibração em termos de dose absorvida na água e procedimentos de dosimetria utilizando esses fatores de calibração são redução de incerteza, um sistema padrão primário mais confiável e um formalismo simples para ser seguido ${ }^{9}$.

\subsubsection{Dose absorvida na água para campos pequenos}

Assim como em radioterapia convencional, em campos pequenos todas as medições dosimétricas devem possuir rastreabilidade a um padrão de radiação primário. $A$ rastreabilidade é obtida a partir da calibração do detector. O padrão primário de dose absorvida na água existe para feixes de referência com $10 \mathrm{~cm} \times 10 \mathrm{~cm}$. Este padrão primário é, normalmente, usado num laboratório de calibração primário. Os instrumentos dos usuários podem ser diretamente calibrados com os padrões primários, mas são geralmente calibrados com padrões secundários (calibrados previamente com um padrão primário). 0 padrão primário mais comum para dose absorvida na água em campos de referência é o calorímetro. Câmaras de ionização e dosímetros clínicos também são disponíveis.

Poucos estudos utilizam o calorímetro na dosimetria de campos pequenos, pois o mesmo pode acarretar em aumento da condução de calor em um campo menor do que o de referência. Câmaras de ionização, dosímetros químicos e alanina têm sido usados para cálculo de dose absorvida na água. As medições realizadas neste trabalho na dosimetria do Gamma Knifeß Perfexion utilizaram câmaras de ionização e alanina, que serão discutidas posteriormente ${ }^{13}$.

Os equipamentos mais modernos de radioterapia desenvolvidos para tratamentos estereotáxicos não conseguem empregar condições de referência descritas nos protocolos TRS $398^{9}$, TG $51^{10}$, TG $21^{11}$. Para isso, o TRS $483^{13}$ apresenta um novo formalismo para cálculo da dose absorvida em campos pequenos. Este formalismo é discutido na seção 2.6.

No caso do Gamma Knife® Perfexion, o campo de tratamento é sempre formado da superposição de múltiplos campos pequenos. O campo máximo adquirido para o Gamma Knife $\mathbb{B}$ Perfexion é de $16 \mathrm{~mm}$ de diâmetro e a dosimetria de referência é realizada para este campo com um objeto simulador esférico, utilizando uma câmara de ionização de volume pequeno calibrada em ${ }^{60} \mathrm{Co}$, sem a utilização do fator de correção mencionado na Equação 3, uma vez que ambos os feixes, de calibração e do usuário, são os mesmos. 


\subsection{Teoria da Cavidade e Stopping-power}

Para se medir a dose absorvida em um meio é necessário introduzir um detector de radiação nesse meio. Geralmente, esse detector não possui o mesmo material do meio em que se deseja medir a dose absorvida. A teoria da cavidade relaciona a dose absorvida no meio sensível do detector (cavidade) com a dose absorvida no meio em que o detector está posicionado. Cavidades podem ser pequenas, intermediárias ou largas em comparação com a variedade de partículas secundárias carregadas, produzidas por fótons no meio da cavidade. Caso a quantidade de partículas carregadas seja muito maior que as dimensões da cavidade, esta cavidade é considerada pequena. Algumas teorias da cavidade para feixes de fótons foram propostas, de acordo com o volume da cavidade. Para cavidades pequenas existem as teorias de Bragg-Graye Spencer-Attix, que serão descritas a seguir ${ }^{26}$.

\subsubsection{Teoria da cavidade de Bragg-Graye Spencer-Attix}

A teoria da cavidade de Bragg-Gray foi a primeira teoria que relaciona a dose absorvida em um detector com a dose absorvida no meio contendo este detector. As condições para aplicação da teoria de Bragg-Gray são:

a) A cavidade deve ser pequena quando comparada com a variedade de partículas carregadas incidentes, de forma que sua presença não perturbe a fluência de partículas carregadas no meio;

b) A dose absorvida na cavidade é depositada exclusivamente por partículas carregadas em deslocamento (interações de fótons na cavidade são consideradas desprezíveis e, portanto, ignoradas).

A condição (a) resulta no fato de que a fluência de elétrons é a mesma do que a fluência do equilíbrio definido no meio. Essa condição só é válida nas regiões de equilíbrio de partículas carregadas (CPE) ou equilíbrio de partículas carregadas transitório. Além disso, a presença da cavidade sempre causa algum grau de perturbação de fluência que necessita de um fator de correção para o mesmo.

A condição (b) sugere que todos os elétrons que depositam dose dentro da cavidade são produzidos fora da cavidade e atravessam a cavidade completamente. Elétrons 
secundários não são produzidos dentro da cavidade e não são bloqueados dentro da cavidade.

Nestas circunstâncias, de acordo com a teoria de Bragg-Gray, a dose no meio $D_{\text {med }}$ é relacionada com a dose na cavidade $D_{\text {cav }}$ de acordo com a Equação 4.

$$
D_{\text {med }}=D_{\text {cav }}\left(\frac{\bar{S}}{\rho}\right)_{\text {med,cav }}
$$

Onde $\left(\frac{\bar{s}}{\rho}\right)_{\text {med,cav }}$ é a razão da média de colisão de stopping-power de massa ilimitada do meio e da cavidade. O uso de stopping-power ilimitado exclui a produção de partículas carregadas secundárias, na cavidade e no meio.

As condições para o cumprimento da teoria de Bragg-Gray dependem do tamanho da cavidade, que é baseado na variedade de elétrons secundários na cavidade e na energia dos elétrons.

A teoria da cavidade de Spencer-Attix é considerada uma formulação geral, que considera a formação de elétrons secundários que possuem energia suficiente para produzir ionizações adicionais próprias, alguns com energia suficiente para escapar da cavidade com sua própria energia. Isso resulta numa redução da energia absorvida na cavidade e requer modificações no stopping-power do gás.

Cálculos por simulação de Monte Carlo têm mostrado que a diferença entre as duas cavidades não deve ser desprezível, porém, geralmente, não possuem grande relevância ${ }^{26}$.

\subsubsection{Stopping-power}

O stopping-power, ou poder de freamento, é definido como a perda de energia inelástica de um elétron em um meio. O poder de freamento representa a perda média de energia por unidade de caminho em um determinado meio, considerando-se a média sobre um conjunto grande de partículas idênticas e com a mesma energia. 
Os dois tipos de stopping-power são por colisão, que resultam em interações de partículas carregadas com elétrons orbitais, e radioativa que resulta em interações de partículas carregadas com o núcleo do átomo.

Em feixes de fótons (exceto na superfície), a média da razão de stopping-power da água para o ar não varia significativamente em função da profundidade. Para cálculos de dose absorvida, a razão stopping-power desempenha um papel importante, tanto para medições absolutas quanto relativas.

A característica mais importante na variação da profundidade da razão de stoppingpower de feixes monoenergéticos de fótons é que as proporções são quase constantes além da profundidade de dose máxima. Em feixes de fótons produzidos por aceleradores lineares, por exemplo, a razão de stopping-power é alcançada em profundidades mais superficiais devido à presença de fótons de energia mais baixa no espectro ${ }^{25,26}$.

\subsection{Detectores de radiação}

\subsubsection{Câmaras de lonização}

Câmaras de ionização são utilizadas para determinação da dose de radiação. Podem ter várias formas e tamanhos, dependendo da necessidade de seu uso. Uma câmara de ionização é basicamente uma cavidade preenchida com gás, cercada por uma parede externa condutora e por um eletrodo central coletor.

Os tipos de câmaras de ionização existentes são: ar livre, cilíndricas, placas paralelas, cavitárias, transmissão e de extrapolação.

Idealmente, câmaras de ionização utilizadas para medições em feixes de fótons num objeto simulador de água são equivalentes em água e não perturbam a fluência de radiação, além de possuir resposta independente da direção, alta sensibilidade, resposta linear à taxa de dose absorvida na água e dependência energética limitada. Enquanto muitas características podem ser alcançadas apenas de forma aproximada, as câmaras de ionização cilíndricas provaram ser robustas, simples e são adequadas para dosimetria clínica de referência em campos pequenos, utilizadas na água ou em objetos simuladores sólidos ${ }^{25,26}$. 
Muitos tipos de detectores têm sido usados para dosimetria relativa em feixes pequenos e nenhum se destaca em possuir características próximas do ideal. Como 0 detector ideal não existe, o protocolo TRS $483^{13}$ recomenda o uso de dois ou mais detectores diferentes que sejam adequados para a dosimetria, de forma que a repetição das medições forneça confiabilidade e a garantia de que erros dosimétricos não estão sendo cometidos.

Este trabalho utilizou quatro tipos diferentes de câmaras de ionização de volume pequeno, sendo duas específicas para a dosimetria do Gamma Knife® Perfexion.

\subsubsection{Câmara de lonização PTW Pinpoint 3D 31016}

A câmara de ionização PinPoint 3D, modelo 31016, da PTW, foi desenvolvida para dosimetria relativa (dose de saída, curvas de dose na profundidade e perfis do feixe), assim como para determinação da dose absoluta de feixes pequenos de fótons de alta energia. Essa câmara possui um volume de $0,016 \mathrm{~cm}^{3}$ e um diâmetro interno de $2,9 \mathrm{~mm}$. É uma câmara de ionização à prova d'água, sendo, assim, usada em objetos simuladores de água. Essa câmara demonstra uma resposta angular insignificante, uma vez que seu volume é esférico ${ }^{27}$.

Este tipo de câmara é ideal para medição de dose em feixes de fótons muito pequenos, como é o caso dos equipamentos Gamma Knife $\Theta^{\circledR}$ Perfexion para radiocirurgia estereotáxica. A câmara também tem a propriedade de medição de dose fora da extremidade de campos pequenos. Uma grande vantagem do uso dessa câmara de ionização é a capacidade de ser usada para determinação da dose com energia limitada e dependência da taxa de dose. Além disso, possui boa resolução espacial, aumento da resposta com a profundidade e o tamanho de campo, tornando-a um detector útil para caracterização de campos pequenos.

Em contrapartida, este tipo de câmara de ionização é mais sensível a efeitos que são desprezíveis para câmaras com volumes maiores, como a radiação induzida, a radiação de fuga e a multiplicação de carga ${ }^{28}$.

Por causa de interações fotoelétricas no eletrodo central de aço, a câmara claramente não responde bem ao espalhamento Compton de baixa energia. $O$ resultado disso é um aumento na sensibilidade com o tamanho de campo e profundidade, e esse efeito é mais dominante para fótons de energias menores ${ }^{29}$. 
A câmara também demonstra uma forte dependência do tamanho de campo para fatores de correção da polaridade e um excesso de carga coletada, que pode levar a uma subestimativa na eficiência de coleção de carga ${ }^{30}$.

Estudos evidenciam que desvios de medições de valores de dose, utilizando a câmara PinPoint, são muito menores do que utilizando uma câmara do tipo Farmer. A diferença máxima encontrada para medições com a câmara PinPoint foi de menos de 2\%, enquanto para a Farmer foram de mais de $6 \%{ }^{14}$.

A câmara de ionização Pinpoint 31016 é uma das câmaras recomendadas pelo protocolo TRS $483^{13}$ para dosimetria de equipamentos Gamma Knife® Perfexion.

\subsubsection{Câmara de Ionização Exradin A16}

A câmara de ionização da Standard Imaging, Exradin, modelo A16, é considerada a menor câmara de ionização existente atualmente. Possui um volume de $0,007 \mathrm{~cm}^{3} \mathrm{e}$ diâmetro interno de 2,4 mm. Consegue medir campos extremamente pequenos, permitindo boa resolução espacial e exata caracterização do perfil de feixe de radiação.

Diversas pesquisas já foram realizadas com a câmara de ionização Exradin A16 em feixes de radioterapia de intensidade modulada, feixes de fótons de alta energia, cálculo de fatores de correção para radiocirurgia, etc ${ }^{31-33}$.

A Figura 7 mostra uma imagem das câmara de ionização Exradin A16 e Pinpoint 31016.

Figura 7 - Câmaras de ionização Exradin A16 (preta) e PinPoint 31016 (azul)

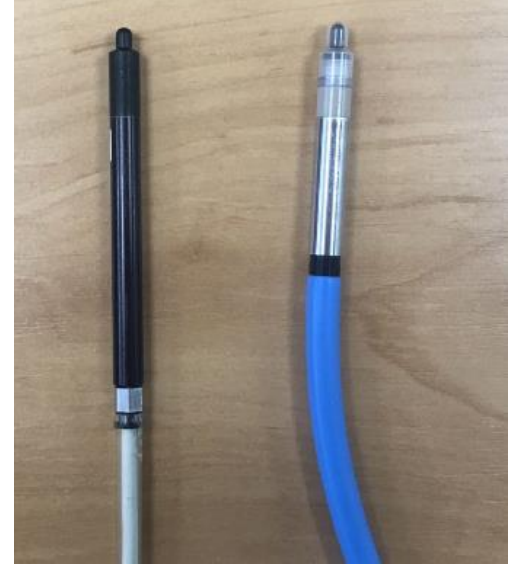

Fonte: autora da tese. 


\subsubsection{Câmara de lonização Semiflex PTW 31010}

A câmara de ionização PTW Semiflex, modelo 31010 (Figura 8), é utilizada para dosimetria, possui volume de $0,125 \mathrm{~cm}^{3}$ e um diâmetro interno de $2,75 \mathrm{~mm}$. É ideal para medições entre campos pequenos, para resolução espacial satisfatória e possui um volume sensível maior, para medições precisas de dose. É uma câmara comum para uso em objetos simuladores de água e seu volume fornece sinal suficiente para uso em medições de dose absoluta ${ }^{27}$.

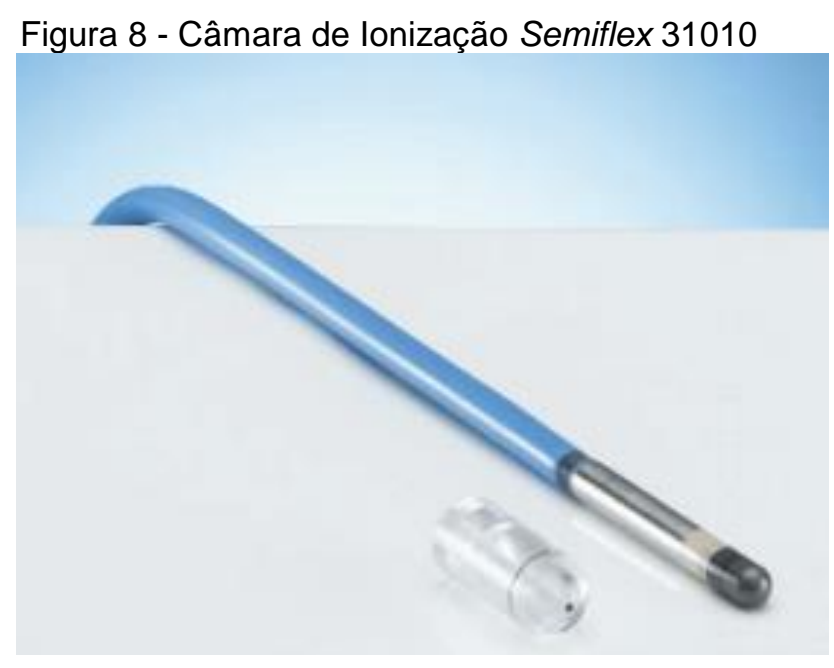

Fonte: PTW 27.

\subsubsection{Câmara de lonização NE2611}

A câmara de ionização NE2611 é utilizada como padrão secundário para calibração em feixes de radioterapia, no laboratório de calibração do National Physical Laboratory (NPL). A calibração de câmaras de ionização padrão secundário no NPL, em termos de dose absorvida, envolve medições de pelo menos quatro qualidades de radiação diferentes para as quais o coeficiente de calibração $\mathrm{N}_{\mathrm{D}, \mathrm{w}}$ é determinado. Possui um volume de $325 \mathrm{~mm}^{3} \mathrm{e}$ diâmetro interno de $7,35 \mathrm{~mm}^{34}$.

Neste trabalho, ambas as câmaras de ionização Pinpoint e Exradin foram calibradas no NPL com a câmara padrão secundário NE2611, no método da substituição. A Figura 9 mostra a câmara de ionização NE2611 utilizada. 
Figura 9 - Câmara de ionização NE2611, padrão secundário do NPL

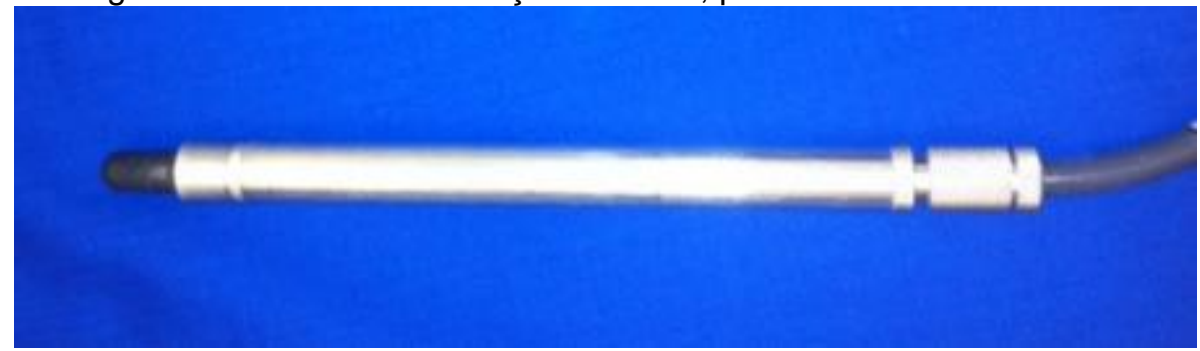

Fonte: $\mathrm{NPL}^{34}$.

\subsubsection{Alanina}

A alanina é usada para dosimetria de alta taxa de dose. O aminoácido da alanina utiliza o cristal orgânico $\mathrm{CH}_{3}-\mathrm{CH}\left(\mathrm{NH}_{2}\right)-\mathrm{COOH}$ como material de detecção da radiação, onde radicais livres são produzidos após irradiação. É um dosímetro bem caracterizado e é amplamente utilizado em serviços de dosimetria postal. Possui número atômico próximo à água e sua dependência energética, em relação à da água, é pequena. $\mathrm{A}$ alanina é apresentada, tipicamente em forma de pastilhas com $5 \mathrm{~mm}$ e $2,5 \mathrm{~mm}$ de diâmetro. Sua densidade é, aproximadamente, $1,2 \mathrm{~g} / \mathrm{cm}^{3}$ e sua massa é em média de $55 \mathrm{mg}$. É formada por uma mistura de $90 \%$ de alanina e $10 \%$ de parafina. Tais propriedades, que oferecem a combinação de equivalência em água, alta precisão e estabilidade, estabeleceram a escolha da alanina como dosímetro de referência neste trabalho.

A alanina pode ser usada em doses de 10 Gy ou mais com precisão para radioterapia. A interação da radiação resulta na formação de radicais em concentração suficiente para serem medidos, utilizando um espectrômetro de ressonância paramagnética eletrônica. A concentração de radicais livres produzidos pela radiação na alanina (que é considerada estável) é proporcional à dose absorvida e pode ser medida por espectroscopia de Ressonância Paramagnética Eletrônica (RPE).

O RPE mede as transições entre os níveis energéticos de elétrons livres e determina a frequência de ressonância em um campo magnético. A intensidade é medida na altura do pico da linha central do espectro. Além disso, a alanina é equivalente ao tecido e não requer correção da energia em feixes de qualidade de radiação em radioterapia. A resposta depende de condições ambientais durante a irradiação, como temperatura e umidade, e também possui perturbação do efeito de volume ${ }^{26}$. Para a medição da dose são utilizados dois tipos de suporte para a alanina: um cilindro com diâmetro externo de $12 \mathrm{~mm}$ e altura de $17 \mathrm{~mm}$, onde as pastilhas são empilhadas umas em cima das outras, e um disco com 
diâmetro de $25 \mathrm{~mm}$ e espessura de $6 \mathrm{~mm}$, em que as pastilhas são posicionadas lado a lado. As pastilhas de alanina são medidas separadamente. A reprodutibilidade no posicionamento das pastilhas e do suporte dentro da cavidade do RPE é essencial para precisão na dose. Para garantir a reprodutibilidade no posicionamento, o NPL projetou um suporte com base em dois tubos concêntricos de quartzo. Este suporte também permite a rotação automática das pastilhas em $90^{\circ}$, a fim de calcular a média de efeitos anisotrópicos. Também foi desenvolvido um sistema automático de carregamento das pastilhas no suporte.

A alanina é um dosímetro sensível para medições em campos pequenos e possui boa concordância com a resposta dos detectores de volume pequeno. A utilizada neste trabalho foi produzida pelo NPL. As pastilhas de alanina produzidas pelo NPL são calibradas em termos de dose absorvida na água utilizando ${ }^{60} \mathrm{Co}$, em um campo cuja taxa de dose possui rastreabilidade direta ao padrão primário do NPL, que é o calorímetro de grafite. A incerteza total associada com esta calibração é estimada a $\pm 2 \%$.

As pastilhas de $2,5 \mathrm{~mm}$, utilizadas neste trabalho para campos pequenos, (Figura 10) requerem uma dose maior do que 30 Gy para possibilidade de leitura, dada a sua baixa sensibilidade ${ }^{35}$.

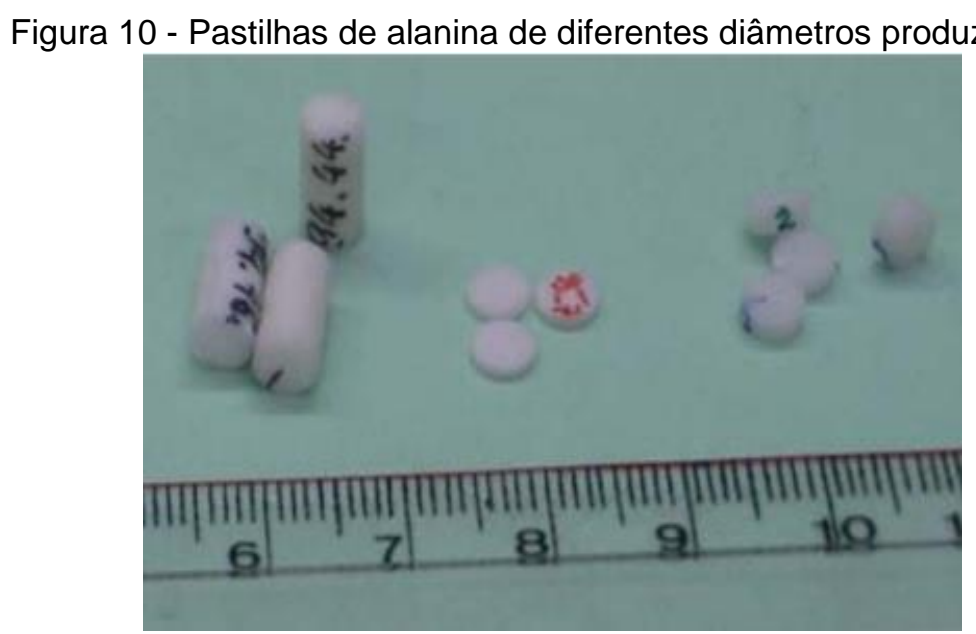

Fonte: autora da tese.

A alanina tem sido também usada como padrão de transferência para determinação da dose em campos pequenos. Considerando que a densidade das pastilhas de alanina é muito próxima à densidade da água, a maioria das correções pode ser determinada com boa acurácia, uma vez que é influenciado pela média de volume. Este trabalho utilizou a 
alanina como dosímetro de referência em um objeto simulador de acrílico para a dosimetria de equipamentos Gamma Knife® Perfexion.

\subsection{Objetos simuladores}

Para um objeto simulador, o material mais indicado como referência nas medições é a água. Alguns equipamentos radioterápicos impossibilitam a utilização da água como material que compõe o objeto simulador, como é o caso do Gamma Knife®. Portanto, objetos simuladores sólidos devem ser utilizados.

O material sólido do objeto simulador deve possuir densidade o mais próxima possível da água, para utilização em dosimetria de referência. Além disso, deve ter acurácia no posicionamento, de forma que o ponto de medição esteja no eixo central do feixe de radiação ${ }^{13}$.

Os objetos simuladores fornecidos pela Elekta, um de poliestireno ABS e outro de Solid Water $\AA$, (Figura 11) para dosimetria do Gamma Knife $\Theta$ possuem densidades equivalentes à água, propriedades atômicas bem definidas e foram produzidos para exatidão no posicionamento do detector. Ambos possuem $16 \mathrm{~cm}$ de diâmetro e são usados para medições de dose absorvida com acurácia. O objeto simulador de ABS é formado por duas semiesferas com $130 \mathrm{~mm}$ de largura e $5 \mathrm{~mm}$ de profundidade da abertura central. Essas semiesferas são unidas por dois pinos de Lucite (PMMA), e os furos correspondentes estão localizados na área periférica de cada semiesfera. A abertura central é usada para acomodar uma placa plana de $130 \mathrm{~mm} \times 160 \mathrm{~mm} \times 10 \mathrm{~mm}$, feita de plástico ABS. A placa é arredondada em duas extremidades, de modo que a sua superfície esteja nivelada com a superfície esférica do objeto simulador. Além disso, esse objeto simulador é mantido por um adaptador de alumínio com o formato de "C" e que possui parafusos de fixação de aço inoxidável. O objeto simulador de Solid Water ${ }^{\circledR}$ compõe-se de uma única esfera que possui um encaixe para a inserção de diferentes detectores de radiação ${ }^{23}$. 
Figura 11 - Objeto simulador de poliestireno (ABS) e de água sólida (Solid Water®)
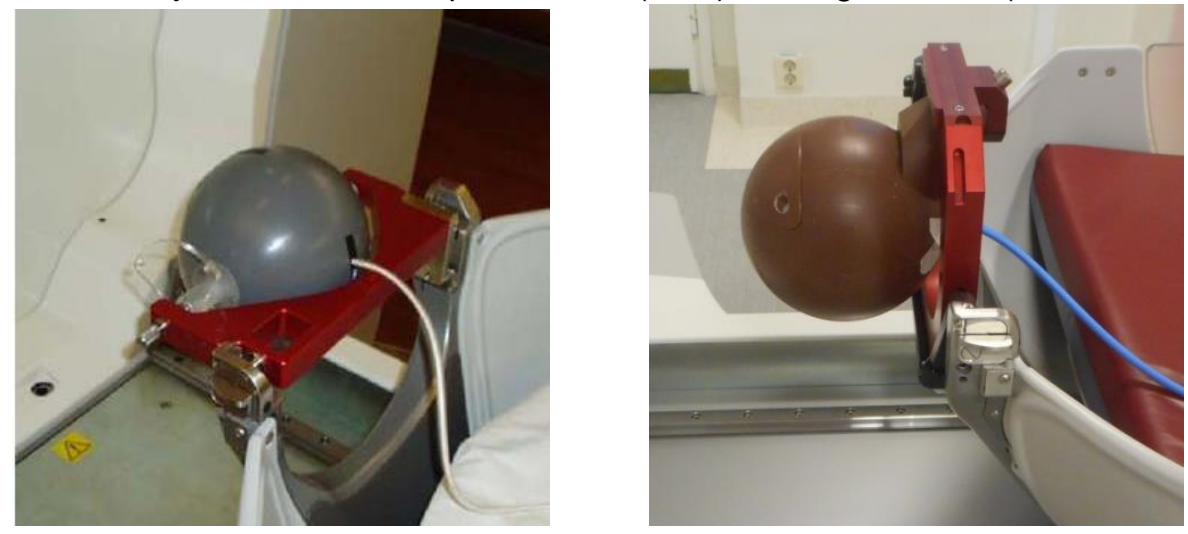

Fonte: autora da tese.

\subsection{Dosimetria em campos pequenos}

O protocolo TRS $398^{9}$ da Agência Internacional de Energia Atômica (Absorbed dose determination in external beam radiotherapy) trata da dosimetria de radioterapia convencional, baseada em dose absorvida na água em condições de referência e com rastreabilidade a um laboratório de calibração primária. Porém, em radioterapia, especialmente em radiocirurgia estereotáxica, o uso de campos de radiação menores têm aumentado a incerteza na dosimetria clínica e diminuído a rastreabilidade a uma dosimetria de referência, baseada em Códigos de Prática existentes ${ }^{10,11}$, como o TRS $398^{9}$. Ao mesmo tempo, erros dosimétricos são maiores do que em feixes de referência, principalmente por duas razões: as condições de referência não podem ser alcançadas por certos equipamentos (como o Gamma Knifeß) e os procedimentos de medição de dose absorvida na água, e campos de radiação pequenos e complexos, não são padronizados.

Dada a necessidade de padrões na dosimetria de campos pequenos, o protocolo TRS $483^{13}$ foi lançado no ano de 2017 para a dosimetria de campos pequenos em feixes de radioterapia.

O protocolo TRS $483^{13}$ descreve um campo pequeno quando possuir pelo menos uma das três condições abaixo:

a) Perda de equilíbrio lateral de partículas carregadas (LCPE);

b) Obstrução parcial do feixe primário de fótons por meio de colimadores;

c) O tamanho do detector é similar ou grande comparado às dimensões do feixe de radiação. 
Todas as três condições resultam na sobreposição entre a penumbra do campo e o volume do detector.

A perda de equilíbrio lateral de partículas carregadas em feixes de fótons ocorre quando a largura média do feixe é menor do que o alcance máximo do feixe de elétrons secundários, que contribuem para medição da dose absorvida. Essa condição foi quantificada avaliando o raio mínimo de um campo circular de fótons, nas quais colisões de kerma e dose absorvida em água alcançaram valores determinados por equilíbrio de partículas carregadas de feixes largos. Essa condição é mostrada na Figura 12.

Figura 12 - Razão da dose na água pela colisão do kerma na água calculado por Monte Carlo numa profundidade de $5 \mathrm{~cm}$ no centro do feixe de fótons.

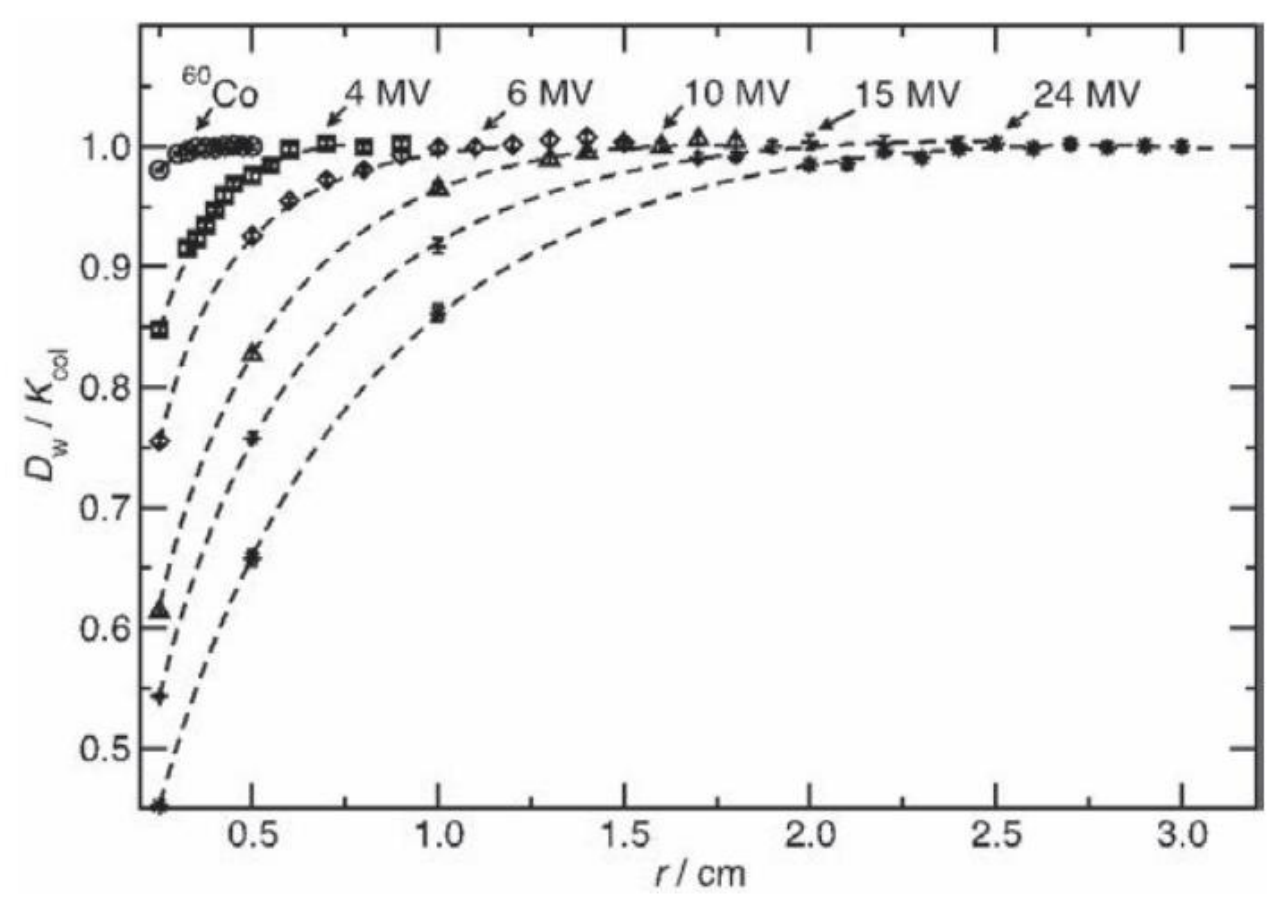

Fonte: TRS 483, $2017^{13}$.

A obstrução parcial do feixe de fótons é relacionada ao tamanho limitado do feixe de fótons, que é determinado pela largura à meia altura de seu valor máximo (FWHM), na distribuição de fluência de fótons de Bremsstrahlung ao saírem do alvo. Um campo pequeno criado por colimação que bloqueia parte do feixe primário de fótons irá produzir um output de feixe menor, comparado a campos onde o feixe não é bloqueado. Essa oclusão parcial do feixe primário de fótons influencia o espectro de partículas e é responsável pela inclinação do gradiente de dose absorvida, que pode ter uma grande influência na resposta do detector. A Figura 13 demonstra essa condição. 
Figura 13 - Ilustração do efeito de oclusão da fonte de radiação. Em A visão total do feixe direto de radiação estendido e em B visão parcial do feixe direto de radiação estendido.

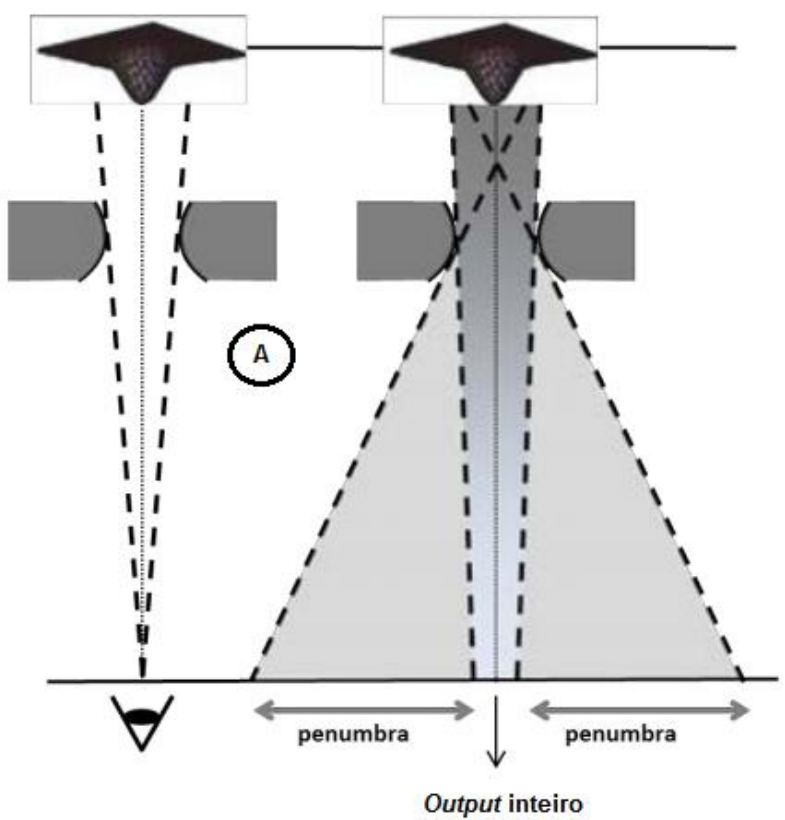

Fonte: TRS 483, $2017^{13}$.

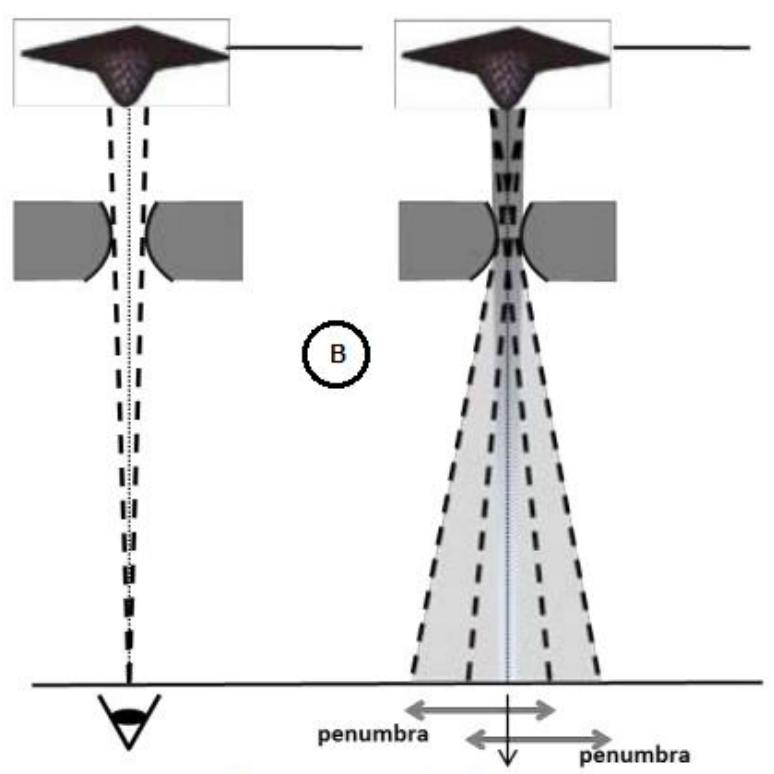

Oclusão da fonte de radiação com sobreposição da penumbra e diminuição do output

A última condição que descreve um campo pequeno é o tamanho do detector ser igual ou maior do que o feixe de radiação. Um detector de radiação produz um sinal que é proporcional à média de dose absorvida no seu volume sensível, e este sinal é afetado pela homogeneidade da dose absorvida no volume de detecção (média de volume). Este efeito é mostrado na Figura 14.

Além da média de volume, a perturbação da fluência de partículas carregadas (e assim o desvio das condições da teoria de Bragg-Gray) devido à presença do detector é um ponto importante e deve ser notado que ambos os efeitos estão ligados. Na presença de gradientes de dose altos e na ausência de equilíbrio lateral de partículas carregadas, perturbações de fluência se tornam extensas e difíceis de modelar. Correções para média de volume também apresentam incertezas maiores. 
Figura 14 - llustração do efeito de volume em uma dimensão. A curva preta é a curva Gaussiana que representa um perfil de campo pequeno. A curva tracejada representa a medição de um detector com $5 \mathrm{~mm}$ de comprimento. A seta dupla representa a dimensão do detector ao longo do eixo. A linha tracejada com pontos mostra a diferença entre as duas curvas como fração da dose máxima.

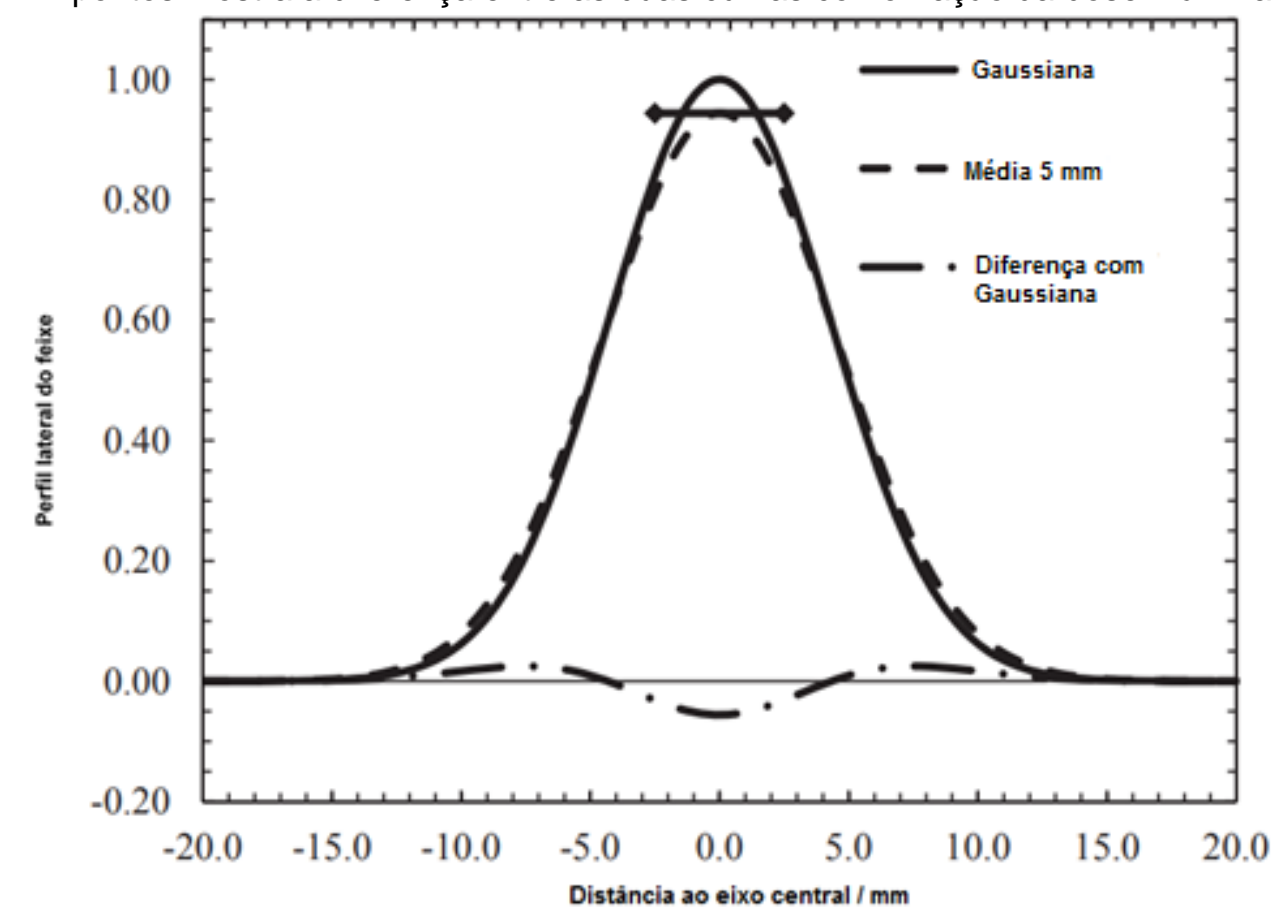

Fonte: TRS 483, $2017^{13}$.

A nova dosimetria de referência para campos pequenos adota o conceito de um campo intermediário de calibração denominado como campo de máquina estática específica de referência (MSR). É recomendado que o campo da MSR possua dimensões mais próximas possíveis do campo de referência $(10 \mathrm{~cm} \times 10 \mathrm{~cm})$, de acordo com os Códigos de Prática ${ }^{9,10}$, e que o limite exterior da câmara de ionização de referência se estenda pelo menos ao alcance da distância do equilíbrio lateral de partículas carregadas ( $\mathrm{rLCPE}$ ). Esse critério limita a variedade de câmaras de ionização adequadas para medições em campos pequenos.

O parâmetro rLCPE determina quando o tamanho do campo é considerado pequeno e é definido como o raio mínimo de um campo de fótons circular no qual a colisão de kerma e dose absorvida na água são iguais no centro do campo.

Para campos em Gamma Knife $\Theta$, o fato de que o fator de correção para a qualidade do feixe é pequeno deve-se ao tamanho da cavidade, com valores entre $2 \mathrm{~mm}$ e $4 \mathrm{~mm}$ para detectores de volume pequeno, de modo que o acúmulo de carga lateral total, que não é alcançado pelas bordas externas do detector, é parcialmente alcançado dentro da espessura adicional do material da parede. Esse raciocínio ignora o fato de que 
entre a conexão do material do objeto simulador e a parede existe um componente adicional de desequilíbrio de partículas carregadas, e que a interação deste efeito com a ausência de LCPE pode resultar em um fator de correção da perturbação diferente do utilizado para feixes maiores.

Algumas câmaras de ionização que não são adequadas para feixes de alta energia, preenchem os requisitos para uso em Gamma Knifeß. Isto pode ser explicado pelo fato de que apenas parte da haste da câmara é irradiada, o que significa que efeitos da polaridade, observados em feixes largos com esses tipos de câmara de ionização, não são observados em medições no Gamma Knife®.

As câmaras de ionização utilizadas para dosimetria de campos pequenos em Gamma Knife® neste trabalho são câmaras que estão incluídas na lista do TRS $483^{13}$ como recomendadas e são consideradas adequadas para a dosimetria de referência do Gamma Knife $\AA$.

\subsubsection{Dosimetria do Gamma Knife®}

O recém publicado protocolo TRS $483^{13}$ fornece as condições de referência necessárias para a determinação da dose absorvida na água em equipamentos Gamma Knife®. Essas condições são:

a) O material do objeto simulador deve ser de água ou plástico (poliestireno, ABS, Solid Water ${ }^{\circledR}$, etc.);

b) Deve ter formato hemisférico (cilíndrico), com $16 \mathrm{~cm}$ de diâmetro;

c) A câmara de ionização deve ser uma câmara cilíndrica de volume pequeno;

d) A profundidade das medições deve estar localizada no centro hemisférico;

e) O ponto de referência da câmara deve estar no eixo central (centro do volume da cavidade = centro hemisférico);

f) SSD de $32 \mathrm{~cm}$;

g) Tamanho de campo máximo disponível (colimador de $16 \mathrm{~mm}$ para o Gamma Knife® Perfexion).

O formalismo proposto por Alfonso ${ }^{36}$ et al. e utilizado no TRS 483 para determinação da dose absorvida na água em MSR, neste caso o Gamma Knife®, depende da disponibilidade do coeficiente de calibração da câmara de ionização utilizada para a 
dosimetria. Este coeficiente de calibração $N_{D, w, Q_{0}}^{f_{r e f}}$ é obtido em condições referência que são: qualidade do feixe $Q_{0}$; campo $f_{\text {ref }}=10 \mathrm{~cm} \times 10 \mathrm{~cm}$; e fator de correção da qualidade do feixe de radiação $k_{Q_{m s r, Q_{0}}}^{f_{m s r, f_{r e f}}}$, que corrige o uso do coeficiente de calibração no campo $f_{\mathrm{msr} \text {, (campo }}$ do Gamma Knifeß). Assim, a Equação 5 para cálculo da dose absorvida em um equipamento Gamma Knife® é:

$$
D_{w, Q_{m s r}}^{f_{m s r}}=M_{Q_{m s r}}^{f_{m s r}} N_{D, w, Q_{0}}^{f_{r e f}} k_{Q_{m s r, Q_{0}}}^{f_{m s r, f}}
$$

Para Gamma Knifeß, o fator $k_{Q_{m s r, Q_{0}}}^{f_{m s r, f}}$, com referência a uma câmara de ionização $\operatorname{com} N_{D, w, Q_{0}}^{f_{r e f}}$ e sendo $Q_{0}={ }^{60} \mathrm{Co}$, possui conformidade para a maioria das câmaras de ionização, que são adequadas para dosimetria de referência em Gamma Knifeß. Porém, uma vez que a dosimetria de Gamma Knifeßé é realizada em objetos simuladores de plástico ou Solid Water $\AA$, o fator de correção inclui a conversão para dose absorvida na água. Além disso, os valores de $k_{Q_{m s r}}^{f_{m s r, f}}$ para o Gamma Knifeß Perfexion, modelo utilizado neste trabalho, são fornecidos no TRS $483^{13}$, e para as câmaras de ionização utilizadas neste trabalho são mostradas na Tabela 1.

Tabela 1 - Fatores de correção $\boldsymbol{k}_{\boldsymbol{Q}_{\boldsymbol{m}} \boldsymbol{s} \boldsymbol{r}}^{\boldsymbol{f}_{\boldsymbol{m}} \boldsymbol{f}_{\text {ref }}}$ para o Gamma Knife® Perfexion

Gamma Knife® Perfexion

Câmara de lonização $f_{\mathrm{msr}}=16 \mathrm{~mm}$

Solid Water® $\quad$ ABS Água

PTW Pinpoint 31016

$1,0040 \quad 1,0110$

0,9991

Exradin A16

1,0167

1,0295

1,0127

Fonte: TRS 483, $2017^{13}$. 
Deve-se ainda considerar o fator de correção do objeto simulador, $k_{Q_{m s r}}^{w, p l a s t i c}$, que pode ser considerado experimentalmente por simulação Monte Carlo, como a razão da leitura da câmara de ionização (corrigida pelas grandezas de influência) na água, a uma profundidade Zref e no objeto simulador de plástico substituto da água, numa profundidade Zeq,plástico.

\subsection{Fator output de campo}

O fator output de campo é definido pela razão entre a dose absorvida na água, em qualquer campo não-referência, e o campo referência a uma dada profundidade. $\mathrm{Na}$ dosimetria de campos pequenos, o fator output de campo requer um fator de correção do output que deve ser aplicado à razão da leitura do detector medido. O cálculo deste fator é dado pela Equação 6.

$$
\Omega_{Q_{c l i n, Q_{m s r}}}^{f_{c l i n, f m s r}}=\frac{M_{Q_{c l i n}}^{f_{c l i n}}}{M_{Q_{m s r}}^{f_{m s r}}} k_{Q_{c l i n, Q_{m s r}}}^{f_{c l i n, f}}
$$

Onde: $M_{Q_{c l i n}}^{f_{c l i n}}$ e $M_{Q_{m s r}}^{f_{m s r}}$ são as leituras do detector (corrigidas pelas grandezas de influência) no campo clínico e no campo MSR, respectivamente. Para um equipamento Gamma Knife® Perfexion, o campo clínico é considerado o campo com o uso do colimador de $8 \mathrm{~mm}$ ou $4 \mathrm{~mm}$ e o campo MSR é o campo com o uso do colimador de $16 \mathrm{~mm}$, considerado como referência para sua dosimetria.

O TRS $483^{13}$ mostra que muitos erros entre a razão da medição de leituras têm sido publicados com diferentes tipos de detectores, quando comparados com os valores de dose absorvida na água. Esses erros são principalmente relacionados ao tamanho de campo e à dependência do detector e podem ser extremamente altos quando detectores com grande volume realizam medições de campos pequenos.

Para a determinação do fator output, o efeito da média de volume pode ser um fator limitante na escolha do detector. Portanto, a escolha do tamanho do detector deve ser tal que a fluência de radiação seja relativamente uniforme na área do detector. Além disso, a dependência da taxa de dose absorvida, equivalência à água, dependência energética devido à resposta do detector quanto ao tamanho do campo e outras perturbações podem afetar a determinação do fator output. 
Ainda não existe na literatura dados e informações suficientes que forneçam um guia para este método. Devido à dificuldade de medição do fator output de campo, o TRS $483^{13}$ fornece a opção de sair da condição de referência e apresenta uma metodologia e fatores para que seja determinado o fator de output do campo. A determinação desse fator é tão importante quanto a dosimetria de referência e requer a aplicação de fatores de correção precisos. Portanto, é possível encontrar valores tabulados de correção do fator output no TRS $483^{13}$, como função do quadrado equivalente para campos pequenos. Para campos não-quadrados, um método é fornecido para determinação do campo quadrado equivalente para campos pequenos, no qual o fator de correção deve ser o mesmo. Para o equipamento Gamma Knife® Perfexion, o fator output é expresso apenas para a câmara de ionização PTW Pinpoint 31016 para o campo de $8 \mathrm{~mm}$. Esse valor é de 1,032.

\subsection{Fatores de Correção}

Para cada câmara de ionização, as condições de referência são descritas por uma série de influências para as quais o coeficiente de calibração é válido. Se uma câmara de ionização é utilizada em condições diferentes da condição de referência, correções para essas influências devem ser realizadas, de forma a se obter o sinal correto ${ }^{25,26}$. Essas influências podem ser relacionadas à:

\section{a) Temperatura, Pressão e Umidade}

Uma vez que a maioria das câmaras de ionização são abertas ao ambiente atmosférico, a densidade do ar é função da pressão atmosférica, da temperatura e da umidade, portanto a carga coletada pela câmara também é função da mesma, uma vez que a densidade do ar e a carga coletada estão correlacionadas. A umidade relativa do ar não é corrigida uma vez que durante uma calibração ela é controlada na faixa de 20 a $70 \%$, de forma que o coeficiente de calibração se aplica para uma umidade relativa em torno de $50 \%$.

O fator de correção utilizado para correção de temperatura e pressão do ar $\left(k_{t, p}\right)$ é dado pela Equação 7.

$$
k_{T, P}=\frac{(273.2+T)}{\left(273.2+T_{0}\right)} \frac{P_{0}}{P}
$$


Onde T é a temperatura $\mathrm{P}$ é a pressão no momento das medições; $\mathrm{T}_{0}$ e $\mathrm{P}_{0}$ são temperatura e pressão em condições normais utilizadas nos laboratórios padrão.

b) Polaridade

Em condições de irradiação idênticas, o uso de potenciais de polaridade opostos em uma câmara de ionização pode produzir leituras diferentes, um fenômeno conhecido como efeito da polaridade. $O$ fator de correção da polaridade $k_{p o l}$ é dado pela seguinte Equação 8.

$$
\mathrm{k}_{\mathrm{pol}}=\frac{\left|M_{+}\right|+\left|M_{-}\right|}{2 M}
$$

Onde $M_{+}$e $M_{-}$são os sinais da câmara de ionização obtidos em condições de irradiação idênticas com polaridades positiva e negativa da câmara, respectivamente, e $M$ é o sinal obtido na polaridade utilizada na rotina (seja positiva ou negativa).

c) Recombinação lônica

A resposta de uma câmara de ionização depende da dose de radiação, da taxa de dose, da polaridade e da tensão aplicada entre os eletrodos da câmara. A carga produzida na câmara pela radiação pode ser diferente da carga coletada e essa diferença ocorre como resultado de restrições impostas pela física do transporte de íons no volume sensível da câmara e pelo modelo elétrico da câmara. Tanto a recombinação de carga quanto a multiplicação de carga são influenciadas pelo potencial aplicado à câmara de ionização.

Para feixe de radiação contínua, como é o caso do Gamma Knife® Perfexion, a Equação 9 deve ser utilizada para correção: 


$$
k_{\text {ion }}=\frac{\left(\frac{V_{1}}{V_{2}}\right)^{2}-1}{\left(\frac{V_{1}}{V_{2}}\right)^{2}-\frac{M_{1}}{M_{2}}}
$$

Onde $M_{1}$ e $M_{2}$ são as cargas coletadas na tensão de polarização $V_{1}$ e $V_{2} \operatorname{com} M_{1}$ em operação na tensão normal de operação $V_{1}$ e $V_{2}$ com tensão menor. Essa relação é baseada na dependência linear de $1 / M$ em $1 / V^{2}$, que descreve o efeito da recombinação em feixes contínuos.

d) Fator de calibração do eletrômetro $N_{\text {elec }}$

Quando a câmara de ionização e o eletrômetro são calibrados separadamente, o coeficiente de calibração para a câmara de ionização é dado em $\mathrm{Gy} / \mathrm{nC}$. O fator de calibração Nelec obtido para o eletrômetro converte a leitura do eletrômetro para carga e é expresso em C/u.e., sendo u.e. a unidade da escala do eletrômetro. 


\section{METODOLOGIA}

Este trabalho foi desenvolvido em algumas etapas principais:

a) Controle de qualidade do sistema de referência;

b) Dosimetria de três sistemas Gamma Knife ${ }^{B}$ Perfexion, um no Brasil, um em Estocolmo, Suécia e o terceiro em Londres, Inglaterra;

c) Desenvolvimento no Brasil e aperfeiçoamento na Inglaterra de um objeto simulador específico para dosimetria e calibração das câmaras de ionização de volume pequeno;

d) Calibração das câmaras de ionização de volume pequenos em um laboratório primário de calibração na Inglaterra.

Neste capítulo serão descritos os materiais e métodos aplicados para cada etapa.

\subsection{Materiais}

\section{Sistemas de medição:}

Câmaras de ionização utilizadas para dosimetria:

- Três câmaras de lonização da marca PTW, PinPoint 31016, de volume 0,016 cm³, pertencentes ao Hospital do Coração (São Paulo-SP), à Elekta Instrument AB (Estocolmo-Suécia) e ao NPL (Londres - Inglaterra). Fig.7

- Câmara de Ionização Exradin de volume $0,007 \mathrm{~cm}^{3}$, modelo $A 16$, pertencente ao Hospital Albert Einstein em São Paulo. Fig. 7

- Câmaras de lonização da marca PTW, Semiflex de volume 0,125 cm³ pertencentes ao Hospital Karolinska, à Elekta e ao Hospital Queen Square Radiosurgery Center (QSRC). Fig. 8

Câmara de ionização de referência para a calibração no laboratório primário NPL:

- Câmara de Ionização tipo NE2611, padrão secundário no Reino Unido. Fig. 9

Eletrômetros utilizados para acoplar as câmaras de ionização:

- Eletrômetros PTW Unidos Webline pertencentes ao HCor, Hospital Karolinska e NPL. 
- Eletrômetros PTW Unidos E, pertencente ao Instituto de Pesquisas Energéticas e Nucleares (IPEN) e ao QSRC.

Alanina

- Pastilhas cilíndricas de alanina de 2,5 mm, confeccionadas no NPL. Fig.10

\section{Espectrômetro}

- Espectrômetro Bruker ESP 300 X-band para leitura das alaninas.

\section{Sistemas de Irradiação:}

- Fonte de controle ${ }^{90} \mathrm{Sr}$ da marca PTW, atividade nominal de $33,3 \mathrm{MBq}$, modelo Kontrollvorrichtung Typ 48002.

- Theratron Irradiator: Unidade de ${ }^{60} \mathrm{Co}$ presente no NPL, com atividade de 336,6TBq.

- Equipamento Gamma Knife $\Theta$ Perfexion da marca Elekta com 192 fontes de ${ }^{60} \mathrm{Co}$ para tratamento clínico, presente em São Paulo, Estocolmo e Londres. (Figura 1)

- Acelerador Linear Elekta, modelo Synergy, presente no NPL com energias de 4 a $25 \mathrm{MV}$.

Objetos simuladores:

- Esfera de poliestireno (ABS) e de água sólida (Solid Water $\circledast$ ) $\mathrm{com} 16 \mathrm{~cm}$ de diâmetro. (Figura 11).

- Acrílico (PMMA) para desenvolvimento e execução do objeto simulador.

\subsection{Métodos}

Serão detalhadas a seguir as etapas realizadas para a conclusão deste trabalho. Estas etapas se dividem em controle de qualidade de uma câmara de ionização de volume pequeno, dosimetria de equipamentos Gamma Knife® Perfexion, construção de um objeto simulador, calibração das câmaras de ionização de volume pequeno em um laboratório primário e dosimetria do equipamento Gamma Knife® Perfexion com as câmaras de ionização calibradas.

As medições deste trabalho foram realizadas em hospitais e laboratórios de calibração. A dosimetria do equipamento Gamma Knife® Perfexion foi realizada em três 
hospitais de países diferentes. Já a calibração das câmaras de ionização de volume pequeno utilizadas foi realizada no laboratório de calibração primário do NPL.

\subsubsection{Controle de qualidade da câmara de ionização Exradin A16}

Alguns testes de controle de qualidade da câmara de ionização de volume pequeno Exradin A16 foram realizados no Laboratório de Calibração de Instrumentos do IPEN. O protocolo utilizado foi o International Electrotechnical Commission (IEC) 60731: $2011^{37}$ Medical electrical equipment - Dosimeters with ionization chambers used in radiotherapy.

De acordo com a norma IEC 60731, os testes realizados possuem os seguintes objetivos:

- Repetibilidade: repetição das medições e cálculo do desvio-padrão relativo das leituras, expresso em porcentagem;

- Tempo de estabilização: durante um período entre 15 minutos e 2 horas depois da aplicação da tensão de polarização, os limites de variação da resposta não devem ser maiores do que $\pm 0,5 \%$ da resposta medida depois de 1 hora da aplicação da tensão, para o caso onde a câmara de ionização é continuamente irradiada, desde a aplicação da tensão.

- Estabilidade ao longo do tempo: os limites de variação da câmara de ionização, quando irradiada em um campo reprodutível de ${ }^{60} \mathrm{Co}$ ou ${ }^{137} \mathrm{Cs}$, não deve ser maior do que: $\pm 1 \%$ em um ano, para o conjunto de câmaras de campo de referência; $\pm 0,5 \%$ em um ano, para o conjunto de câmaras de referências e $\pm 1 \%$ em um mês para conjunto de câmaras de varredura.

- Fuga pós-irradiação: dentro de 5 segundos após uma irradiação de 10 minutos, a fuga de corrente deve ter diminuído para $\pm 1 \%$ da corrente de ionização produzida no volume medido durante a irradiação.

- Efeito de fuga de corrente: a corrente de fuga deve ser menor do que $\pm 1 \%$ da corrente de ionização produzida pela taxa de dose efetiva.

As medições foram realizadas com a câmara de ionização inserida na fonte de controle. Foram realizadas dez leituras para cada teste. Esta câmara de ionização pertence ao Hospital Albert Einstein e foi utilizada durante todo o período de medições deste trabalho. 


\subsubsection{Dosimetria de equipamentos Gamma Knife $\AA^{\circledR}$ Perfexion}

A dosimetria em um equipamento Gamma Knife® Perfexion é realizada com o todos os oito setores abertos (cada setor com 24 fontes de ${ }^{60} \mathrm{Co}$ ) e com o colimador de $16 \mathrm{~mm}$ de diâmetro. A câmara de ionização deve estar posicionada de forma que seu volume efetivo esteja no centro do objeto simulador. $O$ centro do objeto simulador no momento da irradiação é posicionado em $\mathrm{X}=\mathrm{Y}=\mathrm{Z}=100$.

Em parceria com o Hospital do Coração (HCor) de São Paulo, as primeiras medições de dosimetria no Gamma Knife $\Theta$ do hospital foram realizadas com o objeto simulador ABS e com a câmara de ionização PTW Pinpoint 31016. A Figura 15 mostra a configuração de dosimetria (objeto simulador e câmara de ionização), original deste hospital, para a realização das medições.

Para estas medições, foram realizadas 10 leituras de carga, calculada a média das leituras, corrigida paraas condições ambientais de referência de temperatura e pressão, e calculada a dose absorvida, utilizando a equação 2 e o ND,w do fabricante, disponível no certificado da câmara de ionização.

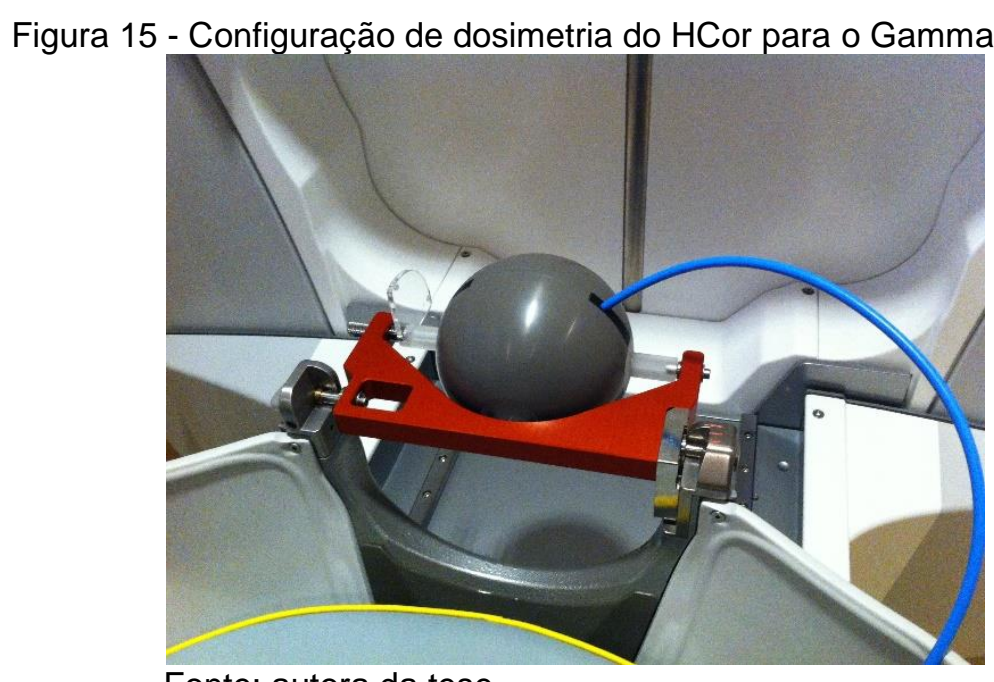

Fonte: autora da tese.

A segunda dosimetria foi realizada no Gamma Knife ${ }^{\circledR}$ do Hospital Karolinska em Estocolmo, Suécia, de forma a verificar a utilização e o comportamento de outras câmaras de ionização e dos objetos simuladores de ABS e Solid Water ${ }^{\circledR}$. Foram utilizadas oito câmaras de ionização, sendo seis PTW 31010 Semiflex e duas PTW Pinpoint 31016, e dois objetos simuladores, ABS e Solid Water ${ }^{\circledR}$. 
Dez leituras de carga foram obtidas para cada câmara de ionização com cada um dos objetos simuladores. Fatores de correção para temperatura e pressão foram calculados para cada câmara de ionização. A dose absorvida foi calculada utilizando o $\mathrm{N}_{\mathrm{D}, \mathrm{w}}$ de cada câmara de ionização, obtido no certificado de calibração fornecido pelo fabricante. Nenhuma dessas câmaras de ionização utilizadas em Estocolmo foi calibrada em um laboratório primário. A Figura 16 mostra as duas configurações utilizadas neste hospital.

Figura 16 - Configuração de dosimetria realizada no Hospital Karolinska em Estocolmo, Suécia
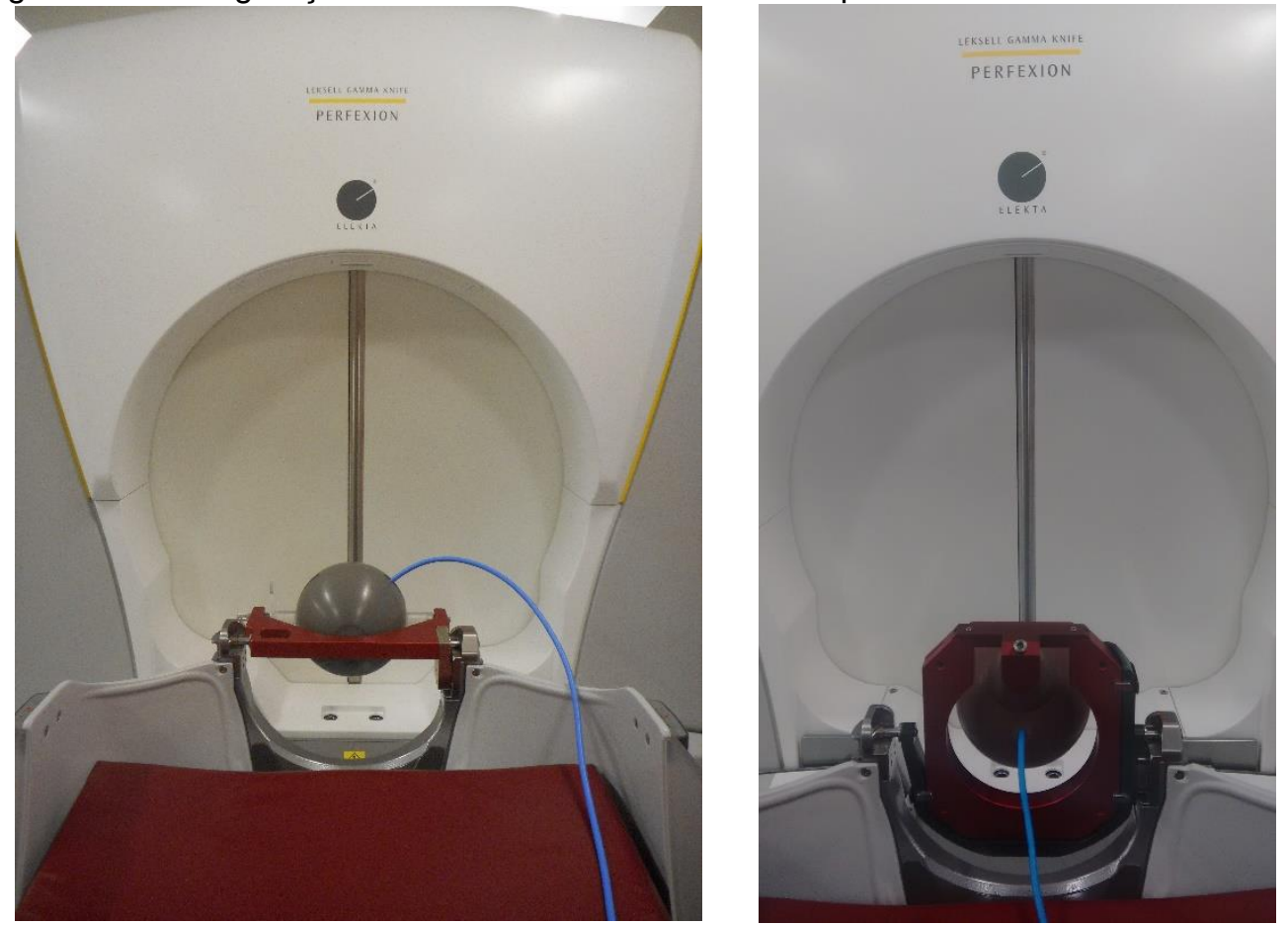

Fonte: autora da tese.

3.2.3 Construção de um objeto simulador de acrílico para dosimetria em equipamentos Gamma Knife $\AA$

\section{Primeira etapa: construção e testes}

Um objeto simulador foi construído para a dosimetria de equipamentos Gamma Knife $\Theta$ realizadas neste trabalho. A geometria dos objetos simuladores fornecidos pela Elekta, de $16 \mathrm{~cm}$ de diâmetro, foi considerada na construção deste objeto simulador.

A partir de análises de dados das dosimetrias realizadas, estudos de materiais e suas densidades, custo e tempo de fabricação, o material escolhido para produção do 
objeto simulador foi o acrílico. O acrílico possui um custo razoável, dentre os materiais que possuem densidade próxima à água, teve uma rápida produção de acordo com a geometria do adaptador do Gamma Knife® e possui fácil manuseio. Seu projeto foi baseado e desenvolvido semelhante ao modelo do objeto simulador ABS, de forma que pudesse ser conectado ao mesmo adaptador.

A esfera do objeto simulador de acrílico foi confeccionada por uma empresa especializada em acrílicos, em São Paulo. Após a obtenção da esfera, a oficina de materiais do IPEN foi responsável pela perfuração do objeto simulador para inserção da câmara de ionização PTW Pinpoint 31016, de acordo com as dimensões da câmara, que foram encontradas em seu manual de instruções ${ }^{27}$. Inicialmente, devido à limitação de tempo e recursos financeiros, o objetivo era apenas a utilização desta câmara. A Figura 17 mostra as etapas de montagem e preparo da perfuração do objeto simulador na oficina de materiais do IPEN.

Figura 17 - Produção do furo no objeto simulador para inserção da câmara de ionização

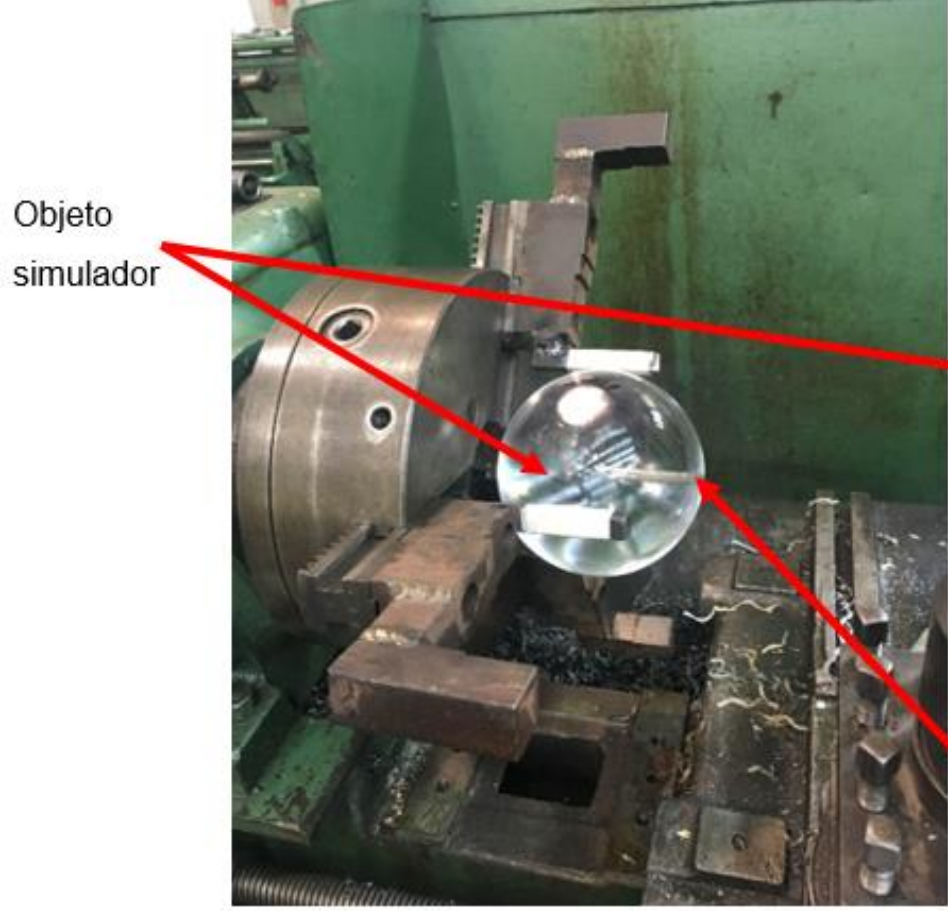

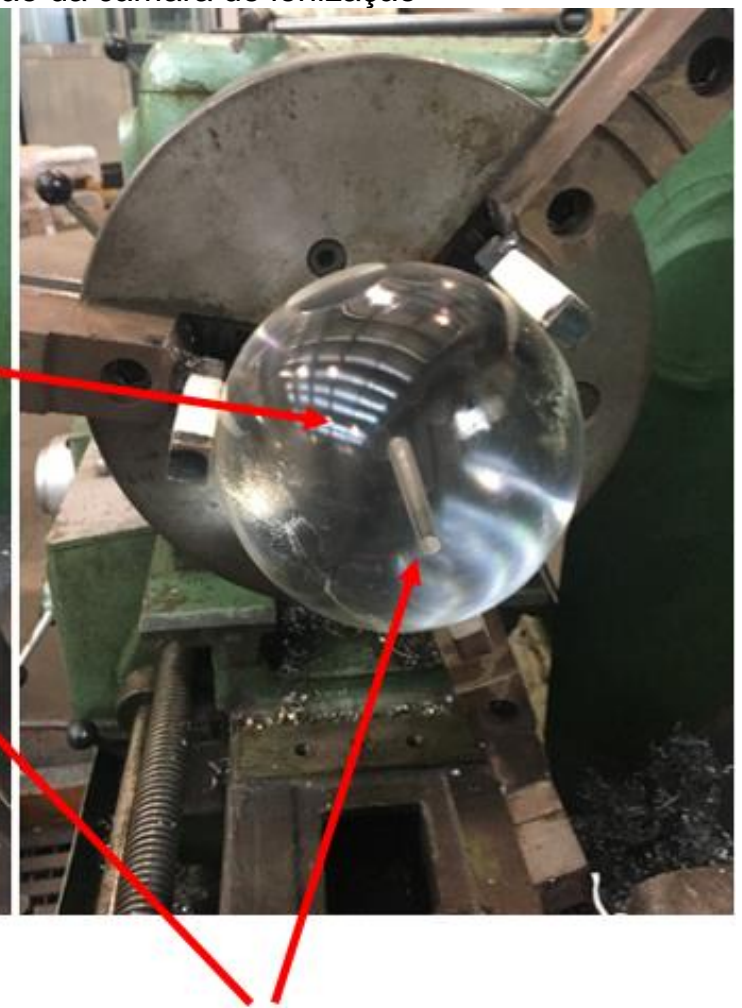

Furo para a câmara de ionização

Após a construção do objeto simulador e entrega pela oficina do IPEN, uma pré-validação foi realizada no Gamma Knife® Perfexion do HCor de forma a analisar sua resposta na dosimetria com a câmara de ionização PTW Pinpoint 31016, pertencente ao 
hospital. A dosimetria foi realizada com o objeto simulador de acrílico e comparada com a dosimetria com o objeto simulador ABS e a mesma câmara de ionização.

A Figura 18 mostra a imagem do objeto simulador com a câmara de ionização inserida após finalização da construção pela oficina do IPEN.

Figura 18 - Objeto simulador de acrílico finalizado com a PTW Pinpoint 31016.

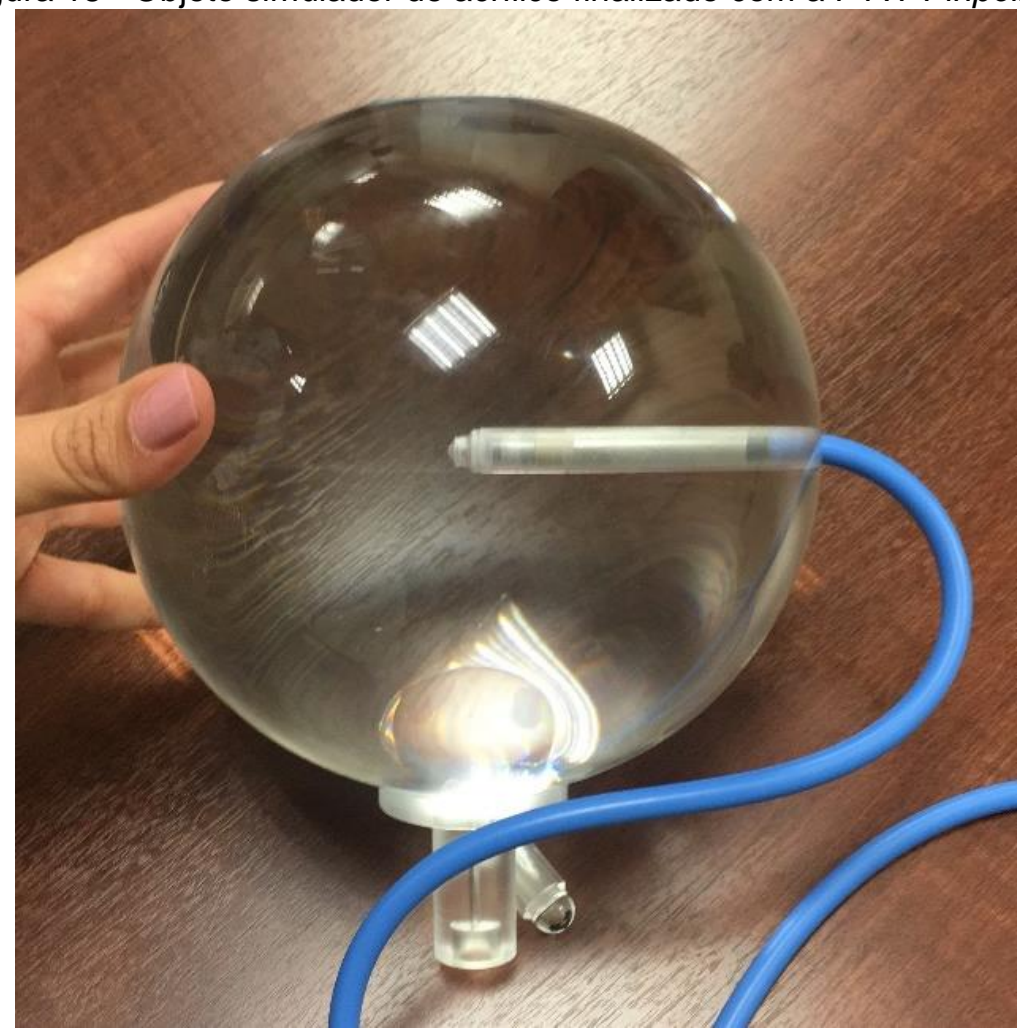

Fonte: autora da tese.

A Figura 19 mostra a imagem da primeira dosimetria do Gamma Knife® Perfexion realizada com o objeto simulador de acrílico no HCor. 
Figura 19 - Dosimetria do objeto simulador de acrílico com a PTW Pinpoint 31016 no HCor.
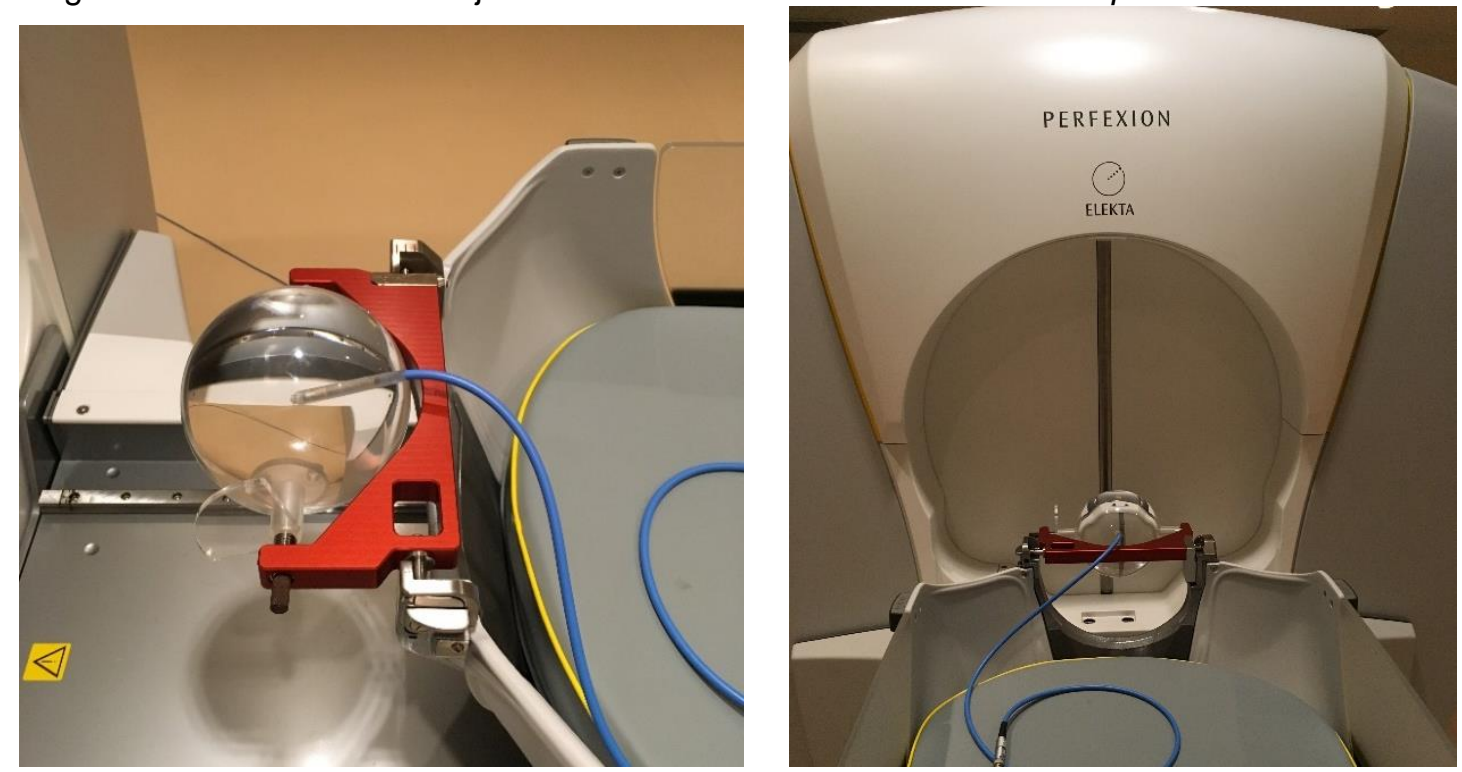

Fonte: autora da tese.

\section{$\underline{\text { Segunda etapa: alterações e medições finais }}$}

O objeto simulador de acrílico foi, então, levado para o NPL na Inglaterra e, após testes iniciais, foram realizadas algumas modificações, pela oficina do NPL, que permitiram a utilização de mais de um detector no objeto simulador.

A perfuração, que antes era exclusiva para a câmara de ionização PTW Pinpoint 31016, foi removida e uma perfuração interna maior foi feita de forma que fosse possível inserir encaixes para mais de um detector. Cada encaixe construído possui uma perfuração específica para os detectores utilizados.

O objeto simulador pode, então, ser utilizado com três detectores diferentes:

a) A câmara de ionização Exradin A16;

b) A câmara de ionização PTW Pinpoint 31016;

c) Pastilhas de alanina de $2,5 \mathrm{~mm}$.

Os encaixes devem ser inseridos dentro do objeto simulador de forma que seus volumes sensíveis fiquem no centro do mesmo. 


\subsubsection{Calibração das câmaras de ionização em laboratório padrão primário}

A calibração das câmaras de ionização de volume pequeno (Exradin A16 e Pinpoint 31016) utilizadas neste trabalho foi realizada de acordo com o TRS $398^{9}$ e foi obtido o coeficiente de calibração em termos de dose absorvida na água. Esta calibração foi realizada no laboratório de calibração primário do NPL. O arranjo dessa calibração está ilustrado na Figura 20.

Figura 20. Arranjo de calibração de câmaras de ionização cilíndricas utilizadas em radioterapia no laboratório de calibração.

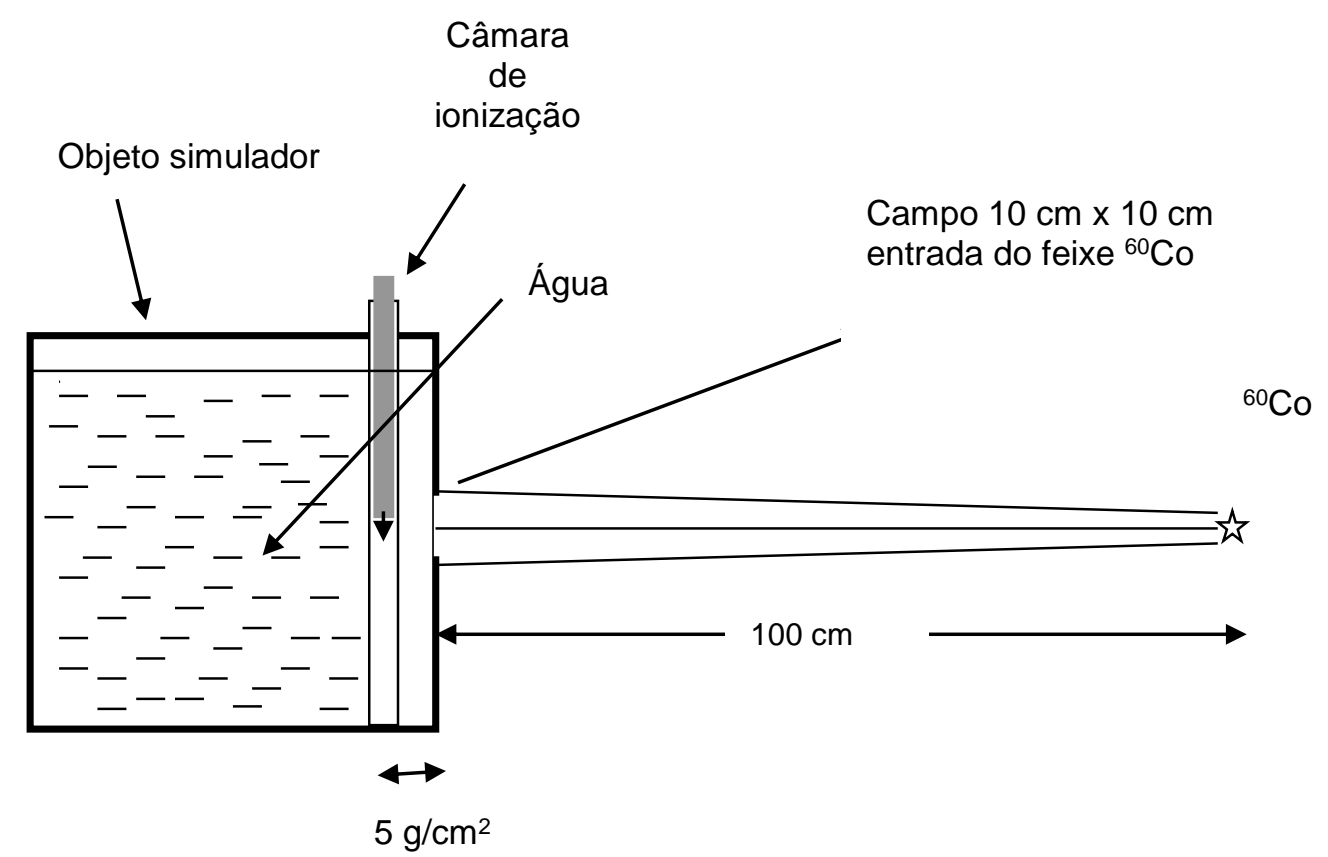

Fonte: autora da tese.

As câmaras de ionização foram calibradas em termos de dose absorvida na água, com rastreabilidade ao padrão primário do Reino Unido de dose absorvida para feixes de fótons no NPL. O padrão primário é um calorímetro de grafite, que é usado para calibrar as câmaras padrão de referência, neste trabalho a câmara NE 2611, em um objeto simulador de grafite. A dose absorvida no grafite é convertida para dose absorvida na água utilizando fatores previamente estabelecidos no NPL ${ }^{38}$.

O método de calibração utilizado neste procedimento é o de calibração por substituição, na qual as medições são feitas em um objeto simulador de água, de dimensões $30 \mathrm{~cm}$ x $30 \mathrm{~cm}$ x $30 \mathrm{~cm}$, preenchido com água bidestilada. A câmara é 
posicionada de acordo com a geometria de referência, utilizada no laboratório de calibração primário, num campo de $10 \mathrm{~cm} \times 10 \mathrm{~cm}$, estabelecido a $100 \mathrm{~cm}$ de distância da fonte e coincidindo com a superfície da janela de entrada do objeto simulador. Essa distância é medida com um micrômetro. O centro do volume da câmara de ionização deve estar a $5 \mathrm{~cm}$ da janela de entrada do objeto simulador. $O$ objeto simulador deve estar com a janela de entrada perpendicular ao feixe de radiação.

Um teste de fuga das câmaras de ionização é realizado antes das medições e não deve ser maior do que $\pm 60 f A$. Medições são realizadas primeiramente com a câmara padrão de referência NE2611, então com a câmara a ser calibrada, neste caso a Exradin A16 e a PTW Pinpoint 31016 e, por último, novamente com a câmara padrão de referência NE2611. São realizadas 300 leituras para cada câmara de ionização no modo integrado, com intervalos de 1 segundo entre cada leitura. Temperatura e pressão são obtidas utilizando o programa LabVIEW, que realiza o cálculo do fator de correção para temperatura e pressão, com termômetro e barômetro diretamente conectados ao programa. No laboratório do NPL, a calibração só é realizada com umidade relativa dentro da faixa de $20 \%$ a $70 \%$.

Dois tipos de medições são realizadas para a obtenção da dose absorvida na água: fator derivado, para medições somente com a câmara de ionização, que usa o eletrômetro do NPL para ambas as câmaras de ionização, e fator direto, quando as medições são realizadas com o eletrômetro do NPL para a câmara padrão de referência e para a câmara a ser calibrada com o eletrômetro conjunto da câmara de ionização. Para a calibração dessas câmaras, foi utilizada o fator derivado. A Figura 21 mostra o procedimento de calibração da câmara Exradin A16.

O laboratório de calibração do NPL calcula a dose absorvida na água $\left(D_{w}\right)$ através da equação 10 , derivada da equação 2 :

$$
D_{W}=M N_{W, Q} f_{T P} f_{\text {ion }} f_{\text {non lin }} N_{\text {elec }}
$$

Onde: $\mathrm{M}$ é a leitura não-corrigida do instrumento na água;

$N_{W, Q}$ é o fator de calibração da dose absorvida na água na qualidade $Q$ em Gy/nC ou Gy/u.e.;

$f_{T P}$ é a o fator de correção para temperatura e pressão; 
$f_{i o n}$ é o fator de correção para recombinação iônica;

$f_{\text {non lin }}$ é o fator de correção da não-linearidade do eletrômetro;

$N_{\text {elec }}$ é o fator de calibração do eletrômetro para o intervalo de uso adequado.

Figura 21 - Calibração da câmara de ionização Exradin A16 no laboratório de calibração primário do NPL

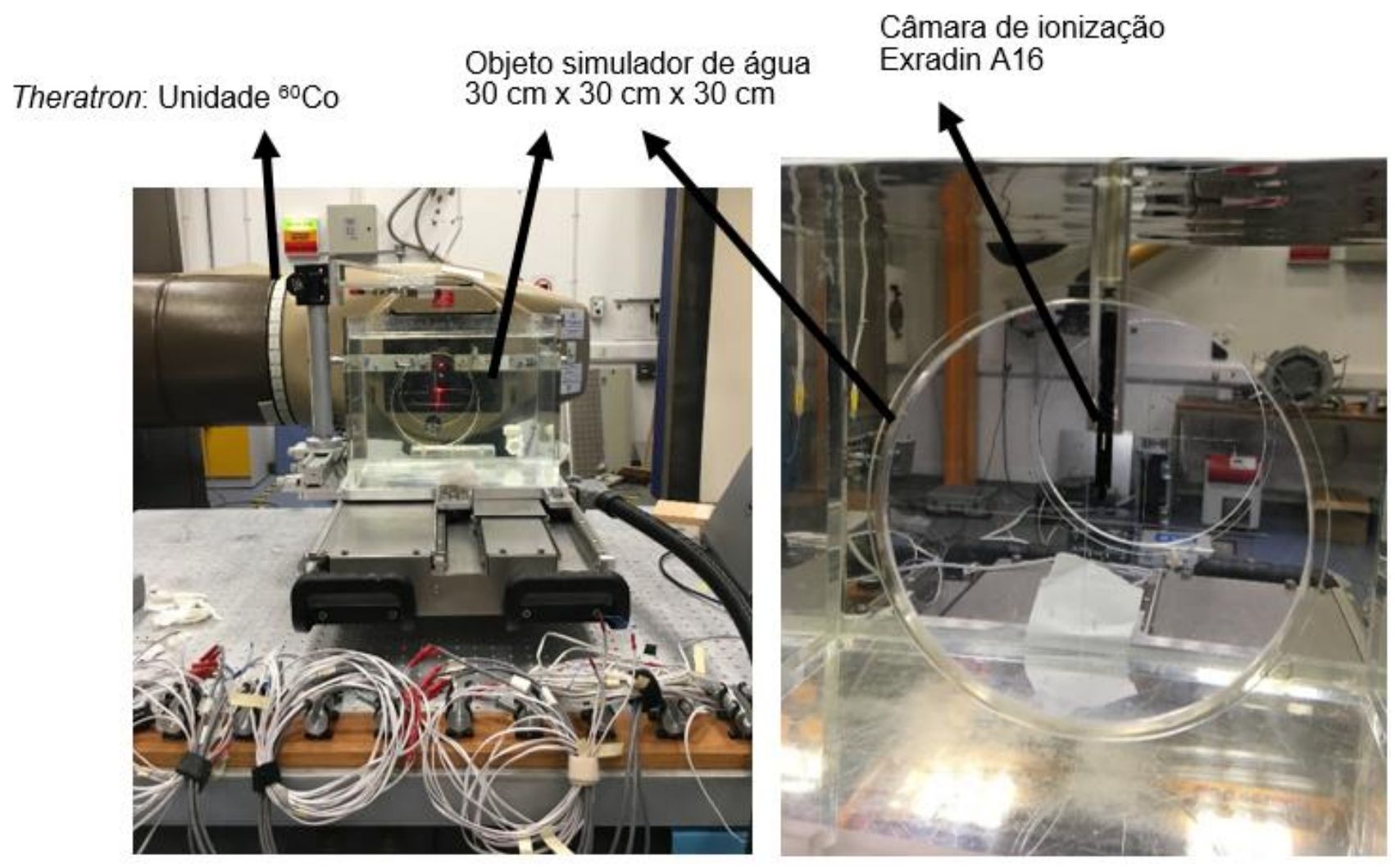

Fonte: autora da tese.

\subsubsection{Dosimetria do Gamma Knife® Perfexion com as câmaras de ionização calibradas}

A dosimetria do equipamento Gamma Knife® foi, então, realizada no QSRC, localizado em Londres, Inglaterra, utilizando a metodologia descrita em 2.6.1. O QSRC utiliza o objeto simulador Solid Water® e uma câmara de ionização PTW 31010 Semiflex para dosimetria do Gamma Knife $\Theta^{B}$. Além desta configuração presente no hospital, foram utilizadas também as câmaras de ionização calibradas no NPL, PTW Pinpoint 31016, pertencente ao NPL e a câmara de ionização Exradin A16, pertencente ao Hospital Albert Einstein. 
Além do objeto simulador de Solid Water®, o objeto simulador de acrílico, projetado para este trabalho, foi utilizado para essas medições (Figura 22).

Figura 22 - Dosimetria realizada no QSRC com o objeto simulador de acrílico desenvolvido neste trabalho.

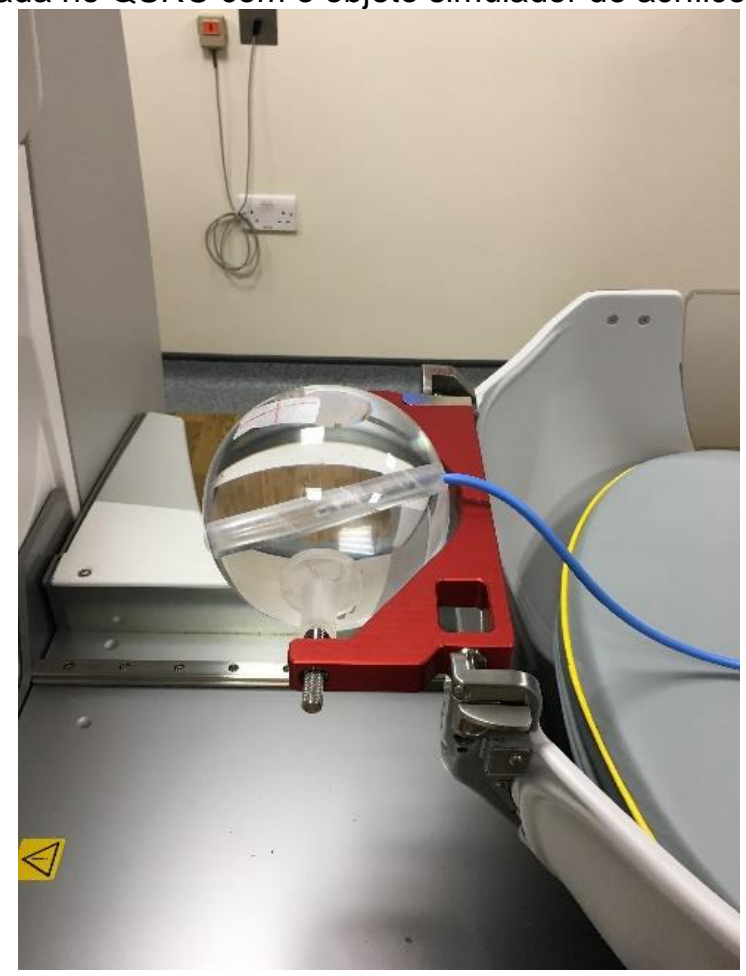

Fonte: autora da tese.

Para cada configuração de dosimetria utilizada neste hospital foram realizadas 5 leituras de carga, foi encontrada a média das leituras e a dose absorvida foi calculada utilizando a equação 5 , considerando os fatores de correção como temperatura, pressão, polaridade, recombinação iônica e outros (mencionados no capítulo 4), e o ND,W das câmaras calibradas no laboratório do NPL.

\subsubsection{Análise de Incertezas}

Para a estimativa das incertezas apresentadas nas medições realizadas, foram utilizadas as recomendações do Guia Para a Expressão da Incerteza de Medição ${ }^{39}$ e estudos anteriores de medições similares ${ }^{12,40-44}$. Foram consideradas as incertezas do tipos A e $B$, para um nível de confiança de 95\% (k=2).

A incerteza tipo A é avaliada através de análise estatística de uma série de medições. Para estimar a incerteza do tipo A para cada medição foi calculado o desvio padrão e o 
desvio padrão da média. Para se obter o desvio padrão ui de uma série de medições realizadas utiliza-se a Equação 11.

$$
u_{i}=\sqrt{\frac{1}{n-1} \sum_{i=1}^{n}\left(y_{i}-\bar{y}\right)^{2}}
$$

No qual,

n é o número de medições realizadas

$y_{i}$ é o valor medido

$\bar{y}$ é a média desses valores.

O desvio padrão caracteriza a dispersão dos valores $y_{i}$ em torno de sua média $\bar{y}$. Já o desvio padrão da média quantifica quão bem $\bar{y}$ estima a esperança $\mu_{y}$ de $y$, ou seja, ele nos mostra o quão distante a média das medições realizadas está do valor esperado, e é obtido dividindo-se o desvio padrão, calculado na Equação 11, por $\sqrt{n}$ (raiz quadrada do número de medições realizadas).

Por outro lado, a incerteza do tipo B é um método de avaliação da incerteza por outros meios que não a análise estatística. Ela é avaliada por julgamento científico, baseando-se em todas as informações disponíveis sobre a possível variabilidade de $X_{i}$ (grandeza de entrada qualquer). O conjunto de informações pode incluir especificações do fabricante, dados fornecidos em certificados de calibração e outros certificados.

Os componentes utilizados para o cálculo das incertezas neste trabalho são demonstrados na Tabela 2. 
Tabela 2 - Componentes de incerteza que foram considerados para os cálculos das medições realizadas neste trabalho.

Componentes de Incerteza

Tipo A

Tipo B

Calibração de referência ${ }^{60} \mathrm{Co}$

$\mathrm{X}$

Variação posicionamento da câmara

$\mathrm{X}$

Resolução do dosímetro

$x$

Repetibilidade

$\mathrm{X}$

Polaridade

$\mathrm{X}$

$x$

Recombinação lônica

X

$\mathrm{X}$

Fator de correção da temperatura

$\mathrm{X}$

Fator de correção da pressão

$X$

Fuga de corrente

$\mathrm{X}$

$k_{Q}$

$\mathrm{X}$

$X$

Variação entre as câmaras

$\mathrm{X}$

Estabilidade do acelerador linear

X

Incerteza residual do material do objeto simulador

$\mathrm{X}$

$\mathrm{X}$ 


\section{RESULTADOS E DISCUSSÕES}

\subsection{Programa de controle de qualidade de uma câmara de ionização de volume pequeno}

A parte inicial deste trabalho consistiu no estabelecimento de um programa de controle de qualidade da câmara de ionização Exradin, modelo A16, que foi utilizada como objeto desse estudo. Foi utilizada uma fonte de ${ }^{90} \mathrm{Sr}$ para o controle de qualidade da câmara. As medições foram realizadas com a câmara inserida na blindagem da fonte de radiação.

Todos os testes demonstraram valores menores do que os estabelecidos de acordo com a norma. Os valores obtidos estão demonstrados na Tabela 3. Concluiu-se que a câmara de ionização analisada está dentro dos padrões estabelecidos pela norma e que pode ser utilizada na dosimetria de campos pequenos em radioterapia ${ }^{45}$.

Tabela 3 - Variação máxima obtida nos testes da IEC 60731:2011 para a câmara de ionização Exradin A16

$\begin{array}{cc}\text { Máxima Variação } \\ \text { Permitida } & \begin{array}{c}\text { Máxima Variação } \\ \text { Obtida }\end{array}\end{array}$

\begin{tabular}{|c|c|c|}
\hline Repetibilidade & $\pm 0,5 \%$ & $0,1 \%$ \\
\hline Tempo de estabilização & $\pm 0,5 \%$ & SVS* \\
\hline $\begin{array}{c}\text { Estabilidade ao longo } \\
\text { do tempo }\end{array}$ & $\pm 1,0 \%$ & SVS* \\
\hline Fuga pós-irradiação & $\pm 1,0 \%( \pm 0,5 \%)$ & $0,01 \%$ \\
\hline Efeito de fuga de corrente & $\pm 1,0 \%$ & SVS* \\
\hline
\end{tabular}

\subsection{Estudo da variação no posicionamento do objeto simulador na dosimetria do Gamma Knife $\circledast$ Perfexion}

Como parte do estudo em feixes clínicos, foi realizado um estudo sobre a variação no posicionamento do objeto simulador na dosimetria do Gamma Knife® Perfexion, com o objetivo de variar o posicionamento do objeto simulador durante sua dosimetria. Nesta 
dosimetria, o colimador utilizado foi o de 16 mm e a câmara de ionização Pinpoint 31016 foi posicionada no centro geométrico do objeto simulador.

O objetivo foi de variar o posicionamento deste objeto simulador, durante a dosimetria, de modo a verificar se há atenuação significativa com esta variação. Três posições foram verificadas: sem inclinação (neutra), inclinação interna e inclinação externa. A Figura 23 mostra a variação de posicionamento.

Figura 23: Posições do objeto simulador: Em A, sem inclinação, em B inclinação externa e em C inclinação interna.

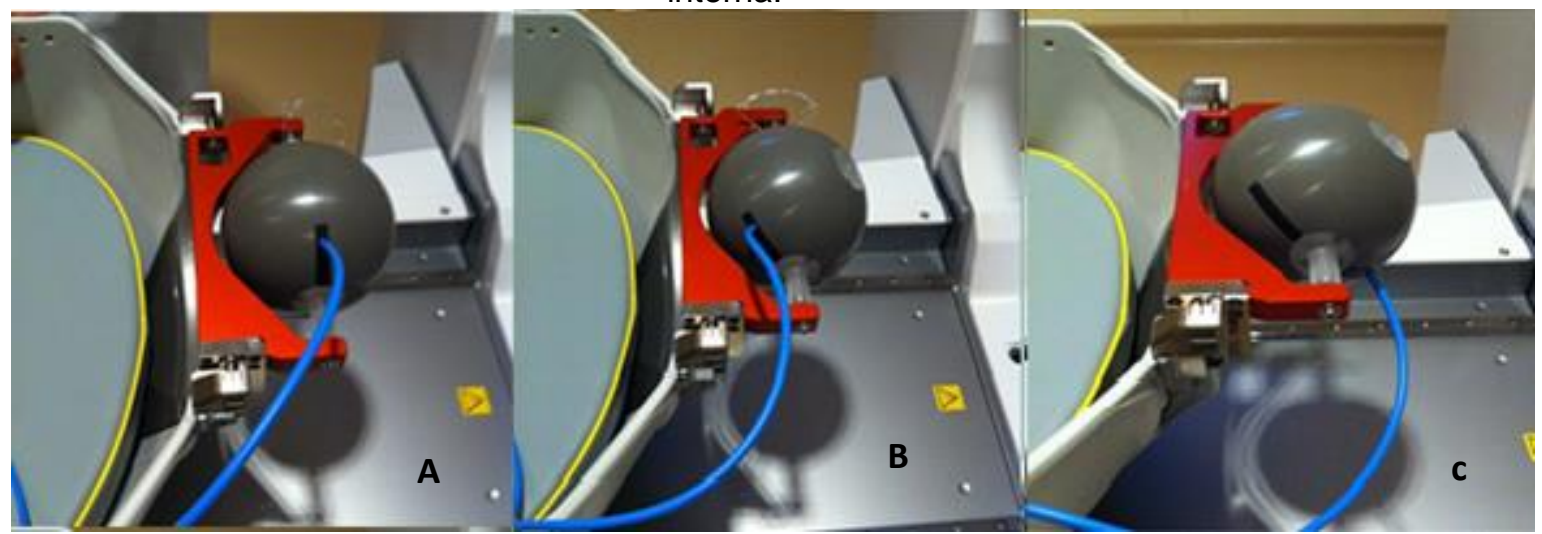

Fonte: autora da tese.

Foram realizadas três leituras com três minutos de irradiação para cada posição. $O$ resultado das leituras é mostrado na Tabela 4.

Tabela 4 - Resultado das leituras para as variações de inclinação do objeto simulador

Posição A:

Sem inclinação $(\mathrm{nC})$
Posição B: Inclinação

externa $(\mathrm{nC})$
Posição C: Inclinação

interna $(\mathrm{nC})$
3,610
3,643
3,627
3,619
3,659
3,603
3,629
3,634
3,608

Fonte: autora da tese.

A incerteza máxima das medições foi de $\pm 1,5 \%$. A variação encontrada para a posição sem inclinação foi de $0,53 \%$. Para a posição $B$ foi de $0,68 \%$ e para a posição $C$ foi de $0,66 \%$. Considerando todas as posições, a variação foi de 1,5\%. Assim, concluiu-se que 
a posição A, sem inclinação, mostrou maior estabilidade entre as leituras, sendo, portanto a melhor a ser utilizada ${ }^{46}$.

\subsection{Dosimetria de um equipamento Gamma Knife® Perfexion em Estocolmo-Suécia, no hospital Karolinska}

Em maio de 2016, foi realizada a dosimetria de um equipamento Gamma Knife® Perfexion localizado no hospital Karolinska em Estocolmo, Suécia, numa parceria de colaboração do Banco Santander.

Foram utilizadas oito câmaras de ionização de volume pequeno, sendo elas: seis PTW Semiflex 31010 e duas PTW Pinpoint 31016. A câmara de ionização Semiflex e o objeto simulador de Solid Water formam a configuração de dosimetria (câmara de ionização + objeto simulador) do Gamma Knife® Perfexion deste hospital.

Essas câmaras possuíam o $\mathrm{N}_{\mathrm{D}, \mathrm{w}}$ do fabricante e não foram calibradas em um laboratório de calibração. Dois objetos simuladores foram utilizados, o de ABS e o Solid Wate $\AA^{\circledR}$. Foi determinada a taxa de dose no ponto focal do equipamento Gamma Knife $\AA$ Perfexion e o objetivo dessas medições foi o de avaliar a resposta de diferentes câmaras de ionização quando submetidas à mesma configuração de irradiação com o ${ }^{60} \mathrm{Co}$.

Cada câmara de ionização foi irradiada em cada um dos objetos simuladores. Foram obtidas dez leituras para cada configuração de medição. O eletrômetro utilizado para todas as medições foi o PTW Unidos Webline. Os fatores de correção considerados para cada configuração de medição foram temperatura e pressão. A fuga das câmaras de ionização foi avaliada com leituras de cinco minutos, utilizando a mesma geometria para medições de dosimetria.

A taxa de dose absorvida foi calculada utilizando a Equação 2. A Tabela 5 mostra cada câmara de ionização utilizada, a média de carga coletada $(\mathrm{nC})$ das dez leituras de cada configuração de medição utilizada e a taxa de dose calculada. 
Tabela 5 - Média de carga coletada para cada câmara de ionização com ambos os objetos simuladores (ABS e Solid Water®) e a taxa de dose calculada.

\begin{tabular}{|c|c|c|c|c|}
\hline $\begin{array}{l}\text { Câmara de } \\
\text { lonização }\end{array}$ & Modelo & $\begin{array}{c}\text { Média carga } \\
\text { coletada ABS } \\
(\mathrm{nC})\end{array}$ & $\begin{array}{c}\text { Média carga } \\
\text { coletada Solid } \\
\text { Water }(\mathrm{nC})\end{array}$ & $\begin{array}{c}\text { Taxa de } \\
\text { dose ABS } \\
\text { (Gy/min) }\end{array}$ \\
\hline
\end{tabular}

\begin{tabular}{|c|c|c|c|c|c|}
\hline 1 & & 9,524 & 9,782 & 2,961 & 3,042 \\
\hline 2 & & 9,605 & 9,854 & 2,923 & 2,998 \\
\hline 3 & PTW & 10,15 & 10,40 & 2,946 & 3,021 \\
\hline 4 & 31010 & 9,823 & 10,09 & 2,947 & 3,030 \\
\hline 5 & & 9,450 & 9,714 & 2,963 & 3,045 \\
\hline 6 & & 9,209 & 9,462 & 2,960 & 3,046 \\
\hline 7 & PTW & 1,145 & 1,164 & 2,978 & 3,028 \\
\hline 8 & 31016 & 1,200 & 1,219 & 2,972 & 3,020 \\
\hline
\end{tabular}

Fonte: autora da tese.

Considerando que câmaras de ionização do mesmo modelo foram utilizadas, espera-se que seja apresentada a mesma taxa de dose, quando irradiadas nas mesmas condições e sabendo que cada uma delas possui um coeficiente de calibração fornecido pelo fabricante.

A média de valores de carga para o objeto simulador ABS e Solid Water $^{\circledR}$ para a PTW Semiflex 31010 foi 9,522 e 9,703 nC, respectivamente. Para a PTW Pinpoint 31016, 1,173 e $1,192 \mathrm{nC}$, respectivamente.

Todas as câmaras apresentaram bom comportamento em relação à repetibilidade das medições. A incerteza máxima calculada para a câmara PTW Semiflex 31010 foi de $\pm 2,9 \%$ e para a câmara PTW Pinpoint 31016 foi de $\pm 1,5 \%$.

A diferença encontrada entre as médias de carga coletada para os dois modelos de câmara de ionização se deve à diferença de volume entre ambas (Semiflex $0,125 \mathrm{~cm}^{3} \mathrm{e}$ Pinpoint $\left.0,016 \mathrm{~cm}^{3}\right)$.

A Tabela 6 mostra a diferença percentual para cada configuração de medição com a taxa de dose fornecida pelo Gamma Plan (dose de simulação obtida pelo sistema do 
Gamma Knife®). No dia em que as medições foram realizadas, a taxa de dose fornecida pelo Gamma Plan foi de 3,012 Gy/min.

Tabela 6 - Comparação da taxa de dose calculada para cada configuração de medição com a taxa de dose fornecida pelo Gamma Plan

\begin{tabular}{|c|c|c|c|}
\hline Câmara de lonização & Modelo & $\begin{array}{c}\text { Diferença Percentual } \\
\text { ABS (\%) }\end{array}$ & $\begin{array}{c}\text { Diferença Percentual } \\
\text { Solid Wateß }(\%)\end{array}$ \\
\hline 1 & \multirow{6}{*}{ PTW 31010} & 1,69 & 1,00 \\
\hline 2 & & 2,95 & 0,46 \\
\hline 3 & & 2,19 & 0,30 \\
\hline 4 & & 2,16 & 0,59 \\
\hline 5 & & 1,63 & 1,10 \\
\hline 6 & & 1,73 & 1,13 \\
\hline 7 & \multirow{2}{*}{ PTW 31016} & 1,13 & 0,53 \\
\hline 8 & & 1,33 & 0,27 \\
\hline
\end{tabular}

Fonte: autora da tese.

A câmara de ionização que apresentou a taxa de dose mais próxima do Gamma Plan para a dosimetria com o objeto simulador ABS foi a número 7, a PTW Pinpoint 31016. A diferença entre elas foi de $1,13 \%$. Para a dosimetria com o Solid Water $\circledast$, a câmara de ionização 8 apresentou $0,27 \%$ de diferença com o Gamma Plan. Por outro lado, a taxa de dose mais distante do Gamma Plan para o ABS e Solid Water foram as câmaras 2 e 6, com $2,95 \%$ e $1,13 \%$ de diferença.

Portanto, a dosimetria realizada mostrou que o objeto simulador Solid Water ${ }^{\circledR}$ apresenta uma dosimetria mais próxima ao Gamma Plan do que o ABS. Para ambos os objetos simuladores a câmara de ionização que apresentou a melhor resposta foi a PTW Pinpoint 31016, mesmo sendo o valor do ABS maior do que o Solid Water®.

Esse estudo mostrou a importância do tamanho da câmara de ionização utilizada na dosimetria do Gamma Knife® e ajudou na decisão da escolha do material para construção do objeto simulador utilizado nesse projeto. 


\subsection{Primeira dosimetria realizada com o objeto simulador de acrílico.}

As primeiras medições com o objeto simulador de acrílico desenvolvido neste trabalho foram realizadas no HCor, em São Paulo. A configuração de dosimetria deste hospital (objeto simulador ABS e câmara de ionização Pinpoint 31016) foi utilizada e comparada com a configuração utilizando o objeto simulador de acrílico e a mesma câmara de ionização.

Dez leituras de um minuto para cada objeto simulador foram obtidas e foi calculada a média das leituras. Então, a taxa de dose foi calculada utilizando a Equação 2.

A taxa de dose para o objeto simulador de acrílico foi de 2,23 Gy/min $\pm 1,7 \%$ e a taxa de dose do ABS foi de 2,31 Gy/min $\pm 1,0 \%$. A taxa de dose do Gamma Plan no dia das medições foi de 2,29 Gy/min.

Portanto, a diferença obtida entre os dois objetos simuladores foi de $4,12 \%$ e entre o objeto simulador de acrílico e o Gamma Plan foi de 2,94\%. Estas medições foram realizadas com o objeto simulador de acrílico que foi construído na primeira etapa, antes de sofrer as alterações no NPL. Estudos adicionais, como correções ao material, foram posteriormente analisados e utilizados na dosimetria do Gamma Knife® com o objeto simulador de acrílico. A Figura 24 mostra o objeto simulador de acrílico sendo utilizado para medições no Gamma Knifeß do HCor.

Figura 24: Objeto simulador de acrílico, obtido na primeira etapa de sua construção, posicionado no Gamma Knife® do HCor.

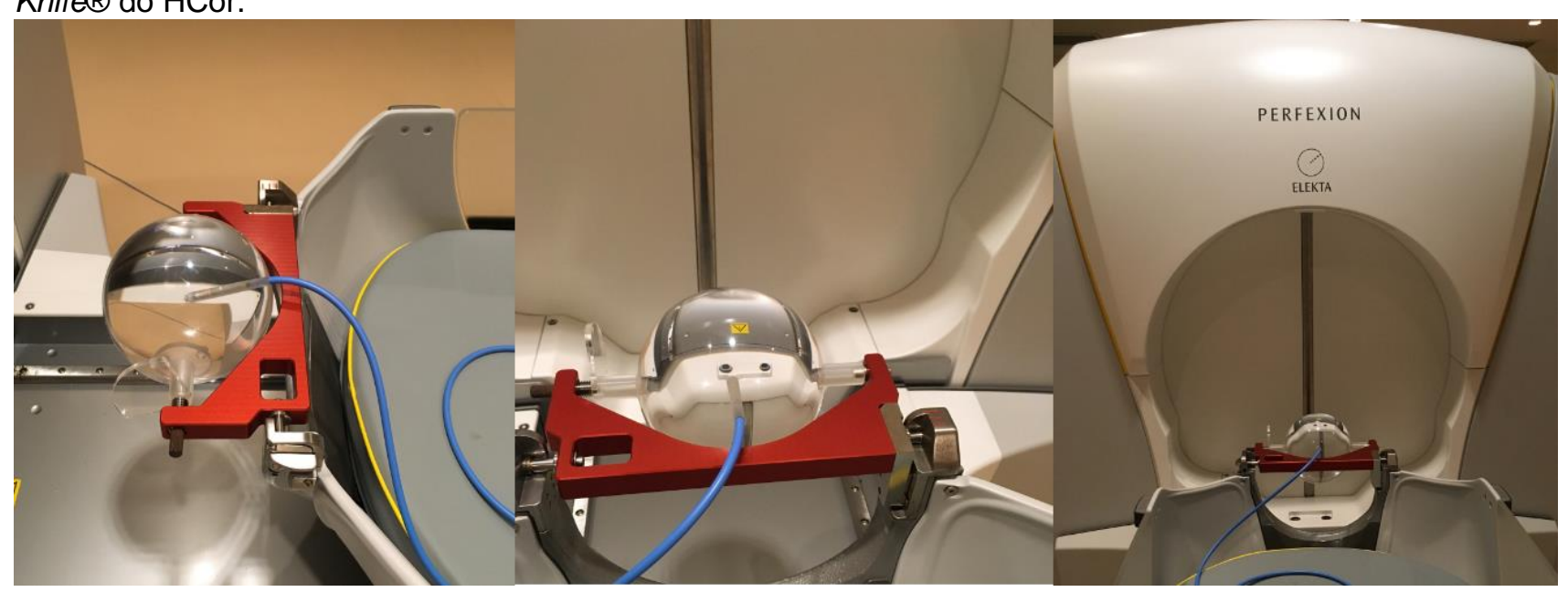

Fonte: autora da tese. 
4.5 Resultado do projeto, construção e aperfeiçoamento do objeto simulador de acrílico

O objeto simulador de acrílico sofreu alterações após sua construção, que foram realizadas na oficina do NPL. Essas alterações resultaram na disponibilidade de utilização de mais de um tipo de detector. Encaixes foram, então, construídos e podem ser utilizados com os seguintes detectores: as câmaras de ionização Exradin A16, PTW Pinpoint 31016 e pastilhas de alanina de $2,5 \mathrm{~mm}$. Esta modificação permitiu a utilização destes três detectores para este trabalho e tornou a utilização de diferentes detectores viável para trabalhos futuros.

A Figura 25 mostra o objeto simulador modificado e atualmente utilizado para a dosimetria do Gamma Knifeß Perfexion.

Figura 25 - Objeto simulador de acrílico modificado para dosimetria do Gamma Knife® Perfexion

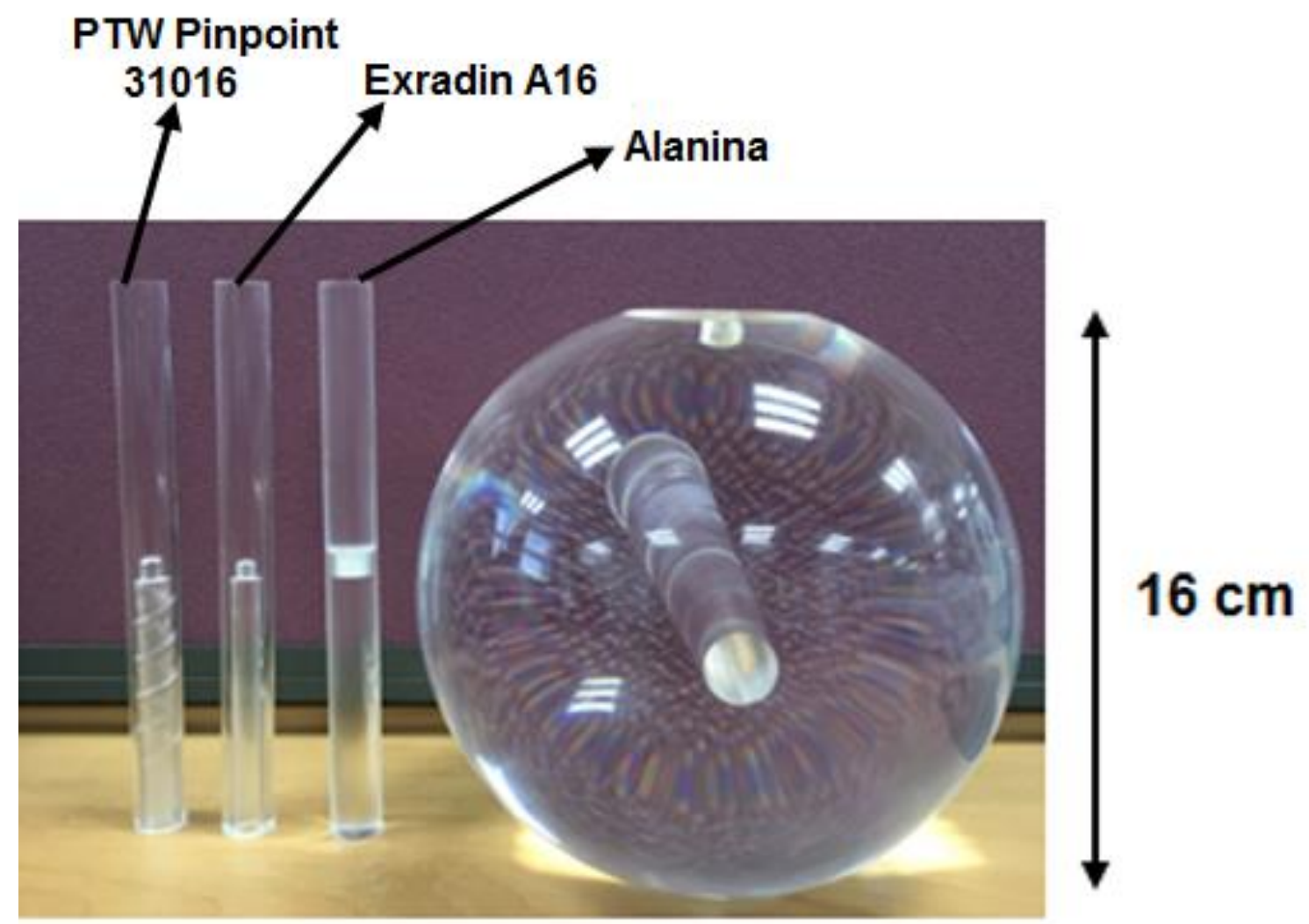

Fonte: autora da tese. 


\subsection{Cálculo do coeficiente de calibração $\mathrm{ND}_{\mathrm{D}, \mathrm{w}}$ em um feixe padrão primário para as câmaras de ionização PTW Pinpoint 31016 e Exradin A16}

As câmaras de ionização de volume pequeno utilizadas neste trabalho (PTW Pinpoint 31016 pertencente ao NPL e Exradin A16) foram submetidas à calibração no Laboratório de Calibração Primário do NPL. Para esta calibração, foi utilizada uma câmara padrão secundário NE 2611, que é utilizada para dosimetria de câmaras de terapia padrão secundário. A câmara NE 2611 é calibrada anualmente com o calorímetro padrão primário do NPL.

A calibração das câmaras de ionização de volume pequeno foi realizada pelo método da substituição, conforme o procedimento da Figura 21 , no equipamento ${ }^{60} \mathrm{Co}$.

Foram realizadas cinco leituras de carga para cada câmara de ionização. O eletrômetro utilizado para a leitura de carga foi o PTW Unidos Webline. Para o cálculo do coeficiente de calibração foram considerados os seguintes fatores de correção: temperatura, pressão, polaridade, recombinação iônica. Os valores encontrados de $\mathrm{N}_{\mathrm{D}, \mathrm{w}}$ para as câmaras de ionização são apresentados na Tabela 7.

Tabela 7 - Coeficiente de calibração para as câmaras de ionização de volume pequeno em feixe de ${ }^{60} \mathrm{Co}$

Câmara de lonização

${ }^{60} \mathrm{Co}$ ND,w $(\mathrm{Gy} / \mathrm{nC})$

Exradin A16

PTW Pinpoint 31016
$4,161 \pm 2,0 \%$

$2,546 \pm 1,5 \%$

Fonte: autora da tese.

Medições foram também realizadas no acelerador linear do NPL de forma a ratificar a calibração no ${ }^{60} \mathrm{Co}$. As medições foram realizadas na mesma configuração que no ${ }^{60} \mathrm{Co}$, porém foi utilizado 6MV para ambas as câmaras. Os resultados são apresentados na Tabela 8. 
Tabela 8 - Coeficiente de calibração para as câmaras de ionização de volume pequeno em feixe de 6MV de um acelerador linear

Câmara de lonização

$$
\text { Exradin A16 }
$$

PTW Pinpoint 31016
$6 \mathrm{MV} \mathrm{N}_{\mathrm{D}, \mathrm{w}}(\mathrm{Gy} / \mathrm{nC})$

$$
4,131 \pm 2,3 \%
$$

$2,543 \pm 1,7 \%$

Fonte: autora da tese.

Com a realização das medições em diferentes qualidades de radiação é possível encontrar o fator kQ, que é o fator de correção para a qualidade do feixe de radiação. Este fator é dado pela Equação 12.

$$
k_{Q, Q 0}=\frac{N_{D, W Q}}{N_{D, W Q 0}}
$$

Onde: $N_{D, W Q}$ é o coeficiente de calibração para outras qualidades de radiação e $N_{D, W Q 0}$ é o coeficiente de calibração para câmaras calibradas no ${ }^{60} \mathrm{Co}$.

Em dosimetria com câmaras de ionização de volume pequeno que não utilizam o ${ }^{60} \mathrm{Co}$, esse fator de correção torna-se de grande importância no cálculo da taxa de dose absorvida na água, pois ele converte a qualidade do feixe de radiação para a qualidade do feixe de ${ }^{60} \mathrm{Co}^{26}$.

Portanto, os valores de ka para o feixe de $6 \mathrm{MV}$ encontrados para as câmaras de ionização Exradin A16 e PTW Pinpoint foram, respectivamente, 0,993 e 0,998.

\subsection{Dosimetria no Gamma Knife ${ }^{\circledR}$ Perfexion}

Os dados da dosimetria do Gamma Knife® Perfexion citados a seguir foram obtidos utilizando a câmara Exradin A16 e a PTW Pinpoint 31016 pertencente ao NPL. A câmara de ionização Exradin A16, pertencente ao Hospital Albert Einstein, passou pelo programa de controle de qualidade citado no item 4.1 e pela calibração no laboratório padrão primário

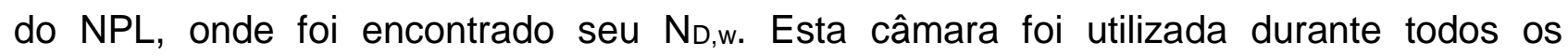
procedimentos realizados neste trabalho. A câmara de ionização PTW Pinpoint 31016 foi também utilizada na dosimetria e calibrada no laboratório padrão primário do NPL. 
Como já citado anteriormente, a dosimetria do Gamma Knife ${ }^{\circledR}$ utiliza ou o objeto simulador ABS ou o Solid Water® e um detector escolhido pelo usuário.

A dosimetria neste trabalho foi realizada no Gamma Knife® Perfexion do Queen Square Radiosurgery Center, localizado em Londres, Inglaterra. A configuração de dosimetria nesse centro utiliza o objeto simulador de Solid Wateß̊ e uma câmara de ionização PTW Semiflex, modelo 31010. Essa câmara de ionização não foi calibrada no laboratório de calibração do NPL. Essa foi a configuração utilizada no comissionamento do Gamma Knife® Perfexion neste hospital.

As configurações utilizadas para realização da dosimetria do Gamma Knife® Perfexion para este trabalho foram as seguintes:

1. Dosimetria com a configuração utilizada no Queen Square Radiosurgery Center (Solid Water® e PTW Semiflex 31010);

2. Dosimetria com o objeto simulador Solid Water $\AA^{\circledR}$ a câmara de ionização Exradin A16.

3. Dosimetria com o objeto simulador Solid Water e a câmara de ionização PTW Pintpoint 31016;

4. Dosimetria com o objeto simulador de acrílico e a câmara de ionização Exradin A16;

5. Dosimetria com o objeto simulador de acrílico e a câmara de ionização PTW Pinpoint 31016;

6. Dosimetria com o objeto simulador Solid Water ${ }^{\circledR}$ e pastilhas de alanina de $2,5 \mathrm{~mm}$.

7. Dosimetria com o objeto simulador de acrílico e pastilhas de alanina de $2,5 \mathrm{~mm}$.

Foram realizadas 10 leituras de carga de um minuto para cada configuração de dosimetria. O colimador utilizado para a dosimetria foi o de $16 \mathrm{~mm}$. O cálculo da taxa de dose do Gamma Knife® realizado em todas as sete configurações utilizou a Equação 5, assim como os fatores de correção utilizados para cada medição.

A Tabela 9 mostra o valor da taxa de dose calculada com a configuração que o Queen Square Radiosurgery Center utiliza em sua dosimetria de Gamma Knife® Perfexion. O fator de correção de temperatura e pressão $\left(\mathrm{k}_{\mathrm{t}, \mathrm{p}}\right)$ foi considerado no cálculo da taxa de dose. A diferença da taxa de dose medida com a taxa de dose do Gamma Plan foi de 1,28\%. 
Tabela 9 - Dosimetria do Gamma Knife® com objeto simulador Solid Water® e câmara de ionização PTW Semiflex 31010

\section{Configuração 1}

Data: $27 / 07 / 2017$

Taxa de dose Gamma Plan (Gy/min): 1,859

\begin{tabular}{c|c}
\hline$N_{D, w}(\mathrm{~Gy} / \mathrm{nC})$ & 0,301 \\
Média da carga coletada $(\mathrm{nC})$ & 6,077 \\
$\mathrm{k}_{\mathrm{t}, \mathrm{p}}$ & 1,016 \\
\hline Taxa de dose (Gy/min) & $1,883 \pm 3,0 \%$ \\
\hline
\end{tabular}

Fonte: autora da tese.

A Tabela 10 mostra a dosimetria do Gamma Knife® com o Solid Water $\AA^{\circledR}$ e a câmara de ionização Exradin A16. Os fatores de correção considerados no cálculo da taxa de dose foram kt,p; recombinação iônica (kion) e polaridade (kpol) (medidos na calibração da câmara no laboratório primário); e o fator referência $\left(k_{Q_{m s r}}^{f_{m s} f_{r e f}}\right)$ para a calibração de câmaras de ionização de volume pequeno em ${ }^{60} \mathrm{Co}$ utilizando o objeto simulador Solid Water®. Esse fator $k_{Q_{m s r}}^{f_{m s r, f}}$ é apresentado no protocolo TRS 483 (Tabela 1). A diferença da taxa de dose medida com a taxa de dose do Gamma Plan foi de 2,28\%.

Tabela 10 - Dosimetria do Gamma Knife® com objeto simulador Solid Water® e câmara de ionização Exradin A16

\section{Configuração 2}

Data: 08/06/2017

Taxa de dose Gamma Plan (Gy/min): 1,892

\begin{tabular}{c|c}
\hline$N_{\mathrm{D}, \mathrm{W}}(\mathrm{Gy} / \mathrm{nC})$ & 4,161 \\
Média da carga coletada $(\mathrm{nC})$ & 0,455 \\
$\mathrm{k}_{\mathrm{t}, \mathrm{p}}$ & 1,010 \\
$k_{Q_{m s r} f_{\text {r }}}^{f_{\text {kion }}}$ & 1,017 \\
$\mathrm{k}_{\mathrm{pol}}$ & 0,999 \\
\hline Taxa de dose (Gy/min) & 0,997 \\
\hline
\end{tabular}

Fonte: autora da tese. 
A Tabela 11 mostra a dosimetria do Gamma Knife® com o Solid Water® e a PTW Pinpoint 31016. Os fatores de correção considerados no cálculo da taxa de dose foram $\mathrm{k}_{\mathrm{t}, \mathrm{p}}$, kion, kpol e $k_{Q_{m s r}}^{f_{m s r} f_{r e f}}$. A diferença da taxa de dose medida com a taxa de dose do Gamma Plan foi de $1,86 \%$.

Tabela 11 - Dosimetria do Gamma Knife® com objeto simulador Solid Water $\AA^{\circledR}$ e câmara de ionização PTW Pinpoint 31016

\section{Configuração 3}

Data: 08/06/2017

Taxa de dose Gamma Plan (Gy/min): 1,892

\begin{tabular}{c|c}
\hline$N_{D, w}(\mathrm{~Gy} / \mathrm{nC})$ & 2,546 \\
Média da carga coletada $(\mathrm{nC})$ & 0,751 \\
$\mathrm{k}_{\mathrm{t}, \mathrm{p}}$ & 1,011 \\
$k_{Q_{m s r}}^{f_{m s r} f_{r f}}$ & 1,004 \\
$\mathrm{k}_{\text {ion }}$ & 0,999 \\
$\mathrm{kpol}$ & 0,994 \\
\hline Taxa de dose (Gy/min) & $1,928 \pm 1,7 \%$ \\
\hline
\end{tabular}

Fonte: autora da tese.

A Tabela 12 mostra a dosimetria do Gamma Knife® com o objeto simulador de acrílico e a câmara Exradin A16. Os fatores de correção considerados no cálculo da taxa de dose foram $\mathrm{k}_{\mathrm{t}, \mathrm{p}}, \mathrm{k}_{\text {ion, }}$ kol e $k_{Q_{m s r}}^{w \text {,acrilic }}$. $\mathrm{O} k_{Q_{m s r}}^{w \text {,acrilic }}$ é um fator de correção que foi calculado por simulação Monte Carlo para correção do material do objeto simulador ${ }^{47}$. A Equação 13 apresenta como o $k_{Q_{m s r}}^{\text {,acrilic }}$ é obtido.

$$
k_{Q_{m s r}}^{w, a c r i l i c}=K_{q}{ }^{\prime}\left[\left(\rho_{e}^{r e l}-1\right) b+1\right]
$$

Onde: $K_{q}{ }^{\prime}$ é o fator de correção para cada câmara de ionização de volume pequeno, calculado por simulação Monte Carlo (nesse caso a câmara Exradin A16);

$\rho_{e}^{r e l}$ é a densidade eletrônica relativa do acrílico;

b possui valor fixo de $0,4285 \pm 2,5 \%$. 
A diferença da taxa de dose medida com a taxa de dose do Gamma Plan foi de $3,35 \%$.

Tabela 12 - Dosimetria do Gamma Knife® com objeto simulador de acrílico e câmara de ionização Exradin A16

\section{Configuração 4}

Data: 27/07/2016

Taxa de dose Gamma Plan (Gy/min): 1,859

\begin{tabular}{c|c}
\hline$N_{\mathrm{D}, \mathrm{w}}(\mathrm{G} / \mathrm{nC})$ & 4,161 \\
Média da carga coletada $(\mathrm{nC})$ & 0,418 \\
$\mathrm{k}_{\mathrm{t}, \mathrm{p}}$ & 1,024 \\
$k_{Q_{m s r}^{w}, \text { acrilic }}$ & 1,084 \\
$\mathrm{k}_{\text {ion }}$ & 0,999 \\
$\mathrm{k}_{\mathrm{pol}}$ & 0,997 \\
\hline Taxa de dose (Gy/min) & $1,924 \pm 2,7 \%$ \\
\hline
\end{tabular}

Fonte: autora da tese.

A Tabela 13 mostra a dosimetria do Gamma Knife® com o objeto simulador de acrílico e a câmara PTW Pinpoint 31016. Os fatores de correção considerados no cálculo da taxa de dose foram $\mathrm{k}_{\mathrm{t}, \mathrm{p}}$, $\mathrm{k}_{\mathrm{ion}, \mathrm{k} \text {, }}$ e $k_{Q_{m s r}}^{w \text {,acrilic }}$. A diferença da taxa de dose medida com a taxa de dose do Gamma Plan foi de 2,59\%. 
Tabela 13 - Dosimetria do Gamma Knife® com objeto simulador de acrílico e câmara de ionização PTW Pinpoint 31016

\section{Configuração 5}

Data: 27/07/2016

Taxa de dose Gamma Plan (Gy/min): 1,859

\begin{tabular}{c|c}
\hline No,w $(\mathrm{Gy} / \mathrm{nC})$ & 2,546 \\
Média da carga coletada $(\mathrm{nC})$ & 0,690 \\
$\mathrm{k}_{\mathrm{t}, \mathrm{p}}$ & 1,019 \\
$k_{Q_{m s r}}^{\text {,acrilic }}$ & 1,072 \\
$\mathrm{k}_{\text {ion }}$ & 0,999 \\
$\mathrm{~K}_{\mathrm{pol}}$ & 0,994 \\
\hline Taxa de dose (Gy/min) & $1,908 \pm 2,2 \%$ \\
\hline
\end{tabular}

Fonte: autora da tese.

A Tabela 14 mostra o resultado da dosimetria realizada com os objetos simuladores de Solid Water ${ }^{\circledR}$ e acrílico, e com pastilhas de alanina de $2,5 \mathrm{~mm}$. Neste trabalho, as pastilhas de alanina foram consideradas como dosímetro de referência. Foram utilizadas 3 pastilhas para cada medição.

Cada irradiação foi realizada durante $20 \mathrm{~min}$ de forma a alcançar os 30 Gy necessários para cada alanina. Doses menores para as pastilhas de 2,5 mm podem causar ruído e distorção de frequência. Para o objeto simulador de acrílico, o fator de correção $k_{Q_{m s r}}^{w, a c r i l i c}$ foi considerado no cálculo da dose absorvida e seu valor segundo a Equação 13 é de 1,067 .

A dose absorvida esperada pelo Gamma Plan para a dosimetria realizada com o Solid Water ${ }^{\circledR}$ e as pastilhas de alanina por $20 \mathrm{~min}$ foi de 37,1 Gy. A média das três pastilhas foi de 36,39 Gy. A diferença entre o Gamma Plan e a dosimetria foi de 1,9\%.

A dose absorvida esperada pelo Gamma Plan para a dosimetria realizada com o objeto simulador de acrílico e as pastilhas de alanina por $20 \mathrm{~min}$ foi de 37,18 Gy. A média das três pastilhas foi de 37,71 Gy. A diferença entre o Gamma Plan e a dosimetria foi de $1,4 \%$.

Deve-se considerar que ambos os encaixes dos objetos simuladores de Solid Water ${ }^{\circledR}$ e de acrílico para inserção das pastilhas de alanina foram produzidos pelo NPL. Na construção dos encaixes, a ideia inicial seria de que para ambos os objetos 
simuladores a pastilha do meio seria a que deveria estar no centro do campo ( $X=Y=Z=100$ ) e, portanto, receber o maior valor de dose. Porém, foi observado que para ambos os encaixes a pastilha 1 foi a que recebeu maior dose. A construção desses encaixes seguiu o mesmo princípio e é considerada crítica para campos pequenos, pois a medição de suas dimensões é de grande dificuldade. Essa construção não foi perfeitamente alcançada. Considerando que se trata de um campo de $16 \mathrm{~mm}$, é perceptível que a construção de um objeto simulador deve ser realizada minuciosamente, pois a posição e o tamanho do detector pode alterar significativamente o resultado da dosimetria, principalmente para campos pequenos.

Tabela 14 - Dosimetria do Gamma Knife® com objeto simulador de Solid Water® e acrílico e pastilhas de alanina de 2,5 mm. Tempo de irradiação: $20 \mathrm{~min}$

\begin{tabular}{ccc} 
Configurações & $\begin{array}{c}\text { Solid Water e pastilhas de } \\
6 \text { e } 7\end{array}$ & Acrílico e pastilhas de \\
Data: $02 / 08 / 2017$ & alanina de $2,5 \mathrm{~mm}$ \\
Taxa de dose Gamma $2,5 \mathrm{~mm}$ & Data: $27 / 07 / 2017$ \\
Plan (Gy/min): 1,855 & Taxa de dose Gamma \\
& Plan (Gy/min): 1,859 \\
\hline
\end{tabular}

Pastilha 1

Dose absorvida (Gy)

$37,165 \pm 3,2 \%$

$37,745 \pm 3,6 \%$

Pastilha 2

Dose absorvida (Gy)

$36,480 \pm 3,2 \%$

$37,656 \pm 3,5 \%$

Pastilha 3

Dose absorvida (Gy)

$35,523 \pm 3,2 \%$

$37,741 \pm 3,5 \%$

\begin{tabular}{lcc}
\hline Média Dose absorvida (Gy) & $36,389 \pm 4,0 \%$ & $37,714 \pm 3,9 \%$ \\
Diferença Gamma Plan (\%) & 1,9 & 1,4
\end{tabular}

Fonte: autora da tese.

\subsection{Uso do objeto simulador de acrílico e pastilhas de alanina como dosimetria de referência}

A Tabela 15 mostra o percentual entre todas as configurações de dosimetria utilizando, como referência, a configuração do objeto simulador de acrílico e a alanina. A 
dose absorvida média calculada com essa referência foi 37,714 Gy para vinte minutos. Portanto, a taxa de dose dessa configuração seria de 1,885 Gy/min.

Tabela 15 - Diferença percentual das taxas de dose de todas as configurações de dosimetria utilizando o objeto simulador de acrílico e a alanina como dosimetria referência

\begin{tabular}{|c|c|c|c|}
\hline Configuração & $\begin{array}{c}\text { Taxa de Dose } \\
\text { (Gy/min) }\end{array}$ & $\begin{array}{c}\text { Diferença } \\
\text { Gamma Plan (\%) }\end{array}$ & $\begin{array}{c}\text { Diferença } \\
\text { Alanina (\%) }\end{array}$ \\
\hline Solid Water ${ }^{\circledR}+$ Semiflex & 1,883 & 1,28 & 0,10 \\
\hline Solid Water ${ }^{\circledR}+$ Exradin & 1,936 & 2,28 & 2,63 \\
\hline Solid Water $\AA^{\circledR}$ Pinpoint & 1,928 & 1,86 & 2,23 \\
\hline Acrílico + Exradin & 1,924 & 3,35 & 2,02 \\
\hline Acrílico + Pinpoint & 1,908 & 2,59 & 1,20 \\
\hline Solid Water ${ }^{\circledR}$ + Alanina & 1,819 & 1,90 & 3,62 \\
\hline
\end{tabular}

Fonte: autora da tese.

Considerando que o posicionamento do encaixe da alanina no objeto simulador foi construído de maneira não minuciosa, as diferenças entre a taxa de dose medida e a taxa de dose com a configuração de referência (acrílico e alanina) não chegaram a ser maiores do que $3 \%$.

\subsection{Cálculo do Fator Output}

O equipamento Gamma Knife® possui três colimadores de tamanhos diferentes. $\mathrm{O}$ maior deles, de $16 \mathrm{~mm}$, é o colimador utilizado para dosimetria. Porém, as mesmas medições dosimétricas foram realizadas nos colimadores de $8 \mathrm{~mm}$ e $4 \mathrm{~mm}$ para que fosse calculado o fator output.

O campo referência para dosimetria em Gamma Knife $\Theta$ é o colimador de $16 \mathrm{~mm}$. Portanto, a dose absorvida para os colimadores de $8 \mathrm{~mm}$ e $4 \mathrm{~mm}$ foram divididas pela dose absorvida do colimador de $16 \mathrm{~mm}$ no cálculo do fator output, conforme Equação 6 .

A Elekta apresenta os valores do fator output para o Gamma Knife $\AA$, que foram calculados por simulação Monte Carlo, e seus valores são mostrados na Tabela 16. 
Tabela 16 - Fator output fornecido pela Elekta para o Gamma Knife®, calculado por simulação Monte Carlo.

\begin{tabular}{cccc}
\hline Colimador & $16 \mathrm{~mm}$ & $8 \mathrm{~mm}$ & $4 \mathrm{~mm}$ \\
Fator Output Elekta & 1 & 0,9 & 0,814 \\
\hline
\end{tabular}

A Tabela 17 mostra os valores de output para todas as configurações de medição de dosimetria citadas anteriormente e a diferença percentual de cada um deles com o fator output fornecido pela Elekta.

Tabela 17 - Fator output para todas as configurações de dosimetria realizadas e o valor da diferença percentual em relação ao fator estabelecido pela Elekta por simulação.

\begin{tabular}{|c|c|c|c|c|c|c|}
\hline \multirow[b]{3}{*}{ Configuração } & \multicolumn{5}{|c|}{ Colimador } & \multirow[b]{3}{*}{ Incerteza } \\
\hline & \multirow[t]{2}{*}{$16 \mathrm{~mm}$} & \multicolumn{2}{|c|}{$8 \mathrm{~mm}$} & \multicolumn{2}{|c|}{$4 \mathrm{~mm}$} & \\
\hline & & Output & $\begin{array}{c}\text { Diferença } \\
\%\end{array}$ & Output & $\begin{array}{c}\text { Diferença } \\
\%\end{array}$ & \\
\hline Solid Water® + Semiflex & 1 & 0,734 & $18,37 \%$ & 0,328 & $60,02 \%$ & $\pm 3,5 \%$ \\
\hline Solid Water ${ }^{\circledR}+$ Exradin & 1 & 0,887 & $1,37 \%$ & 0,812 & $0,19 \%$ & $\pm 2,9 \%$ \\
\hline Solid Water ${ }^{\circledR}+$ Pinpoint & 1 & 0,893 & $0,71 \%$ & 0,817 & $0,46 \%$ & $\pm 2,5 \%$ \\
\hline Acrílico + Exradin & 1 & 0,904 & $0,44 \%$ & 0,689 & $15,23 \%$ & $\pm 3,2 \%$ \\
\hline Acrílico + Pinpoint & 1 & 0,871 & $3,21 \%$ & 0,637 & $21,63 \%$ & $\pm 2,9 \%$ \\
\hline Solid Water $\AA^{-}$Alanina & 1 & 0,890 & $1,04 \%$ & 0,726 & $10,81 \%$ & $\pm 3,7 \%$ \\
\hline Acrílico + Alanina & 1 & 0,889 & $1,21 \%$ & 0,631 & $22,48 \%$ & $\pm 4,0 \%$ \\
\hline
\end{tabular}

Fonte: autora da tese.

Os valores para o objeto simulador Solid Water $\Theta$ e ambas as câmaras de ionização evidenciam que, quando aplicados os fatores de correção adequados, os resultados são muito próximos aos valores obtidos por simulação Monte Carlo. Tal resultado demonstra confiabilidade nas medições de dosimetria de campos pequenos. 


\section{CONCLUSÕES}

O recém publicado protocolo TRS 483 fornece um guia padronizado para dosimetria de campos pequenos usados em radioterapia e recomenda um formalismo para esta dosimetria, utilizando preferencialmente câmaras de ionização de volume pequenos calibradas em um laboratório padrão de calibração. O TRS 483 enfatiza ainda que o detector ideal para medições em campos pequenos não existe e que para a determinação de fatores output de campo e perfis laterais do feixe, dois ou três tipos diferentes de detectores adequados para essas medições são recomendados, para que a repetição nos resultados forneça mais confiança e assegure que erros dosimétricos significativos não estejam sendo cometidos.

Seguindo a recomendação do TRS 483, este trabalho teve como principal objeto a construção de um objeto simulador para a dosimetria de equipamentos Gamma Knifeß. $\mathrm{O}$ objeto simulador construído é de acrílico e possui dimensões semelhantes aos objetos simuladores originalmente utilizados para esta dosimetria, fornecidos pela Elekta.

Foi realizada ainda a análise do comportamento das câmaras de ionização de volume pequeno para dosimetria de Gamma Knife®. A calibração dessas câmaras de ionização foi realizada em um laboratório padrão primário, onde o coeficiente de calibração $\mathrm{N}_{\mathrm{D}, \mathrm{w}}$, em termos de dose absorvida na água, foi obtido. A alanina foi considerada como detector de referência na dosimetria do Gamma Knife® e foi utilizada com os objetos simuladores fornecidos pela Elekta e com o objeto simulador de acrílico construído.

Os estudos e testes dosimétricos realizados com o objeto simulador que foi projetado e construído como principal objetivo deste trabalho demonstraram resultados próximos aos simuladores existentes. Todos os fatores de correção indicados pelo TRS 483 foram considerados para o cálculo da dose absorvida.

Foi constatado que o novo objeto simulador pode ser utilizado na dosimetria de Gamma Knife® e também para calibração de câmaras de ionização de volume pequeno, garantindo uma configuração de dosimetria e calibração similares e proporcionando ao usuário uma calibração próxima à configuração da dosimetria clínica.

Recomenda-se para trabalhos futuros a obtenção de imagens na construção de encaixes do objeto simulador de forma a garantir que o detector esteja no centro do objeto simulador em todas as direções, considerando sua forma circular. Além disso, a realização de novos testes para utilização deste objeto simulador na calibração de câmaras de ionização de volume pequeno no laboratório de calibração secundário do IPEN. 


\section{REFERÊNCIAS BIBLIOGRÁFICAS}

1. PEREZ, C.A.; BRADY, L.W.; HALPERIN, E.C.; WAZER, D.E. Principles and practice of radiation oncology. Lippincott Williams e Wilkins, Philadelphia, 2004.

2. MARSOLAT, F.; TROMSON, D.; TRANCHANT, N.; POMORSKI, M.; LE ROY, M.; DONOIS, M.; MOIGNAU, F.; OSTROWSKY, A.; DE CARLAN, L.; BASSINET, C.; HUET, C.; DERREUMAUX, S.; CHEA, M.; CRISTINA, K.; BOISSERIE, G.; BERGONZO, P. A new single crystal diamond dosimeter for small beam: comparison with different commercial active detectors. Physics in Medicine \& Biology, v. 58, p. 7647-7660, 2013.

3. HALL, E.J.; GIACCIA, A.L. Radiobiology for the radiologist. Lippincott Williams e Wilkins, Philadelphia, 2012.

4. DEVITA JUNIOR, V.T.; LAWRENCE, T.S.; ROSENBERG, S.A. Cancer principles and practice of oncology. Lippincott Williams e Wilkins, Philadelphia, 2011.

5. CUNNINGHAM, J.H.E.; JOHNS, H.E. The physics of radiology. 4. ed. Charles C, Thomas Publisher, llinois, 1983.

6. KHAN, F.M. The physics of radiation therapy. 4. ed. Lippincott Williams e Wilkins, Philadelphia, 2010.

7. LEKSELL, L. Stereotactic radiosurgery. Journal of Neurology, Neurosurgery and Psychiatry, v. 46, p.797-803, 1951.

8. BANK, M.I. Ion chamber measurements of transverse gamma knife beam profiles. Journal of Applied Clinical Medical Physics, v. 3, p.12-18, 2002.

9. INTERNATIONAL ATOMIC ENERGY AGENCY. Absorbed dose determination in external beam radiotherapy. An International code of practice for dosimetry based on standards of absorbed dose to water. Vienna, 2004. (Technical Report Series, 398).

10. AMERICAN ASSOCIATION OS PHYSICISTS IN MEDICINE. Protocol for clinical reference dosimetry of high-energy photon and electron beams. Louisville, 1999. (Report Task Group 51). 
11. AMERICAN ASSOCIATION OF PHYSICISTS IN MEDICINE. A protocol for the determination of absorbed dose from high-energy photon and electron beams. Task Group 21, Radiation Therapy Committee. Medical Physics, v. 10, p. 741-771, 1983.

12. BENMAKHLOUF, H.; JOHANSSON, J.; PADDICK, I.; ANDREO, P. Monte Carlo calculated and experimentally determined output correction factors for small field detectors in Leksell Gamma Knife Perfexion beams. Physics in Medicine \& Biology, v. 60, p. 3959-3973, 2015.

13. INTERNATIONAL ATOMIC ENERGY AGENCY, AMERICAN ASSOCIATION OF PHYSICISTS IN MEDICINE. Dosimetry of Small Static Fields Used in External Beam Radiotherapy. Vienna, 2017. (Technical Report Series, 483).

14. WU, A.; LINDNER, G.; MAITZ, A.H.; KALEND, A.M.; LUNSFORD, L.D.; FLICKINGER, J.C.; BLOOMER, W.D. Physics of Gamma Knife approach on convergent beams in stereotactic radiosurgery. International Journal of Radiation Oncology, Biology and Physics, v. 18, p. 941-949, 1990.

15. TYLER, M.; LIU, P.Z.; CHAN, K.W.; RALSTON, A.; MCKENZIE, D.R.; DOWNES, S.; SUCHOWERSKA, N. Characterization of small field stereotactic radiosurgery beams with modern detectors. Physics in Medicine \& Biology, v. 58, p. 7595-7608, 2013.

16. PANTELIS, E.; MOUTSATSOS, A.; ZOURARI, K.; PETROKOKKINOS, L.; SAKELLIOU, L.; KILBY, W.; ANTYPAS, C.; PAPAGIANNIS, P.; KARAISKOS, P.; GEORGIOU, E; SEIMENIS, I. On the output factor measurements of the CyberKnife iris collimator small fields: Experimental determination of the ${ }^{k} \boldsymbol{Q}_{\text {clin }} \boldsymbol{Q}_{m s r} f_{m s}$ correction factors for microchamber and diode detectors. Medical Physics, v. 39, p. 4875-4885, 2012.

17. SYAM KUMAR, S.A.; SUKUMAR, P.; SRIRAM, P.; DHANABALAN, R.; AKETI, S.; VIVEKANANDAN, N. A patient specific quality assurance study on absolute dose verification using ionization chambers of different volumes in RapidArc treatments. Medical Dosimetry, v. 37, p. 436-441, 2012.

18. PAPPAS, E.; MARIS, T.G.; ZACHAROPOULOU, F.; PAPADAKIS, A.; MANOLOPOULOS, S.; GREEN, S.; WOJNECKI, C. Small SRS photon field profile dosimetry performed using a PinPoint air ion chamber, a diamond detector, a novel silicondiode array (DOSI), and polymer gel dosimetry. Analysis and intercomparison Medical Physics, v. 35, p. 4640-4648, 2008.

19. BHATNAGAR, J.P.; NOVOTNY, J.; QUADER, M.A.; BEDNARZ, G.; HUQ, M.S. Unintended attenuation in the Leksell Gamma Knife ${ }^{\circledR}$ Perfexion ${ }^{\mathrm{TM}}$ calibration-phantom adaptor and its effect on dose calibration. Medical Physics, v. 36, p. 1208-1211, 2009. 
20. SWANPALMER, J.; JOHANSSON, K.A. The effect of air cavity size in cylindrical ionization chambers on the measurements in high-energy radiotherapy photon beams- an experimental study. Physics in Medicine \& Biology, v. 57, p. 4671-4681, 2012.

21. ZEVERINO, M.; AGOSTINELLI, S.; PUPILLO, F.; TACCINI, G. Determination of the correction factors for different ionization chambers used for the calibration of the helical tomotherapy static beam. Radiotherapy and Oncology, v. 100, p. 424-428, 2011.

22. MAITZ, A.H.; WU, A.; LUNSFORD, L.D.; FLICKINGER, J.C.; KONDZIOLKA, D.; BLOOMER, W.D. Quality assurance for Gamma Knife stereotactic radiosurgery. International Journal of Radiation Oncology, Biology and Physics, v. 32, p. 14651471, 1995.

23. ELEKTA, Inc. Leksell Gamma Knife Perfexion. Disponível em: $<$ https://www.elekta.com/radiosurgery/leksell-gamma-knife-perfexion.html>. Acesso em 23 ago. 2017.

24. SARAIVA, C.W.C. Gamma Knife Perfexion. In: SOCIEDADE BRASILEIRA DE RADIOTERAPIA. Anais eletrônicos da XIV JORNADA DE FÍSICA MÉDICA, 2014, São Paulo. Disponível em:

$<$ http://www.sbradioterapia.com.br/pdfs/aulas/arqaulaevento723.pdf>. Acesso em jun. 2017.

25. MAYLES, P., NAHUM, A., ROSENWALD, J.C., (2007). Handbook of Radiotherapy Physics: Theory and Practice. Boca Raton, FL: CRC.

26. PODGORSAK, E.B. Radiation oncology physics: a handbook for teachers and students. - Vienna: IAEA, 2005. Disponível em: <http://wwwpub.iaea.org/MTCD/publications>. Acesso em: 8 mar. 2017.

27. PTW Freiburg. Pinpoint 3D lon Chamber. Disponível em: <http://www.ptw.de/3542.html>. Acesso em 11 fev. 2017.

28. AGOSTINELLI, S.; GARELLI, S.; PIERGENTILI, M.; FOPPIANO, F. Response to high-energy photons of PTW31014 PinPoint ion chamber with a central aluminum electrode. Medical Physics, v. 35, p. 3293-3301, 2008.

29. MARTES, C; WAGTER, C.; DE NEVE, W. The value of the PinPoint ion chamber for characterization of small fields segments used in intensity-modulated radiotherapy. Physics in Medicine \& Biology, v. 45, p. 2519-2530, 2000. 
30. LAUB, W.; WONG, T. The volume effect of detectors in the dosimetry of small fields used in IMRT. Medical Physics, v. 30, p. 341-347, 2003.

31. FRANCESCON, P., CORA, S., SATARIANO, N., Calculation of $k_{Q_{c l i n, Q_{m s r}}}^{f_{c l i n, f}}$ for several small detectors and for two linear accelerators using Monte Carlo simulations. Medical Physics, v. 38, p. 6513-6527, 2011.

32. ABREGO, F.C.; CALCINA, C.S.; DE ALMEIDA, A.; DE ALMEIDA, C.E.; BAFFA, O.; Relative output factor and beam profile measurements of small radiation fields with an $L-$ alanine/K-band EPR minidosimeter. Medical Physics, v. 34, p. 1573-1582, 2007.

33. STASI, M.; BAIOTTO, B.; BARBONI, G.; SCIELZO, G. The behavior of several microionization chambers in small intensity modulated radiotherapy fields. Medical Physics, v. 31, p. 2792-2795, 2004.

34. ROSSER, K.E. Investigation of the chamber correction factor $\left(\mathrm{k}_{\mathrm{ch}}\right)$ for the UK secondary standard ionization chamber (NE2561/NE2611) using medium-energy x-rays. Physics in Medicine \& Biology, v. 43, p. 3195-3206, 1998.

35. SHARPE, P.H.G.; SEPHTON, J.P. Alanine dosimetry at NPL - the development of a mailed reference dosimetry service at radiotherapy dose levels. International Atomic Energy Agency. Vienna, 1999 (IAEA-TECDOC-1070).

36. ALFONSO, R.; ANDREO, P.; CAPOTE, R.; HUQ, M.S.; KILBY, W.; KJALL, P.; MACKIE, T.R.; PALMANS, H.; ROSSER, K.; SEUNTJENS, J.; ULLRICH, W.; VATNITSKY, S. A new formalism for reference dosimetry of small and nonstandard fields. Medical Physics, v. 35, p. 5179- 5186, 2008.

37. INTERNATIONAL ELECTROTECHNICAL COMMISSION. Medical electrical equipment - Dosimeters with ionization chambers as used in radiotherapy. Geneva, 2011 (IEC 60731).

38. NATIONAL PHYSICAL LABORATORY. Therapy level calibrations. ${ }^{60} \mathrm{Co}$ absorbed dose calibrations. Middlesex, 2016. Disponível em <http://www.npl.co.uk/upload/pdf/pcrd11-notes.pdf. > Acesso em ago.2017.

39. INSTITUTO NACIONAL DE METROLOGIA, NORMALIZAÇÃO E QUALIDADE INDUSTRIAL (INMETRO). Guia para a expressão da incerteza de medição. Rio de Janeiro, 2003. 
40. ZHU, D.; AUSTERLITZ, C.; BENHABIB, S.; MOTA, H.; ALISON, R.R.; CAMPOS, D. Study of a spherical phantom for Gamma Knife dosimetry. Journal of Applied Clinical Medical Physics, v. 11, p. 222-229, 2010.

41. MCEWEN, M. Measurement of ionization chamber absorbed dose kQ factors in megavoltage photon beams. Medical Physics, v. 37, p. 2179- 2193, 2010.

42. NUTBROWN, R.F.; DUANE, S.; SHIPLEY, D.R.; THOMAS, R.A.S. Evaluation of factors to convert absorbed dose calibrations in graphite to water for the NPL high-energy photon calibration service. Physics in Medicine \& Biology, v. 47, p. 441-454, 2002.

43. ARIB, M.; MEDJADJ, T.; BOUDOUMA, Y. Study of the influence of phantom material and size on the calibration of ionization chambers in terms of absorbed dose to water. Journal of Applied Clinical Medical Physics, v. 7, p. 55-64, 2006.

44. MCEWEN, M.; DEWERD, L.; IBBOTT, G.; FOLLOWILL, D.; ROGERS, D.W.O.; SELTZER, S.; SEUNTJENS, J. Addendum to the AAPM's TG-51 protocol for clinical reference dosimetry of high-energy photon beams. Medical Physics, v. 41, p. 1-20, 2014.

45. COSTA, N.A.; POTIENS, M.P.A.; SAKURABA, R.K.; CRUZ, J.C. Establishment of a quality control program of a pinpoint ionization chamber. Proceedings of $4^{\text {tas }}$ Jornadas de Física Médica en la Frontera. Pucón, Chile. 2014

46. COSTA, N.A.; POTIENS, M.P.A.; SARAIVA, C.W.C. Phantom positioning variation in the Gamma Knife ${ }^{\circledR}$ Perfexion dosimetry. Journal of Physics: Conference Series, v. 733, p. 12098, 2016.

47. MIRZAKHANIAN, L.; BENMAKHLOUF, H.; SEUNTJENS, J. Monte Carlo calculated correction factors for nine detectors in Leksell Gamma Knife unit. Proceedings of International Conference on Advances in Radiation Oncology. Vienna, 2017. 


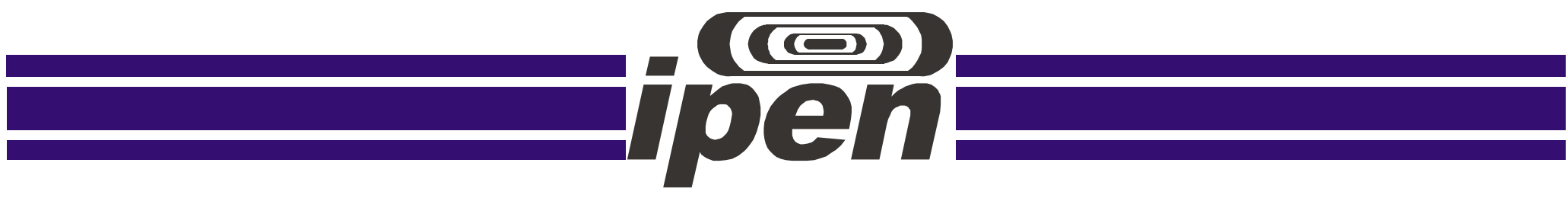

INSTITUTO DE PESQUISAS ENERGÉTICAS E NUCLEARES

Diretoria de Pesquisa, Desenvolvimento e Ensino

Av. Prof. Lineu Prestes, 2242 - Cidade Universitária CEP: 05508-000

Fone/Fax(0XX11) 3133-8908

SÃO PAULO - São Paulo - Brasil

http://www.ipen.br

O IPEN é uma Autaquia vinculada à Secretaria de Desenvolvimento, associada à Universiade de São Paulo e gerida técnica e administrativamente pela Comissão Nacional de Energia Nuclear, órgão do Ministério da Ciência, Tecnologia e Inovação. 